\title{
Towards a specific therapy for myasthenia gravis : a quest for armor against autoantibody attack
}

Citation for published version (APA):

Stassen, M. H. W. (2003). Towards a specific therapy for myasthenia gravis : a quest for armor against autoantibody attack. [Doctoral Thesis, Maastricht University]. Datawyse / Universitaire Pers Maastricht. https://doi.org/10.26481/dis.20031204ms

Document status and date:

Published: 01/01/2003

DOI:

10.26481/dis.20031204ms

Document Version:

Publisher's PDF, also known as Version of record

\section{Please check the document version of this publication:}

- A submitted manuscript is the version of the article upon submission and before peer-review. There can be important differences between the submitted version and the official published version of record.

People interested in the research are advised to contact the author for the final version of the publication, or visit the DOI to the publisher's website.

- The final author version and the galley proof are versions of the publication after peer review.

- The final published version features the final layout of the paper including the volume, issue and page numbers.

Link to publication

\footnotetext{
General rights rights.

- You may freely distribute the URL identifying the publication in the public portal. please follow below link for the End User Agreement:

www.umlib.nl/taverne-license

Take down policy

If you believe that this document breaches copyright please contact us at:

repository@maastrichtuniversity.nl

providing details and we will investigate your claim.
}

Copyright and moral rights for the publications made accessible in the public portal are retained by the authors and/or other copyright owners and it is a condition of accessing publications that users recognise and abide by the legal requirements associated with these

- Users may download and print one copy of any publication from the public portal for the purpose of private study or research.

- You may not further distribute the material or use it for any profit-making activity or commercial gain

If the publication is distributed under the terms of Article $25 \mathrm{fa}$ of the Dutch Copyright Act, indicated by the "Taverne" license above, 
Towards a specific therapy for myasthenia gravis

A quest for armor against autoantibody attack 
(c) M.H.W. Stassen, Limbricht 2003

Omslagfoto: Henk Veldman, Universiteit Utrecht Uitgeverij: Universitaire Pers Maastricht, Maastricht ISBN 90-5278-403-5 


\section{Towards a specific therapy for myasthenia gravis}

A quest for armor against autoantibody attack

\section{Proefschrift}

ter verkrijging van de graad van doctor aan de Universiteit Maastricht, op gezag van de Rector Magnificus, prof. dr. A.C. Nieuwenhuijzen Kruseman, volgens het besluit van het College van Decanen,

in het openbaar te verdedigen

op donderdag 4 december 2003 om 14:00 uur

door

Maurice Henrica Wilhelmus Stassen

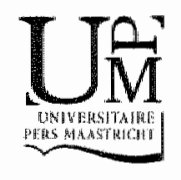


Promotores:

prof. dr. H.W.M. Steinbusch

prof. di.". Troost

Co-promotor:

dr. M.H. De Baets

Beoordelingscommissie:

prof. dr. F.C.S. Ramaekers, voorzitter

prof. dr. I.-W. Cohen Tervaert

prof. dr. J.B.M. Kuks (Rijksuniversiteit Groningen)

prof. dr. F. Spaans 
"What's the point of all this hoax? Is it the chicken and the egg time? Are we just yolks? Or, perhaps, we're just one of God's little jokes [...] In this life, what is our fate? Is there Heaven and Hell? Do we reincarnate? Is mankind evolving, or is it too late? [...] While the scientists say We're just simply spiralling coils of self-replicating DNA." - Eric Idle, The meaning of life

"Een overwinning kan worden voorzien. Ze kan echter niet worden geforceerd."

- Sun-tzu, De kunst van het oorlogvoeren 



\section{Preface}

The human body is protected by the immune system against viruses, bacteria and parasites, but also against malignant tumors that invade healthy tissue. For an adequate immune response, the immune system has to recognize invaders, i.e. it has to differentiate between (healthy) self and foreign. Antibodies and $I$ cell receptors (TCRs) are the proteins that facilitate the identification of foreign antigens, and upon recognition trigger a humoral or cellular immune response, respectively. A foilure of the immune system to be tolerant to self can lead to the unwanted situation were TCRs and antibodies bind to self substances, resulting in an autoimmune disease.

Myasthenia gravis (MG) is a prototype autoimmune disease, since its antibody-mediated pathogenesis is restricted to one target, the postsynaptic membrane of the neuromuscular junction (NMJ). The muscular nicotinic acetylcholine receptor (AChR) is the major autoantigen located at the NMI. Autoantibodies directed to the $\mathrm{AChR}$ lower the number of functional AChRs, leading to an impaired neuromuscular signal transduction, which results in a fatigable skeletal muscle weakness (reviewed in Chapter 1).

MG patients can be successfully treated for their muscle weakness, but most treatments have side effects. Several experimental approaches for a specific immunotherapy of MG have been investigated by others including induction of tolerance by administrating AChR-derived peptides, antiidiotype antibodies, peptides homologue to $A C h R$ that block anti-AChR antibodies and genetically engineered antigen-presenting cells that, as a kind of "guided missile", destroy AChR-specific T cells. The model used for these experiments is experimental autoimmune $M G$ (EAMG), an animal model that closely resembles $\mathrm{MG}$ of patients.

This thesis describes two experimental approaches that could lead to a specific MG therapy. First, the AChR could be protected against degradation by blocking the binding of anti-AChR antibodies by therapeutic antibodies. It is known that rat anti-AChR monoclonal antibodies can block the pathogenic binding of autoantibodies to the AChR. However, therapeutic antibodies should be of human origin to prevent immunologic reactions. The human origin and the AChR specificity of the potential therapeutic antibodies were obtained by isolating antibodies from either transgenic EAMG mice (Chapter 2) or MG patients (Chapters 3,4 and 5). Modifying these cloned anti-AChR antibodies by genetically truncating them to antigen-binding fragments $\left(\mathrm{F}_{\mathrm{a} i} \mathrm{~s}\right)$ or single-chain variable fragments $\left(\mathrm{scF}_{\mathrm{v}} \mathrm{s}\right)$ eliminated their pathogenic characteristics (Chapters 3 and 4). However, a full-size antibody is preferred, considering the low serum half-life of $\mathrm{scF}_{z} s$ and $\mathrm{F}_{\mathrm{alk}} \mathrm{s}$. In order to construct a more metabolically stable protective antibody, a molecule with the characteristics of $F_{u b}$ (monovalent for AChR and no effector functions typical for MG autoantibodies) and IgG (high serum half-life) was 
designed. In a first step towards the production of this therapeutic antibody, a human $\lg G 1$ was reconstructed from an anti-AChR $F_{\text {aix }}$ and one of its effector functions deleted (Chapter 5).

Finally, the postsynaptic membrane of the NMJ could be protected against loss of AChR by overexpression of rapsyn, an AChR clustering and anchoring protein (Chapter 6). In congenital myasthenic syndrome (CMS) patients, mutations in the rapsyn gene can be found. These mutations lower the functional level of rapsyn in the patients' muscles. In some animals resistant to the induction of EAMG, increased levels of rapsyn are found. These findings suggest a role of the level of rapsyn in the susceptibility to (EA)MG. If the level of rapsyn correlates with the susceptibility, modifying the level in vivo could be the basis of a new therapy.

Chapter 1 gives a detailed introduction to MG autoantibodies. Muscle autoantigens, diagnostic value of autoantibody assays, immunopathogenesis, etiology hypotheses and usages of EAMG models are reviewed.

A new transgenic mouse EAMG model is described in Chapter 2. The so-called HuMAb-Mouse is transgenic for human immunoglobulin loci, thereby giving rise to human anti-AChR antibodies upon immunization. This not only models MG more closely, but could also be a source of human antibodies that are the basis of therapeutic antibodies.

The previously cloned human anti-AChR $F_{n k} 637$ is a potential therapeutic agent, since it protects against $A C h R$ loss in vitro. In order to test the in vivo effects of the primate-specific anti-AChR $\mathrm{F}_{a b} 637$, large quantities are needed for a monkey EAMG model. Chapter 3 assessed the large-scale production of $F_{a b} 637$ in yeast, while Chapters 4 and 5 describe alternative recombinant variants of $\mathrm{F}_{\mathrm{w} b \mathrm{~b}} 637$. In Chapter 4, a scF variant of $F_{a b} 637$, scF, 637, was constructed and characterized. It was found that the bacterially produced $S \mathrm{CF}_{v} 637$ could serve as an alternative to $F_{a b} 637$, since it was able to compete for binding to AChR with MG sera. In Chapter 5 , a human $\mathrm{MG}$ autoantibody, IgG1-637, was reconstructed from $\mathrm{F}_{\mathrm{ab}} 637$, by genetically fusing the latter's heavy chain to the human $\gamma 1 \mathrm{~F}_{c}$ IgG1-637, produced by a chinese hamster ovary cell line, was shown to be pathogenic in a monkey LAMG mod!l, as predicted. IgG1-637 could serve as the basis of a therapeutic full-size antibody, which is a good alternative to $F_{a b} 637$ and $\mathrm{sc}, 637$, considering the metabolic stabilities.

In Chapter 6, a second therapeutic strategy for MG is studied. In order to determine if increasing the level of rapsyn is sufficient to induce resistance to $E A M G$, rapsyn was overexpressed in the muscles of rats and subsequently EAMG induced. Rapsyn was overexpressed by a non-viral gene transfer technique, in vivo electroporation. This rapsyn gene therapy was shown to have a protective effect on the induction of EAMG. The finding that the level of rapsyn indeed correlates with the susceptibility to EAMG could be useful in a therapeutic strategy to protect against loss of AChR from inside the muscle fibers. Besides MG patients, such a therapy
mid also benefit CMS potients. 


\section{Contents}

Chapter 1: The role of antibodies in myasthenia gravis (review)

Chapter 2: Experimental autoimmune myasthenia gravis in mice expressing human immunoglobulin loci

Chapter 3: Expression of a human anti-acetylcholine receptor $F_{\text {iab }}$ in Pichia pastoris

Chapter 4: Construction and characterization of a single-chain antibody fragment derived from the thymus of a myasthenia gravis patient

Chapter 5: Characterization of a human IgG1 reconstructed from an anti-acetylcholine receptor $F_{u s}$

Chapter 6: Overexpression of rapsyn in muscles prevents experimental autoimmune myasthenia gravis

Summary and general discussion

Samenvatting

Dankwoord/Acknowledgements

Bibliography

101

Curriculum vitae

105 


\section{Chapter 1}

\section{review \\ The role of antibodies in myasthenia gravis}

Marc H. De Baets \& Maurice H.W. Stassen

published in the

Journal of the Neurological Sciences 202 (2002) pp. 5-11 


\section{Abstract}

Myasthenia gravis is an autoimmune disease associated with antibodies directed to the postsynaptic acetylcholine receptor. These antibodies reduce the number of receptors. Autoantibodies against $A C h R$ and other muscle antigens can be used for the diagnosis of myasthenia gravis and related disorders. The origin and the role of these antibodies in the disease are discussed. Experimental autoimmune myasthenia gravis, an experimental model closely mimicking the disease, has provided answers to many questions about the role of antibodies, complement macrophages and $A C h R$ anchor proteins. Genetically modified anti- $A C h R$ antibodies may also be used in the future to treat myasthenia. 


\section{Introduction}

Myasthenia gravis is an autoimmune disease associated with antibodies directed to the postsynaptic nicotinic acetylcholine receptor (AChR) at the neuromuscular junction. These antibodies reduce the number of $A C h R$, which leads to muscle weakness. This weakness is prominent in muscles that are used frequently and repetitively, for example, the eye muscles, and results in ptosis and double vision. Lennon and Carnegie [1] proposed the concept that anti-AChR antibodies accounted for the clinical symptoms of MG. Antibodies were found to block receptor function or cause local damage to the tissues. They applied this concept to $M S, M G$, and autoimmune endocrine diseases. Antigens of microorganisms that resemble membrane receptors appeared to trigger the autoimmune disease. Overt autoimmune diseases only occurred in genetically predisposed individuals [1].

Since then, the role of antibodies against membrane receptors including calcium channels, glutamate receptors and potassium channels has been demonstrated in the pathogenesis of many other neurological diseases. Table 1 lists the diseases in which anti-AChR antibodies are involved. Channelopathies can also be genetic in origin. The clinical presentation of both genetic and autoimmune types is similar. However, the former usually presents soon after birth while the latter develop later in life.

Table 1: Autoimmune diseases with antibodies against AChRs

\begin{tabular}{|c|c|c|c|}
\hline Diserease & $\mathrm{AACh}$ & Moin symptoms [referencel & Congetinal syndrome \\
\hline mograsthemia gravis & ot 1 subunit (MIR) & muscular weakness [2] & yes \\
\hline whthrogryposis multiplex congenita & Ysubunit & arthrogryposis $[\mathrm{B}]$ & yes \\
\hline acquired slow channe? disease & E stbunt & muscular modoness $[4]$ & yes. \\
\hline Guillain-Barne syndrome & functional assoy & muscle weaknass $|s|$ & no \\
\hline Gutomomis nenropathy & neuronol AGs & orthosionse hymerichsan $|6|$ & yest \\
\hline
\end{tabular}

\section{The players: AChR and antibodies.}

AChR is a pentameric transmembrane protein composed of five subunits in a stoichiometry of $\alpha 1, \beta 1, \gamma, \delta$ (Figure 1). The $\alpha 1$ subunit displays $a$ highly immunogenic epitope at the top of the extracellular part, called the main immunogenic region (MIR), towards which the majority of the autoantibodies detected in MG and EAMG sera are directed [7]. Antibodies against the embryonal $\gamma$ subunits directly inhibit $\mathrm{AChR}$ function and are responsible for the autoimmune type of arthrogryposis multiplex congenita [3]. In adults, the receptor $\gamma$ subunit is replaced by the $\varepsilon$ subunit. Antibodies against the $\varepsilon$ subunits are responsible for delayed closure of the ion channel. This is called myasthenic acquired slow channel syndrome, which is clinically indistinguishable from classic $\mathrm{MG}$ [4]. On nerve trunk 
stimulation, however, a double compound muscle action potential is seen after a single stimulus.

Antibodies are encoded by about 400 immunoglobulin genes. DNA rearrangements in $B$ cells generate an immense diversity $\left(10^{14}\right.$ different antibody molecules per individual), even before the encounter of antigens. Subsequently, class switch and somatic mutation of the Ig variable region occurs. Autoantibodies are not structurally different from antibodies against microbial or other antigens.

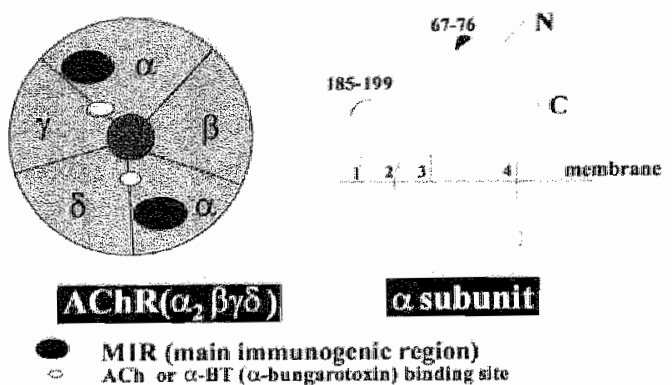

Figure 1

The muscular AChR is a pentameric transmembrane protein composed of five subunits in a stoichiometry of $\alpha_{z}, \beta, y, \delta$. The $\alpha$ subunit displays a highly immunogenic epitope at the top of the extracellular part, called the main immunogenic region (MIR, towards which the mojority of the auroantibodies. detected in MG and EAMG sera are directed. The right panel depicts the a subunit containing the MIR (67-76) and the acetylcholine (ACh)-binding site (185-199).

\section{Diagnostic usage of autoantibodies against muscle antigens}

Reproducible measurements of serum anti-AChR antibodies can be made by means of a radioimmunoassay using solubilized human muscle $A C h R$ labeled with ${ }^{125} \mathrm{I}-\alpha$-bungarotoxin. Fetal $\mathrm{AChR}$ extracted from a more readily available rhabdomyosarcoma cell line (TE671) or adult type receptor from. a genetically modified TE676 cell line (CN21) can be used. The sensitivity of the RIA using TE671 cells is $>1.5$ and $>\mathbb{1} \mathrm{nM}$ for the RIA using CN21 cells. For titers $>2 \mathrm{nM}$ both TE671 and muscle AChR correlate well $[8,9]$. So, for sensitive diagnostic use, human denervated muscle AChR obtained from ischemic amputated legs is to be used (IBL radioimmunoassay information http://www.ibl.com), sensitivity $>0.25 \mathrm{nM}$. The UK extemal quality assessment service (Sheffield, UK http://www.uknequas.org.uk) reported that $2 / 3$ of the European laboratories use human muscle AChR as antigen and $1 / 3$ cell line AChR.

In generalized early or late onset $M G, 90 \%$ of the patients have circulating anti-AChR antibodies. $\mathrm{MG}$ patients with a thymoma are all anti-AChR antibody-positive. In purely ocular $\mathrm{MG}$, only $50 \%$ of the patients are antibody-positive. Titers are highly variable among $M G$ 
patients and correlate weakly with the clinical disease severity [10-13], although in individual patients the titer correlates well with the clinical score. Therefore, several measurements are useful in the follow-up to treatment or to prevent clinical relapse of the disease. A titer decrease of $50 \%$ almost always coincides with a substantial clinical improvement [14].

Finally, anti-AChR antibody measurements are the cornerstone of the confirmatory tests for the diagnosis along with EMG/single-fiber EMG (SFEMG) and perhaps the neostigmine test.

The range of myasthenic antibodies also includes antibodies against other muscular cytosolic proteins, such as actin, myosin, a actinin, titin, rapsyn, ryanodin receptor and muscle specific kinase (MuSK). Of this series of antigens, titin and MuSK are important in the diagnosis of paraneoplastic-associated $\mathrm{MG}$ and seronegative $\mathrm{MG}$, respectively. More than $95 \%$ of the thymoma patients have antibodies against striated muscle antigen, i.e. titin, a very large structural cytoplasmic protein that spans from the $M$ line to the $Z$ line and is associated with myosin [15]. The presence of antistriated muscle antibodies in patients younger than 40 years at disease onset suggests the presence of a thymoma and a more severe disease. In patients older than 40 years, this test is of less diagnostic importance for the presence of a thymoma, since $75 \%$ of the MG patients over 60 years old have antistriated muscle antibodies [16]. Combined testing for antibodies against titin and ryanodin receptors, voltageactivated calcium release channels located in the sarcoplasmic reticulum, yields the highest sensitivity and specificity for the detection of a thymoma in MG irrespective of age [15].

The origin of anti-muscle antigens and their relation to the pathogenesis of a thymoma can best be explained by the presence of a cross-reactive antigen (probably neurofilament $M$ ) in the thymus (crossreacting with anti-AChR at the neuromuscular junction) [17]. This means that, in an effort to eliminate the thymoma, the immune system induces cross-reactive antibodies with AChR and thus myasthenia. In nonthymoma MG patients, antistriated antibodies might be induced secondary to the local muscle damage by anti-AChR antibodies, exposing cytoplasmic proteins including titin and the ryanodin receptor.

A third class of recently discovered antibodies in $\mathrm{MG}$ is directed against MuSK. These antibodies can be detected in $70 \%$ of the so-called seronegative (i.e. no detectable anti-AChR antibodies) generalized MG patients but not in seropositive MG patients or thymoma MG patients. MuSK functions as a receptor for agrin secreted by the nerve terminal, which induces AChR clustering. These clusters at the top of the junctional postsynaptic folds are located closely to the presynaptic active zones providing an optimal interaction between the acetylcholine quantum and A.ChRs. Serum anti-MuSK antibodies interfere with the formation of these clusters in vitro. It is not yet clear how these antibodies induce $M G$ in an adult neuromuscular junction that already contains AChR clusters [18]. 


\section{Immunopathogenesis of myasthenia gravis}

The muscular weakness in $M G$ is a consequence of a reduced number of functional receptors on the postsynaptic membrane. Antibodies that are mainly directed against the a subunit are able to cross-link $A C h R$, thus stimulating the normal internalization and degradation process. Membrane fragments containing $A C h R$ are internalized by endocytosis and degraded by lysosomial enzymes. The half-life of $A C$ h $R$ is reduced from 7 to 2 days. This process is called antigenic modulation. There is a compensatory increase of AChR synthesis as measured by increased mRNA levels for the a receptor subunit $[19,20]$.

A second important mechanism that is responsible for the neuromuscular defect is complement-mediated focal lysis of the postsynaptic membrane. By binding to $\mathrm{AChR}$, antibodies trigger a complement cascade resulting in a focal destruction of the postsynaptic membrane by the membrane attack complex. However no lysis of the entire muscle fiber occurs, because this is a very large syncitium that is resistant to degradation processes. The damage to the postsynaptic membrane is only partially restored, resulting in the reduction of the number of postsynaptic folds. The complement-mediated lysis is also essential for antigenic modulation, because in complement-deficient animals, no experimental autoimmune myasthenia gravis (EAMG) can be induced in spite of the presence of abundant antibodies at the endplate. Complement-mediated attack probably removes the cytoskeletal restraints of $A C h R$ in the membrane, thus facilitating AChR endocytosis $[21,22]$.

Thirdly, antibodies against the acetylcholine-binding site or the ion channel may inhibit AChR function. Also, monoclonal antibodies against the acetylcholine-binding site inhibit ion channel function. Injection of anti-acetylcholine site antibodies into experimental animals (newly hatched chickens) induced an acute curare-like paralysis which differs from EAMG induced by anti-AChR antibodies [23]. In MG sera, low titers of antiAChR-binding site antibodies are detectable but their functional importance is not so clear. However, in the serum of mothers with a baby suffering from arthrogryposis multiplex congenita, antibodies against the $\gamma$ subunit of the fetal AChR interfere with ion channel function [3] of the baby's AChR. The mother has no muscular weakness, because she expresses only adult type AChR with the s subunit instead of the fetal $\gamma$ subunit.

\section{The origin of autoantibodies against muscle antigens}

A large number of young-onset myasthenia gravis patients have a hyperplastic thymic medulla containing anti-AChR-producing B cells and plasma cells, sensitized T cells and antigen-presenting cells, and AChRexpressing myoid cells. This suggests that the primary sensitization against muscle antigen in $\mathrm{MG}$ takes place in the thymus. This intrathymic 
pathogenesis modiel was proposed by Wekerle and Ketelsen [24] in 1977. The most convincing experiment supporting this hypothesis is the transplantation of thymic hyperplastic tissue into mice with severe combined immunodeficiency (SCID) (immunologically cripple mice not able to produce mature $T / B$ cells and therefore not rejecting the thymic graft). The transplantation resulted in a prolonged production of anti$A C h R$ antibodies and $A C h R$ loss in the recipients [25]. Other investigators believe that the sensitization of $\mathrm{T}$ and $\mathrm{B}$ cells occurs in the peripheral lymphoid system. A small proportion of lymphocytes recirculate to the thymus [26], where restimulation occurs. Microbial antigens expressing cross-reactive epitopes can stimulate AChR-reactive $T$ and B cells through a mechanism called molecular mimicry in genetically susceptible individuals [27]. Alteration in AChR expression or structure might trigger the immune response. Analogous to the glutamate type receptor subunit 3 (Glu 3), the target of the immune response in Rasmussen encephalitis, AChR contains an internal N-linked glucosylation site (Asn 141) [28]. If these sites are not glucosylated, autoantigenic peptides might be generated after cleavage with granzyme B, a serine protein released by activated immune cells [29]. In $\mathrm{MG}_{\text {, }}$ an association is found between the AChR $\alpha$ subunit gene (CHRNA), DQA1 * 101 and the DR3 haplotype, suggesting a three-gene disease model associating two HLA and one AChR a gene in MG [30].

Myasthenia gravis associated with thymoma is a paraneoplastic disease, in which proliferating epithelial cells attract large numbers of immature I cells [31]. These epithelial cells may express AChR or AChRrelated epitopes, titin or ryanodyne receptor-like epitopes but not the intact proteins [32-34]. However, the majority of these thymomas lack activation markers. A minute fraction of activated $\mathrm{T}$ cells leave the thymus and are found in the peripheral blood lymphocytes [35] and activate B cells. Indeed, all thymoma patients have circulating anti-AChR antibodies and anti-titin antibodies, and, to a lesser extent, antibodies against the ryanodin receptor, which implicates the autoimmune nature of thymomaassociated MG. Unlike the transplantation of the thymus with follicular hyperplasia in SCID mice that induces high titers of anti-AChR anti-bodies, thymoma explants never cause anti-AChR antibody production nor EAMG [36].

Marx et al. suggest that aberrant expression of neurofilaments expressing AChR or titin-related epitopes induces a false positive selection of immature $T$ cells leaving the thymus. These $T$ cells are activated in the periphery where they are stimulated to maintain a continuous antibody production even after removal of the thymoma. Local destruction of postsynaptic membrane provides a continuous source of autoantigens for the stimulation of autoreactive $T$ and $B$ cells. 
Experimental autoimmune myasthenia gravis: comparison of EAMG and MG

An experimental animal model closely mimicking the disease has provided answers to many questions about the role of anti-AChR antibodies in MG. We will address these questions below.

$M G$ can be reproducibly induced by injecting anti-AChR antibodies into experimental animals. This passively transferred disease occurs within $6 \mathrm{~h}$ to a few days after a single injection of monoclonal antibodies against AChR. Patients' sera or polyclonal antibodies can be used, but this model is not as reproducible and needs repeated injections.

Active immunization with AChR from different species or subunits or peptides derived from $A C h R$ induces a chronic EAMG model with symptoms starting from 30 days after immunization. Both acute and chronic EAMG resemble MG.

Animals have muscular weakness after repetitive use of the muscles. The defective neuromuscular transmission is demonstrated by repetitive neurostimulation. This causes a decremental response by repetitive nerve stimulation showing increased jitters and blocking. Serum antibodies against AChR are mainly directed against the MIR, and anti-MIR mAbs are very effective inducing EAMG. As little as 40 pmol of antibody $35 \mathrm{can}$ induce severe $M G$ in a rat expressing about $70 \mathrm{pmol}$ of $A C h R$ in muscles. So, no higher antibody excess to $A C h R$ is needed to downmodulate $A C h R$. A compensatory increase in AChR mRNA at the synapse can be measured [37].

Are pathogenic antibodies structurally related?

Both in MG and EAMG, two thirds of serum antibodies are directed to the MIR on the a subunit. Apparently in contrast to the restricted specificity of anti-AChR antibodies, the origin of serum [38-40] and endplate antibody is polyclonal, indicating that a large population of plasma cells produce antiAChR antibodies. Sequence analysis of monoclonal antibodies immortalized from $B$ cells of EAMG animals reveals a high number of somatic mutations. These findings indicate that the immune response is antigen-driven and not the result of some accidental mutation. Among pathogenic antibodies a high sequence homology (>90\%) has been found, but none of these antibodies were identical [41].

To investigate the individual contributions of anti-human AChR responses in $M G$, we dissected the immune response into monoclonal antibodies. A phage-display technique was used to immortalize the antiAChR secreting clones from the thymus of myasthenic patients. Four human monoclonal antibodies were isolated by us and showed to bind human AChR more accurately against the main immunogenic region. The antibodies were able to inhibit the binding of human MG sera to human AChR up to $80 \%$. They were also able to protect against AChR loss by antigenic modulation induced by $\mathrm{MG}$ sera, making them potential therapeutic tools for patients with myasthenic crisis. In total, $18 \mathrm{~F}_{\mathrm{ab}}$ s were 
isolated by three different groups. Of the eight published amino acid sequences, all eight were different [41-43].

From the published sequences for antibodies from EAMG animals and MG patients, it can be concluded that pathogenic antibodies are not structurally related. All anti-MIR antibodies recognizing a small decapeptide $a 67-76$ [44] at the top of the external side of a subunits are structurally different. Indeed, antibodies in general recognize pentapeptides, which means that they can recognize at least five partially overlapping epitopes by their linear amino acid structure. Moreover, the MIR, being highly conformationally dependent, expresses additional epitopes that can be recognized by their respective antibodies. The role of antibodies against non-MIR epitopes, i.e. other subunits and cytoplasmic domains in the pathogenesis of myasthenia, has not been proven since only monoclonal antibodies against the MIR are capable of inducing EAMG.

\section{What is the role of complement in EAMG/MG?}

Both in MG and EAMG endplates, the lytic membrane attack complex (MAC) is found at the neuromuscular junction $[45,46]$, suggesting the role of complement in the focal lysis of the postsynaptic membrane. Complement can be activated both by anti-AChR and antibodies against striational antigens [47]. Complement levels are decreased during exacerbation of $\mathrm{MG}$, suggesting increased complement consumption. Complement-mediated focal lysis of the postsynaptic membrane removes the restraint on $A C h R$, thus facilitating $A C h R$ internalization. Muscle cells are able to upregulate the synthesis of complement regulatory proteins (CD55, CD59 and vitronectin) as a defensive mechanism against complementmediated damage [46].

Animals that are deficient of certain proteins for the complement cascade including $\mathrm{C} 3$ or $\mathrm{C} 5$ do not produce $\mathrm{MAC}$ that parallels their resistance against EAMG [21]. Treatments including those with anabolic steroids that increase complement levels also increase the susceptibility to acute EAMG [48]. In view of the important role of complement in the disease and the beneficial effect of complement in inhibitors in EAMG, these inhibitors or non-complement fixing anti-MIR antibodies could be used as therapeutic agents to rapidly reverse a myasthenic crisis.

\section{The role of macrophages in EAMG}

In response to the antibody-mediated attack at the neuromuscular junction and the release of complement components including $\mathrm{C} 3 \mathrm{a}$ and $\mathrm{C} 5 \mathrm{a}$, macrophages migrate to the endplate region. The question is whether these macrophages are a primary cause of AChR loss in EAMG. Therefore we depleted macrophages in rats by means of irradiation. After induction of EAMG with anti-MIR monoclonal antibody 35, muscular weakness developed to a simillar extent in macrophage depleted animals as in control animals. AChR and complement depositions were similar in both groups. However, no infiltrating macrophages were seen in irradiated 
animals. This macrophage depletion does not interfere with the induction of acute EAMG by injection of monoclonal antibody 35 . The macrophage infiltration seen in the non-depleted animals may be secondary to the focal damage at the endplate [49]. In $\mathrm{MG}_{3}$ macrophage infiltrations are present in muscles to a lesser extent, but mostly not in the vicinity of endplates [50]. None of the inflammatory cells penetrate the muscle fiber near the endplate. In contrast, Maselli et al. [51] observed some macrophages in the endplate region. Based on the results of EAMG studies, however, it seems unlikely that macrophages play a role in the endplate damage, because endplate-bound anti-AChR antibodies and complement depositions suffice to induce AChR loss.

\section{Resistance against the induction of EAMG}

Aged rats, contrary to young rats, are resistant to the induction of passive transfer and EAMG induced by active immunization. An injection of a complement-fixing anti-MIR antibody 35 in aged animals does not induce muscular weakness nor clinical signs of EAMG in these old animals. This resistance could not be explained by deficient antibody uptake, increased antibody clearance, inaccessibility of AChRs for antibodies in aged animals, absence of infiltrating macrophages, nor by deficient complement activation. Therefore, it is most likely that the resistance resides at the level of the postsynaptic membrane, more specifically by resistance of the AChR molecules to antibody-mediated degradation. Semiquantative analysis of the several proteins of the postsynaptic membrane in aged rats revealed an increase in the content of some of the anchor proteins including rapsyn, the most important $A C h R$ anchor protein. These results suggest that the susceptibility and clinical course of EAMG and possible MG is not only determined by the immune attack towards the neuromuscular junction, but also by the rigidity and the number of anchor proteins of AChR in the postsynaptic membrane [37].

In this context, we are trying to increase the concentration of rapsyn in the neuromuscular fiber by injecting a rapsyn expression system into muscular fibers by means of electropermeation [52].

The experiments in age resistant animals could explain the absence of a correlation between anti-AChR titer and disease severity. So, procedures aimed at increasing the number of $A C h R$ anchor proteins might protect the endplate against the antibody-mediated attack. Electrotransfer of DNA encoding for rapsyn into the levator palpebrae or orbicularis oculi muscles might result in a long-term overexpression of $\mathrm{AChR}$ at the endplate.

\section{Therapeutic antibodies as a treatment of $M G$}

Antibodies against the extracellular epitopes of the $\alpha$ subunit are capable of cross-linking receptors, thus facilitating AChR internalization and degradation. Monovalent $F_{\text {ait }}$ fragments of anti-AChR antibodies are able to interfere with this process both in vitro $[41,53]$ and in vivo [54].

In order to increase the half-life of the $\mathrm{F}_{\text {ais }}$ molecules, we cloned its chain into an IgG molecule which has only one antigen-binding site and lacking 
the $\mathrm{Clq}$-binding sites that are necessary for complement activation. This molecule will be tested for its capacity to inhibit a passive transfer EAMG using $M G$ patient serum.

In summary, the experimental model has been very useful to elucidate the central role of antibodies in autoimmune $M G$. Pathogenic antibodies binding mainly to the MR are not structurally related. Binding of complement proteins including $\mathrm{C} 1 \mathrm{q}$ to anti-AChR antibodies is essential to activate the complement cascade and remove the restraints of AChR molecules in the postsynaptic membrane, thus facilitating AChR internalization. The use of complement inhibitors is beneficial in EAMG and may also be tried in $M G$ exacerbations. Macrophages are not necessary for the antibody-mediated damage of the neuromuscular junction but are infiltrating to remove the damaged fibers. Serendipitiously, we found that rats older than 1 year (for a life span of 27 months) are resistant against the induction of EAMG. The mechanisms of resistance reside in the postsynaptic membrane that contains more AChR anchor proteins. Based on these findings in $E A M G$, new therapeutical measures could be developed including complement inhibitors, nonpathogenic anti-AChR competitor antibodies, and gene therapy aimed at overexpression of AChR anchor proteins.

\section{References}

[1] Lennon, V.A., P.R. Carnegie, "Immunopharmacological disease: a break in tolerance to receptor sites", Lancet 1 (1971) pp. 630-633.

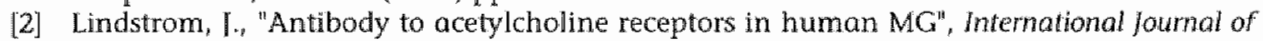
Neurology 14 (1980) pp. 17-24.

[3] Riemersma, S., A. Vincent, D. Beeson, C. Newland, S. Hawke, B. Vemet-der Garabedian, B. Eymard, $\lceil$. Newsom-Davis, "Association of arthrogryposis multiplex congenita with maternal antibodies inhibiting fetal acetylcholine receptor function", Journal of Clinical Investigation 98 (1996) pp. $2358-2363$.

[4] Wintzen, A.R., I.J. Plomp, P.C. Molenaar, I.G. van Dijk, G.T, van Kermpen, R.M. Vos, I.H. Wokke, A. Vincent, "Acquired slow-channel syndrome: a form of myasthenia gravis with prolonged open time of the acetylcholine receptor channel", Amals of Neurology 44 (1998) pp. 657-664.

[5] Buchwald, B., K.V. Toyka, J. Zielasek, A. Weishaupt;, S. Schweiger, I. Dudel, "Neuromuscular blockade by IgG antibodies from patients with Guillain -Barre syndrome: a macro-patch-clamp study", Annals of Neurology 44 (1998) pp. 913-922.

[6] Vernino, S., I. Adamski "T.I. Kryzer, R.D. Fealey, V.A. Lennon, "Neuronal nicotinic ACh receptor antibody in subacute autonomic neuropathy and cancer-related syndromes", Neurology 50 (1998) pp. 1806-1813.

[7] Lindstrom, I.M., "Acetylcholine receptors and myasthenia" "Muscle and Nerve 23. (2000) pp. $453-477$.

[8] Voltz, R, R. Hohlfeld, A. Fateh-Moghadam, T.N. Witt, M. Wick, C. Reirners, B. Siegele, H. Wekerle, "Myasthenia gravis: measurement of anti-AChR autoantibodies using cell line TE671", Neurology 41 (1991) pp. 1836-1838.

[9] Somnier, F.E. "Anti-acetylcholine receptor (AChR) antibodies measurement in myasthenia gravis: the use of cell line TE671 as a source of AChR antigen", Journal of Neuroimmunology 51 (1994) pp. $63-68$.

[10] Vincent, A., ]. Newsom-Davis" "Acetylcholine receptor antibady characteristics in myasthenia gravis. I. Patients with generalized myasthenia or disease restricted to ocular muscles", Clinical and Experimental Immunology 49 (1982) pp. 257-265. 
111) Limburg, P.C., T.H. The, E. Hummel-Tappel, H.\}. Oosterhwis, Anti-acetylcholine receptor antibodies in myasthenia gravis. Part 1. Relation to clinical parameters in 250 patients", Journal of the Neurological Sciences 58 (1983) pp. $357-370$.

[12] Keesey, I. F. Natem, 1. Lindstrom, D. Roe, C. Hermann, Ir., R. Walford, "Acetylcholine receptor antibody titer and HLA-B8 antigen in myasthenia grawis", Archives of Neurology 39 (1982) pp. $73-77$.

[13] Besinger, U.A., K.V. Toyka, M. Homberg, K. Heininger, R. Hohlfeld, A. Fateh-Moghadam. "Myasthenia gravis: long-term correlation of binding and bungarotoxin blocking antibodies against acetylcholine receptors with changes in disease severity" ${ }^{\prime}$ Neurology 33 (1983) pp. 1316-1321.

[14] Seybold, M.E.s "Plasmapheresis in myasthenia gravis", Annals of the New Yark Academy of Sciences 505 (1987) pp. 584-587.

[15] Romi, F, G.O. Skeie, I.A. Aarli, N.E. Gilhus, "Muscle autoantibodies in subgroups of myasthenia gravis patients", lournal of Neurology 247 (2000) pp. 369-375.

[16] Kuks, I.B., P.C. Limburg, G. Horst, H.J. Oosterhuis, "Antibodies to skeletal muscle in myasthenia gravis. Part 3. Relation with clinical course and therapy", foumal of the Neurological Sciences 120 (1993) pp. 168-173.

[17] Marx, A., T. Kirchner, A. Greiner, H.K. Muller-Hermelink, B. Schalke, M. Osborn, "Neurofilament epttopes in thymoma and antiaxonal autoantibodies in myasthenia gravis", Lancet 339 (1992) pp. 707-708.

[18] Hoch, W. I. McConville, S. Helms, I. Newsom-Davis, A. Melms, A. Vincent, "Autoantibodies to the receptor tyrosine kinase MuSK in patients with myasthenia gravis without acetylcholine receptor antibodies", Nature Medicine 7 (2001) pp. 365-368.

[19] Asher, O. W.A. Kues, V. Witzemann, S.]. Tzartos, S. Fuchs, M.C. Souroujon, "Increased gene expression of acetylcholine receptor and myogenic factors in passively transferred experimental autoimmune myasthenia grovis", Joumal of Immunology 151 (1993) pp. 6442-6450.

[20] Ciuyon, T., P. Levasseur, F. Truffoult, C. Cottin, C. Goud, S. Berrih-Aknin, "Regulation of acetylcholine receptor alpha subunit variants in human myasthenia gravis. Quantification of steady-state levels of messenger RNA in muscle biopsy using the polymerase chain reaction", Journal of Clinical Investigation 94 (1994) pp. 16\%24.

[21] Lennon, V.A., M.E. Seybold, J.M. Lindstrom, C. Cochrane, R. Ulevitch, "Role of complement in the pathogenesis of experimental autoimmume myasthenia gravis" fournal of Experimental Medicine 147 (1978) pp. 973-983.

[22] Lennon, V.A., E.H. Lambert, "Monoclonal autoantibodies to acetylcholine receptors: evidence for a dominant idiotype and requirement of complement for pathogenicity", Annals of the New York Academy of Sciences 377 (1981) pp. 77-96.

[23] Souroujon, M.C., A.R. Pachner, S. Fuchs, "The treatment of passively transferred experimental myasthenia with anti-idiotypic antibodies", Neurology 36 (1986) pp. 622 . 625.

[24] Wekerle, H. U.P. Ketelsen, "Intrathymic pathogenesis and dual genetic control of myasthenio gravis", Lancet 1 (1977) pp. 678-680.

25] Schonbeck, S., Padberg. R. Honlfeld, H. Wekerle, "Transplantation of thymic autoimmune microenvironment to severe combined immunodeficiency mice. A new model of myasthenia gravis": Joumal of Clinical Investigation 90 (1992) pp. 245-250.

[26] Sommer, N. N. Willcox, G.C. Harcourt, 1. Newsom-Davis, "Myasthenic thymus and thymoma are selectively enriched in acetylcholine receptor reactive T cells", Amnals of
Neurology $28(1990) \mathrm{pp} .312-319$.

[27] Manfredi, A.A., M.P. Proti, M. Bellone, L. Moiola, B.M. Conti-Tronconi, "Molecular anatomy of an autocintigen: $T$ and $B$ epitopes on the nicotinic acetylcholine receptor in myasthenia gravis", fournal of Laboratory and Clinical Medicine 120 (1992) pp. 13-21.

[28] Claudio, T., M. Ballivet, I. Patrick, S. Heinemann, "Nucleotide and deduced amino acid sequences of Torpedo californica acetylcholine receptor gamma subunit", Proceedings of the National Academy of Sciences of the United States of America 80 (1983) pp. 1111-1115.

[29] Gahring, L., N.G. Corlson, E. L. Meyer, S.W. Rogers, "Cranzyme B proteolysis of a neuronal glutamate receptor generates an autocintigen and is modulated by glycosylation'", Joumal of immunology 166 (2001) pp. 1433-1438

[30] Djabiri, F., S. Caillat-Zucmon, P. Gajdos, J.P. Jais, L. Gomez, I. Khalil, D. Charron, J.F. Bach, Hi.j. Garchon. "Association of the AChRalpha-subunit gene (CHRNA), DQA1*0101, 
and the DR3 haplotype in myasthenia gravis. Evidence for a three-gene disease model in a subgroup of patients", Joumal of Autoimmunity 10 (1997) pp. $407-413$.

[31] Marx, A., R. O'Connor, K.I. Geuder, F. Hoppe, B. Schalke, S. Tzartos, L. Kalies, T. Kirchner, H.K. Muller-Hemelink, "Characterization of a protein with an acetylcholine receptor epitope from myasthenia gravis-associated thymomas", Laboratony investigation 62 (1990) pp. 279.286 .

[32] Kirchner, T., S. Tzartos, T. Hoppe, B. Schalke, H. Wekente, H.K. Muller-Hemelink, "Pathogenesis of myasthenia gravis. Acetylcholine receptor-related antigenic determinants in tumor-free thymuses and thymic epithelial tumors", American pournat of Pathology 130 (1988) pp. 268-280.

[33] Marx, A., A. Wilisch, A. Schultz, S. Gattenlohner, R. Nenninger, H.K. Muller-Hermelink, "Pathogenesis of myasthenia gravis", Virchows Archiv 430 (1997) pp. 355-364.

[34] Mygland, A., G. Kuwajima, K. Mikoshiba, O.B. Tysnes, I.A. Aarlï, N.E. Gilhus, "Thymomas express epitopes shared by the ryanodine receptor" "Joumal of Neuroimmunology 62 (1995) pp. 79-83

[35] Buckley, C., D. Dowek, I. Newsom-Davis, A. Vincent, N. Willcox, "Mature, long-lived CD4+ and CD8+ $\mathrm{I}$ cellis are generated by the thymoma in myasthenia gravis", Annals of Neurology 50 (2001) pp. 64-72.

[36] Spuler, S., A. Sarropoulos, A. Marx, R. Hohlfeld, H. Wekerle, "Thymoma-associated myasthenia gravis. Transplantation of thymoma and extrathymomal thymic tissue into SCID mice", American Journal of Pathology 148 (1996) pp. 1359-1365.

[37] Hoedemaekers, A., I.L. Bessereau, Y. Graus, T. Guyon, I.P. Changeux, S. Berrih-Aknin, P. van Breda Vriesman, M.H. De Baets, "Role of the target organ in determining susceptibility to experimental autoimmune myasthenia gravis", foumal of Neuroimmunology 89 (1998) pp. 131-141.

[38] Bionda, A., M.H. De Baets, S.J. Tzartos, J.M. Lindstrom, W.O. Weigle, A.N. Theophilopoulos, "Spectrotypic analysis of antibodies to acetylcholine receptors in experimental autoimmune myasthenia grawis", Clinical and Experimental Immunology 57 (1984) pp. $41-50$.

[39] Lefvert, A.K., K. Bergstrom, "Acetylcholine receptor antibody in myasthenia gravis: purification and characterization", Scandinavian Journal of Immunology 8 (1978) pp. 525533.

[40] Thompson, P.A., K.A. Krolick, "Acetylcholine receptor-reactive antibodies in experimental autoimmune myasthenia gravis differing in disease-causing potential: subsetting of serum antibodies by preparative isoelectric focusing", Clinical Immunology and Immunopathology 62 (1992) pp. 199-209.

[41] Graus, X.F., M.H. de Baets, P.W. Parren, S. Berrih-Aknin, I. Wokke, P.J. wan Breda Vriesman. D.R. Burton, "Fuman anti-nicotinic acetylcholine recepton recombinant Fab fragments isolated from thymus-derived phage display libraries from myasthenia gravis patients reflect predominant specificities in serum and block the action of pathogenic serum antibodies", Journal of Immunalogy $158(1997)$ pp. 1919.1929.

[42] Farrar, I., S. Portolano, N. Willcox, A. Vincent, L. Jacobson, I. Newsom-Davis, B. Ropoport, S.M. McLachlan, "Diverse Fab specfic for acetylcholine receptor epitopes from a myasthenia gravis thymus combinatorial library", International Immunology 9 (1997) pp. $1311-1318$.

[43] Rey, E., M. Zeidel, C. Rhine, J. Tami, K. Krolick, M. Tischbach, I. Sanz, "Characterization of human anti-acetylcholine receptor monoclonal autoantibodies from the peripheral blood of a myasthenia gravis polient using combinatorial libraries". Clinical Immunology 96 (2000) pp. $269-279$

[44] Tzartos, S.I., T. Barkas, M.T. Cung, A. Mannalaki, M. Marroud, P. Orlewski, D. Papanastasiou, C. Sakarellos, M. Sakarellos-Daitsiotis, P. Tsantili, V. Tsikaris, "Anatomy of the antigenic structure of a large membrane autoantigen, the muscle-type nicotinic acetylcholine receptor", Immunological Reviews 1.63 (1998) pp. 89-120.

[45] Engel, A.G., E.H. Lambert, F.M. Howard, "Immune complexes (1gG and C3) at the motor end-plate in myasthenia gravis: ultrastructural and light microscopic localization and electrophysiologic correlations", Mayo Clinic Proceedings 52 (1977) pp. $267-280$.

[46] Hoedemaekers, A., Y. Graus, P. van Breda Vriesman, M. de Baets, "Age- and sex-related resistance to chronic experimental autoimmune myasthenia gravis (EAMG) in Brown Norway rats", Clinical and Experimental Immunology 107 (1997) pp. 189-197. 
[47 Romi, T, G.O. Skete, C. Vedeler, I.A. Aarli, F. Zorzato, N.E. Gilhus, "Complement activation by titin and ryanodine receptor autoontibodies in myasthenia gravis. A study of IgG subclasses and clinical correlations", Joumat of Neuroimmunolagy 111 (2000) pp. $169-176$.

481 De Baets, M.H. f. Verschuuren, M.R. Daha, P.I. wan Breda Vriesman, "Effects of the rate of acetylcholine receptor synthesis on the severity of experimental autoimmune myasthenia. gravis" immunologic Research 7 (1988) pp. 200-211.

[49] Hoedemakkers, A., Y. Grous, L. Beijleveld, P. van Breda Vriesman, M. De Baets, "Macrophage infiltration at the neuromuscular junction does not contribute to AChR loss and age-related resistance to EAMG", Joumal of Neuroimmunalogy 75 (1997) pp. 147-15.5.

[50] Nakano, 5., A.G. Engel "Myasthenia gravis: quantitative immunocytochemical analysis of inflammatory cells and detection of complement membrane attack complex at the end-plate in 30 patients", Neurology 43 (1993) pp. $1167-1172$.

[51] Maselli, R.A. D.P. Richman, R.L. Wollmann, "Inflammation at the neuromuscular junction in myasthenia gravis", Neuralogy 41 (1991) pp. 1497-1504.

[52] Mir, L.M., M.F. Bureau, I. Gehl, R. Rangara, D. Rouy, J.M. Caillaud, P. Delaere, D. Branellec, B. Schwartz, D. Scherman, "High-efficiency gene transfer into skeletal muscle rnediated by electric pulses", Prockedings of the National Academy of Sciences of the United States of America 96 (1999) pp. 4262-4267.

[53] Mamalaki, A., N. Trakas, S.I. Tzartos, "Bacterial expression of a single-chain Fw fragment which efficiently protects the acetylcholine receptor against antigenic modulation coused by myasthenic antibodies"', European Joumal of Immunology 23 (1993) pp. 1839-1845.

[54] Papanastasiou, D. K. Poulas, A. Kokla, S.I. Tzartos, "Prevention of passively transferred experimental autoimmune myasthenia gravis by fab fragments of monocional antibodies directed against the main immunogenic region of the acetylcholine receptor" Journal of Neuroimmunology 104 (2000) pp. 124-132. 


\section{Chapter 2}

\section{Experimental autoimmune myasthenia gravis in mice expressing human immunoglobulin loci}

Maurice H.W. Stassen, Fanping Meng, Eefje Melgert,

Barbie M. Machiels, Sin-Hyeog Im, Sara Fuchs, Arnout F. Gerritsen, Marc A. van Dijk, Jan G.J. van de Winkel \& Marc H. De Baets

published in the

Journal of Neuroimmunology 135 (2003) pp. 56-61 


\section{Abstract}

Antibodies (Abs) specifically directed against the muscular acetylcholine receptor (AChR) mediate the pathogenesis of myasthenia gravis (MG). The animal model experimental autoimmune MG (EAMG) can be induced by passive transfer or by active immunization of anti-AChR Abs. We report a new EAMG mouse model that generates human anti-AChR Abs upon immunization with Torpedo AChR (tAChR). Mice transgenic for human $\mu_{\text {, }}$ $\psi 1$, and $k$ germ line genes (HuMAb-Mice) were immunized with tAChR. Serum titers of anti-tAChR Abs were in the nanomolar range, and antirodent $A C h R$ Abs were in picomolar range. Some HuMAb-Mice had signs of muscle weakness, clearly indicating their susceptibility to EAMG. Human Ab-mouse AChR complexes were found at the neuromuscular junction, while AChR loss was up to $65 \%$. Spleen and lymph nodes were used for producing hybridomas. Of the anti-tAChR monoclonal Ab-producing hybridomas, $2 \%$ had cross-reactivity with rodent AChR and non with human AChR. Immunization with a fusion protein, Trx-Ha1-21D, displaying the human main immunogenic region did not result in EAMG or the generation of human anti-human AChR monoclonal Abs. These experiments show that the HuMAb-Mouse represents a suitable model to generate and study the effects of human anti-AChR Abs in vivo. 


\section{Introduction}

Autoantibodies in the organ-specific autoimmune disease myasthenia gravis (MG) are directed mainly to the acetylcholine receptor (AChR) [1]. Anti-AChR antibodies (Abs) cause a disturbed neuromuscular transmission, either by decrease of AChR concentration or, to a lesser extent, functional inhibition of the ion channel $[2,3]$. Two mechanisms that lead to this receptor loss are anti-AChR Ab-activated complement reaction, resulting in focal lysis of the membrane [4,5], and cross-linking of receptors by Abs that are capable of binding to two AChRs simultaneously, leading to an increased rate of internalization of the receptor (antigenic modulation) $[6,7]$.

Experimental autoimmune $\mathrm{MG}$ (EAMG) is the animal model that resembles $M G$ closely. Immunization of animals with Torpedo AChR ( $t A C h R)$, isolated from the ray Torpedo californica, gives rise to anti-tAChR Abs, of which a small percentage cross-reacts with autologous AChR and cause EAMG $[1,8]$. Passive transfer of MG patient's immunoglobulins (Igs) in mice also induces EAMG, indicating the importance of these human Igs in the pathogenesis of MG [9]. In another study that used patient material, $\mathrm{MG}$ thymus tissue was transplanted into severe combined immunodeficiency (SCID) mice, resulting in the production of human antiAChR Ab titers, but although human Abs were found at the muscle endplates, EAMG was not induced [10]. Mice have strain-dependent susceptibilities to EAMG, although anti-AChR Ab serum titers and fine specificities are comparable [11-13]. Mice transgenic for different HLA genes have different susceptibilities to EAMG, implying an important role of these human genes in the pathogenesis of MG [14]. The use of human genes and molecules in EAMG clearly matches the model more closely to MG.

In this study, we demonstrate a new EAMG mouse model, using a mouse strain that is transgenic for human $1 \mathrm{~g}$ loci $[15,16]$. Upon immunization, this so-called HuMAb-Mouse is a source of antigen-specific human monoclonal Ab (mAb)-producing lymphocytes. In order to determine if the HuMAb-Mouse is susceptible to EAMG, we immunized the mouse with tAChR. Furthermore, we examined the possibility to generate human anti-human AChR mAbs.

\section{Materials and methods}

\section{Immunization}

HuMAb-Mice transgenic for human $\mu, \gamma 1$, and $\kappa$ germ line genes, while production of endogenous immunoglobulins was inactivated $[15,16]$, were immunized at the base of the tail with $15 \mu \mathrm{g}$ tAChR in CFA and boosted twice with the same dose of tAChR or $500 \mu \mathrm{g}$ Trx-Ha1 210 [1.7] in IFA. Control HuMAb-Mice were immunized with CFA only. 


\section{Clinical scoring}

The severity of clinical signs of disease in EAMG was scored by measuring muscular weakness. The animals' muscle strength was assessed by their ability to grasp and lift repeatedly a $300 \mathrm{~g}$ rack from the table, while suspended manually by the base of the tail for 30 seconds. Clinical scoring was based on the presence of tremor, hunched posture, muscle strength and fatigability. Disease severity was expressed as: 0 , no obvious abnormalities; +, no abnormalities before testing, but reduced strength at the end; ++, clinical signs present before testing, i.e. tremor, head down, hunched posture, weak grip; +++ , severe clinical signs present before testing, no grip, moribund $[8,18]$.

\section{Hybridoma fusion and screening}

Lymph node and spleen cells were isolated and fused with SP2/0 cells for production of hybridomas. Culture supernatants of hybridoma clones were screened for anti-tAChR mAb production using an ELISA. Microtiter plates were coated with $50 \mu \mathrm{l}$ of $5 \mu \mathrm{g} / \mathrm{ml}$ tAChR in a $10 \mathrm{mM}$ bicarbonate buffer, $\mathrm{pH} 9.5$, for $1 \mathrm{~h}$ at $37^{\circ} \mathrm{C}$. After washing three times with water containing $0.5 \%$ Tween 20 (wash buffer), wells were blocked with $200 \mu \mathrm{l}$ PBS containing $0.5 \%$ BSA and $0.5 \%$ Tween 20 (incubation buffer) for $15^{\circ}$. Subsequently, plates were incubated with a appropriate dilution of hybridoma culture supernatant in incubation buffer for $1 \mathrm{~h}$ at room temperature. After washing, plates were incubated with 1/500 alkaline

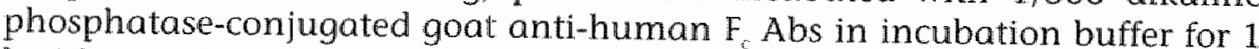
h. After washing, $50 \mu \mathrm{l}$ of alkaline phosphatase substrate solution (Bio-Rad Laboratories, Hercules, CA, USA) was added. The staining reaction was developed for $30^{\prime}$ and $O D$ measured at $450 \mathrm{~nm}$.

\section{Anti-AChR Ab serum titer and mAb cross-reactivity}

$\mathrm{Ab}$ titers against $\mathrm{AAChR}$, human $\mathrm{AChR}$ (hAChR) and rat $\mathrm{AChR}$ ( $\mathrm{ACCh}$ ) and cross-reactivity of mAbs were determined by a RIA, using ${ }^{125} I-\alpha$ bungarotoxin $\left({ }^{i 25} I-\alpha-B T\right)$ labeled $A C h R[1]$. AChR - either purified $t A C h R$, crude extract of denervated rat muscle, or crude extract of hAChRproducing cell line TE671 - was labeled with $2 \mathrm{nM}{ }^{125} \mathrm{I}-\alpha-B T$ for $4 \mathrm{~h}$ at $4^{\circ} \mathrm{C}$. 5 $\mu l$ of serum or $100 \mu \mathrm{l}$ of hybridoma culture supernatant was incubated with $200 \mu 1{ }^{125} \mathrm{I}-\alpha-B \mathrm{~T}$-labeled AChR overnight at $4^{\circ} \mathrm{C}$. Ab-AChR complexes were precipitated by incubating with excess goat anti-human Ig Abs for $4 \mathrm{~h}$ at $4{ }^{\circ} \mathrm{C}$. After washing with PBS containing $0.5 \%$ Triton-X100 and $0.02 \%$ $\mathrm{NaN}_{3}$ radioactivity was counted in a y counter. $\mathrm{Ab}$ titers were expressed as moles of $\alpha$-BT sites per liter. hAChR-specific FACS analysis was performed with permeablized TE 671 cells and FITC-conjugated rabbit anti-human IgG $\mathrm{F}(\mathrm{ab})_{2}$ (1/100; Dako, Glostrup, Denmark), according to the Cytofix/Cytoperm Plus Kit manual (PharMingen, San Diego, CA, USA).

\section{Quantification of AChR in muscle}

To quantify the AChR loss in EAMG mice, the concentration of AChR in muscle was determined as previously described $[19,20]$. In short, mouse 
carcasses were minced and homogenized in $150 \mathrm{ml}$ of $10 \mathrm{mM}$ sodium phosphate pH 7.5, $100 \mathrm{mM} \mathrm{NaN}_{3} 10 \mathrm{mM}$ iodoacetamide and $1 \mathrm{mM}$ PMSF. Homogenate was centrifuged at $12.000 \mathrm{rpm}_{t} 4^{\circ} \mathrm{C}$ for $30^{\prime}$, and pellet was resuspended in $10 \mathrm{ml}$ of $10 \mathrm{mM}$ sodium phosphate $\mathrm{pH} 7.5,100 \mathrm{mM} \mathrm{NaN}_{\text {s. }}$ $10 \mathrm{mM}$ iodoacetamide, $1 \mathrm{mM}$ PMSF and $2 \%$ Triton-X100. Extraction was performed for $1 \mathrm{~h}$ at $4^{\circ} \mathrm{C}$ on a shaker. After centrifugation at $12.000 \mathrm{rpm}$, $4^{\circ} \mathrm{C}$ for $30^{\prime}$, the volume of the supernatant was measured and aliquots of 1 $\mathrm{ml}$ were labeled with ${ }^{125} \mathrm{I}-\alpha-\mathrm{BT}$, with or without $1 \mathrm{mM}$ acetylcholine and neostigmine-bromide. $1 \mu \mathrm{l}$ of pooled high-titer rat anti-AChR serum and normal rat serum were added, and triplicates of $250 \mu \mathrm{l}$ mixture (with or without acetylcholine and neostigmine-bromide) were incubated overnight at $4^{\circ} \mathrm{C}$. Subsequently, $100 \mu \mathrm{l}$ goat anti-rat Ig Abs was added and incubated for $4 \mathrm{~h}$ at $4^{\circ} \mathrm{C}$. After centrifugation for 3', pellet was washed once with PBS counting $0.5 \%$ Triton-X100 and $0.02 \% \mathrm{NaN}_{3}$ and counted in $y$ counter. AChR concentrations were compared with CFA-immunized HuMAb-Mice.

\section{Immunohistochemical staining of muscle}

Muscle biopsies from HuMAb-Mice were frozen in 2-methylbutane, cut at 6 $\mu \mathrm{m}$ and fixated with acetone for $10^{\prime}$ at $4^{\circ} \mathrm{C}$, and air-dried for $5^{\prime}$. After washing three times with PBS, sections were pre-incubated with PBS containing $2 \%$ bovine serum albumin for $15^{\circ}$, and subsequently stained with 1/100-diluted goat anti-human IgG (Cappel, ICN Pharmaceuticals, Aurora, $\mathrm{OH}$, USA) for $45^{\circ}$. After washing with $\mathrm{PBS}$, sections were incubated with 1.50 FITC-conjugated rabbit anti-goat Ig Abs (Cappel, ICN Biochemicals, Eschwege, Germany) together with $1 / 250$ rhodamineconjugated $\alpha$-BT (Molecular Probes, Eugene, OR, USA) for 45, in order to Co-localize human anti-AChR Abs with mouse AChR.

\section{Results}

Table 1: Clinical EAMG signs of Torpedo AGMR-immunized HuMAb-Mice

\begin{tabular}{|c|c|c|c|c|}
\hline Chinical score & 0 & + & $+\infty$ & $+1+4$ \\
\hline Number of mice & 9 & 3 & . & - \\
\hline
\end{tabular}

Clinical scoring: 0 , no obvious abnomalities; + , no abnormalities before teshing, but reduced strength at the end; + , clinical signs present befone testing, i.e. tremor, head down, humched posture, weak grip; tat, severe dinical signs present before testing, no grip, moribund.

\section{Induction of EAMG}

HuMAb-Mice were immunized with TAChR to determine their susceptibility to EAMG. After the second boost, three of the twelve animals had a weak grip, while the other nine mice showed no clinical signs of EAMG (Table 1). The mice had $\mathrm{Ab}$ titers of anti-tAChR ranging from 7 to $296 \mathrm{nM}$ and of anti-rodent $\mathrm{AChR}$ ranging from 155 to $539 \mathrm{pM}$ (Figure 1), indicating a 
successful immunization with tAChR in all mice. The anti-rAChR/antitAChR Ab serum titer ratio was between 0.2 and $4 \%$. Staining of $A C h R$ at the neuromuscular junction in muscle sections with rhodamine-conjugated $\alpha$-BT was co-localized with human Abs, visualized with goat anti-human IgG and FITC-conjugated rabbit anti-goat Ig Abs (Figure 2). To determine the damage that was inflicted by the human anti-mouse AChR (mAChR) Abs, the AChR loss in muscles was measured. The AChR contents in the

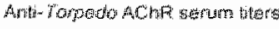

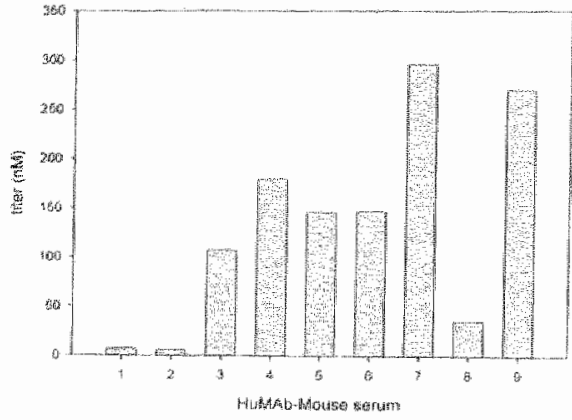

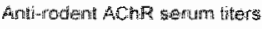

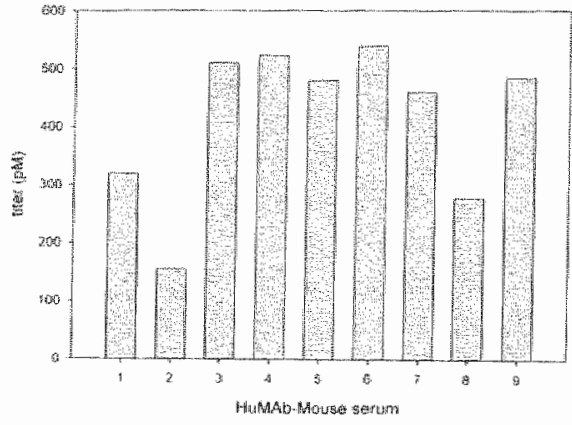

Figure 1

Human anti-AChR $\mathrm{Ab}$ serum titers in Tarpedo AChR-immunized HuMAb-Mice. Serum titers (moles a-bungarotoxim binding sites per lifer senum) were measured by a RIA, using $125 \mathrm{I}$-o-bungarotoxin-labeled forpedo or rat AChRs.
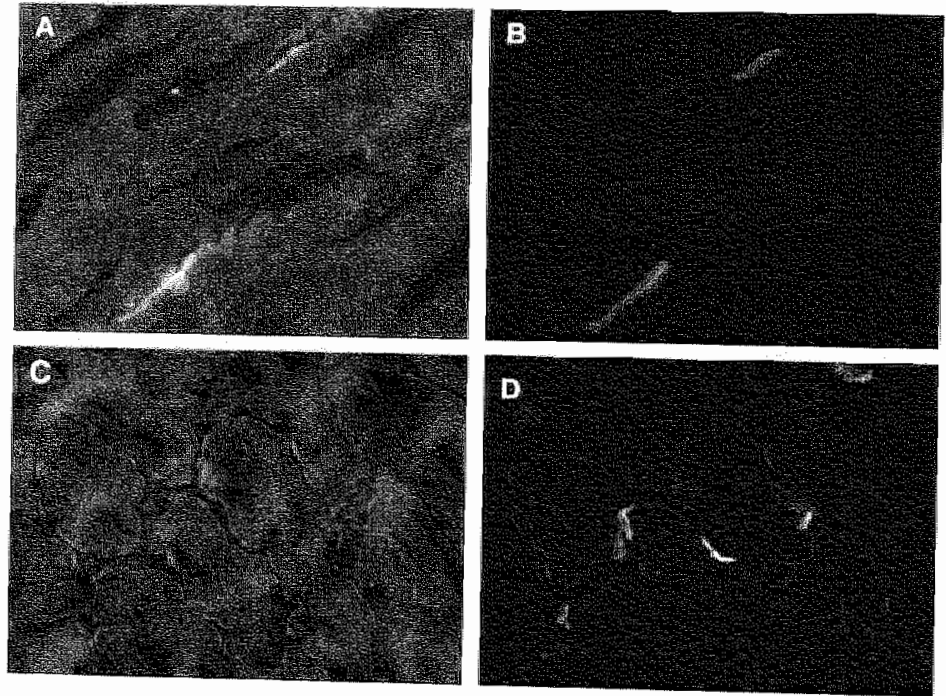

Figure 2

Humary Ab-mouse AChR complexes at the reuromuscular junction of Torpedo AChR-inmunized HuMAD-Mice. Cryosections of Torpedo AChR-immunized $(a$, b) human IgG and FIC-coniugatec rabbites were double stained with goat anticonjugated abungarotoxingated rabbit anti-goat $\mathrm{Ig} \mathrm{Abs}(\mathrm{a}, \mathrm{c})$ and rhodaminein Torpedo AchR-immunized mice. 
tAChR-immunized mouse muscles were 0 to $65 \%$ lower, compared to control mice (Figure 3). These data clearly demonstrate that HuMAb-Mice were susceptible to EAMG.

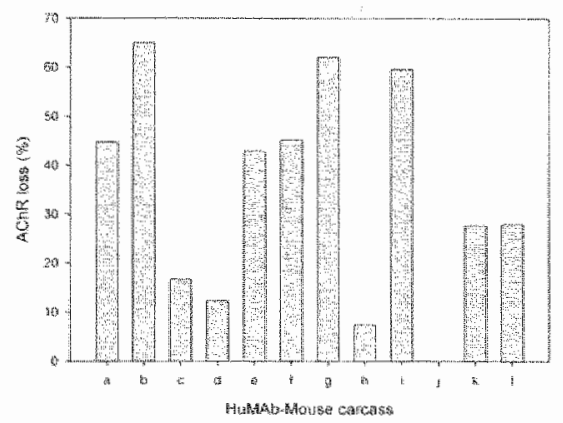

Figure 3

AChR loss in Torpedo AChR-immunized HuMAb-Mice. Total AChR concentrations of mouse muscles were determined by immunoprecipitation, using ${ }^{125}$ [-a-bungarotoxin, and compared to control animals $(\mathrm{p}<0.05)$.

Human anti-tAChR mAbs

Spleens and lymph nodes were isolated for the production of anti-AChRspecific hybridoma cells. 433 anti-tAChR mAb-producing clones were selected after initial screening of the hybridomas by ELISA. The number of hybridomas that had cross-reactivity with rodent $\mathrm{AChR}$ - those mAbs that were most likely pathogenic in the mice - was $7(2 \%)$, as determined by a RIA (Table 2). In order to explore the possibility of a human mAb crossreacting with $h A C h R$, that could be used for studying MG immunotherapy, a hAChR-specific RIA was performed. But no hybridoma mAb could bind hAChR with high specificity.

Table 2: Specificities of mAbs produced by Torpedo AChR-immunized HuMAb-Mouse hybridomas

\begin{tabular}{cc} 
Specificity & Number of mAbs (\%) \\
\hline anti-Torpedo AChR & $433(100)$ \\
anti-rodent AChR & $7(2)$ \\
anti-human AChR & $0(0)$
\end{tabular}

Cross-reactivity of human anti-Torpedo AChR mAbs was determined by "I- $\alpha$ bungarotoxin-labeled AChR immunoprecipitation.

Human anti-hAChR mAbs

In order to generate human anti-hAChR mAbs, HuMAb-Mice were immunized with a fusion protein, Trx-Ha1-210, displaying the human MIR. Irx-Ha1-210 consists of the first 210 amino acids of the hAChR $\alpha$ subunit $(\mathrm{H} \alpha 1-210)$ fused to thioredoxin (Trx), giving $\mathrm{H} \alpha 1-210$ a more 
native conformation [17]. The conformation of the antigen is important, considering that many pathogenic anti-MIR mAbs don't cross-react with Ha1-210. Five animals were immunized with TAChR and boosted twice with Trx-Ha1-210. Sero were anti-hAChR Ab positive, as shown by FACS analysis (Figure 4). No clinical signs of EAMG were observed. Hybridomas were produced as before and selected on Trx-Ha1-210 specificity by ELISA, yielding 20 anti-Irx-Ha1-210 mAb-producing cell lines. The mAbs were screened for binding to unfused Ha1-210 and Trx by ELISA, showing that none of these anti-TrX.Hal-210 mAbs binds to the denatured form of Hal210 or to Trx. But, a hAChR-specific RIA of the mAbs was also negative. These results (Table 3) suggest that all the $m A$ bs are directed against a non-AChR-specific epitope region, unique for the fusion protein.
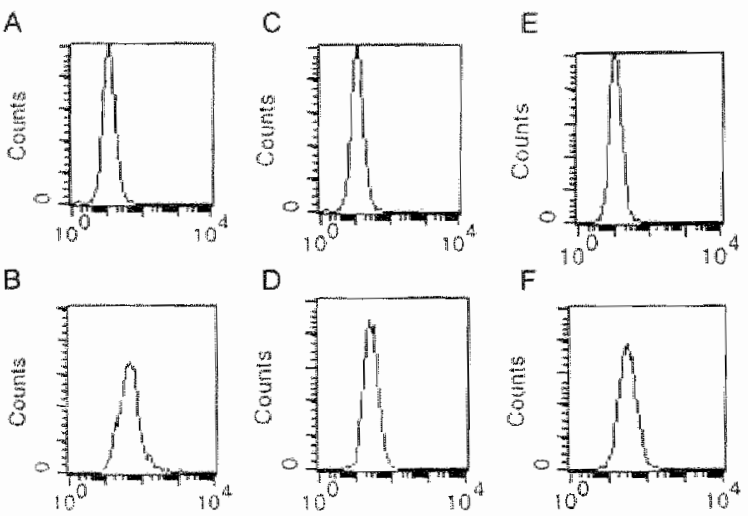

Figure 4

FACS analysis of Trx-Ha1-210-boosted HuMAb-Mouse sera. TE 671 cells were inculated with human anti-AChR IgG1-637 (b), pre-immunization sera $(1 / 25 ; c$, e), post-immunization sera $(1 / 25 ; 0, f)$ or nothing (a).

Tahle 3: specificities of nAb. produced by Trx-flat-210-boosted HuMAb-Mouse hybridomas

$\begin{array}{cc}\text { Specifitity } & \text { Number of mAbs }(\%) \\ \text { anth-Tr-Hol-210 } & 20(100) \\ \text { anti-Hol-210 } & 0(0) \\ \text { anti-TrK } & 0(0) \\ \text { anti-Human AChR } & 0(0)\end{array}$

Cross-reachivity of human anti-Irx-Ha1-210 AChR mAbs was determined by ELISA for Ho $1-210$ and $T \mathrm{rx}$, and by RIA for human AChR. 


\section{Discussion}

Mice transgenic for unrearranged human lg loci make it possible to set up a new mouse EAMG model, in which human anti-AChR Abs are generated upon active immunization. In the study presented here, HuMAb-Mice, which produce human IgGlk and IgMk molecules, were immunized with tAChR extracted from Torpedo californica, in order to determine their susceptibility towards EAMG. After the second booster injection of $t A C h R$, the anti-tAChR and -rAChR Ab titers were determined and the clinical signs of EAMG examined to evaluate if a successful EAMG model had been established. Furthermore, the generation of anti-hAChR mAb-producing hybridoma cells was assessed.

It was found that serum titers of $A b s$ against $t A C h R$ were in the nanomolar range. The anti-rAChR Ab serum titer, ranging from 0.2 to $4.0 \%$ of that to $t A C h R$, was comparable to the findings in other mouse strains [12]. The clinical signs of muscular weakness, a key symbol of EAMG, were successfully induced in some of the HuMAb-Mice, directly indicating that EAMG was established. This was further demonstrated by the deposits of human anti-mAChR Abs at the neuromuscular junction of muscle sections and by muscle AChR loss up to $65 \%$. Human anti-AChR Abs could bind to the postsynaptic membrane, and reduce the amount of mAChR, which impairs the neuromuscular transmission. In contrast, the MG thymus tissue-transplantation model, the only other model in which human Abs are produced in a mouse, is not accompanied by muscular weakness [10].

The $A b$ repertoire was analyzed by hybridoma technology. From tAChR-immunized HuMAb-Mice, hybridomas were made and initially screened for the reactivity to tAChR. Of those with specificity to $t A C h R, 2 \%$ cross-reacted with rAChR and none with hAChR. This result is consistent with our previous study, in which we found a similar pattern of crossreaction in the high-susceptible $\mathrm{C} 5 \mathrm{~b} \mathrm{bl} / 6$ and the low-susceptible $\mathrm{Balb} / \mathrm{C}$ mice [13], and failed to find anti-hAChR mAbs from tAChR-immunized mice.

Human anti-human MIR mAbs could be used as a source for potential therapeutic $A b$ fragments, like $F_{\text {at }}[21,22]$. Since the $t A C h R$ immunization did not generate a set of high-affinity human anti-hAChR $m A b s$, the HuMAb-Mice were immunized with the fusion protein Trx-Ha1-210. Non of the mice developed clinical EAMG, although it has been shown that EAMG can be established in rats by immunization with high doses of Trx-Ha1-210 [17]. Due to the low immunogenicity of Trx-Hal-210 compared to tAChR, we only produced 20 anti-Trx-Ha1-210 hybridomas. Moreover, all these hybridomas were specific for an epitope unique for the fusion protein, so no human anti-hAChR mAb could be cloned.

These experiments show that the HuMAb-Mouse represents a suitable model to study the effects of human anti-AChR Abs in vivo. Although we were unable to clone human anti-hAChR mAbs, the HuMAb-Mouse is a promising source of these Abs. 


\section{This work was supported by a grant from L'Association Française contre les Myopathies.}

\section{References}

(1) Patrick, 1., 1. Lindstrom, "Autommune response to acetylcholine receptor", Science 180 $(1973)$ pp. $871-872$.

[2] Almon, R.R., C.G. Andrew, S.H. Appel, Serum globulin in myosthenia gravis: inhibition of alpha-bungarotoxin binding to acetylcholine receptors: Science 186 (1974) pp. 55-57.

[3] Lang, B., G. Richardson, 1. Rees, A. Vincent, I. Newsom-Davis, "Plasma from myasthenia gravis patients reduces acetylcholine receptor agonist-induced $\mathrm{Na}+$ flux into TE671 cell line", foumal of Neuroimmunology 19 (1988) pp. 141-148.

[4] Engel, A.G., E.H. Lambert, F.M. Howard, "Immune complexes (IgG and C3) at the motor end-plate in myasthenia gravis: ultrastructural and light microscopic localization and electrophysiologic correlations", Mavo Clinic Procedings 52 (1977) pp. 267-280.

[5] Lennon, V.A. ME. Seybold, I.M. Lindstrom, C. Cochrane, R. Ulevitch, "Role of complement in the pathogenesis of experimental autoimmune myasthenia gravis", Journal of Experimental Medicine 147 (1978) pp. 973-983.

[6] Kao, 1. D.B. Drachman, "Myasthenic immunoglobulin accelerates acetylcholine receptor degradation", Science $196(1977)$ pp. 527-529.

[7] Heinemann, S., S. Bevan, R. Kullberg. J. Lindstrom, J. Rice, "Modulation of acetylcholine receptor by antibody against the receptor". Proceedings of the National Academy of Sciences of the Uniled States of America 74 (1977) pp. 3090-3094.

[8] Lennon, V.A., IM. Lindstrom, M.E. Seybold, "Experimental autoimmune myasthenia: A model of myasthenia gravis in rats and guinea pigs", Journal of Experimental Medicine 141 (1975) pp. 1365-1375.

(9) Toyka, K.V., D.B. Drachman, A. Pestronk. I. Kao, "Myasthenia gravis: passive rransfer from man to mouse", science 190 (1975) pp. 397-399.

[10] Schonbeck, S. F. Padberg, R. Hohlfeld, H. Wekerle, "Transplantation of thymic autoimmune microenvironment to severe combined immunodeficiency mice. A new model of myasthenia gravis", Journal of Clinical Investigation 90 (1992) pp. 245-250.

[11] Fuchs, S., D. Nevo, R. Tarrab-Hazdai, 1. Yaar, "Strain differences in the autoimmune response of mice to acetylcholine receptors" Nature 263 (1976) pp. 329-330.

[12] Berman, F.W., I. Patrick, "Experimental myasthenia gravis. A murine system", Journal of Experimental Medicine $151,(1980)$ p) $204-223$.

[13] Graus, Y.M., P.I. van Breda Vriesman, M.H. de Baets, "Characterization of antiacetylcholine receptor (AChlR) antibodies from mice differing in susceptibility for experimental autoimmune myasthenia gravis (EAMG)", Clinical and Experimental Immunology $92(1993)$ pp. 506-513.

[14] Raju, R., W.Z. Zhan, P. Karachunski, B. Conti-Fine, G.C. Steck, C. David, "Polymorphism at the HLA-DQ locus determines susceptibility to experimental autoimmune myasthenia gravis": Joumal of Immunology 160 (1998) pp. 4169-4174.

[15] Lonberg, N., L. D. Taylor, F.A. Harding, M. Trounstine, K.M. Higgins, S.R. Schramm, C.C. Kuo, R. Mashayekh, K. Wymore, J.G. MoCabe, D. Munoz O'Regan, S.L. O'Donnell, E.S.C. Lapachet, T. Bengoechea, D.M. Fishwild, C.C. Cormack, R.M. Kay, D. Huszar, "Antigen. Nature 368 (1994) antibodies from mice comprising four distinct genetic modifications"

[16] Fishwild, D.M., S.L O'Donnell, T. Bengoechea, D.V. Hudson, F. Harding, S.L. Bemhard, D. Jones, R.M. Kay, K.M. Higgins, S.R. Schramm, N. Lonberg, "High-avidity human IgG kappa monoclonal antibadies from a novel strain of minilocus transgenic mice", Nature
Biolechnology 14 (1996) pp. 845-851.

[17] $\mathrm{Im}$, S.H. D. Barchon, M.C. Souroujon, S. Fuchs, "Role of tolerogen conformation in induction of oral tolerance in experimental autoimmune myasthenia gravis" "Ioumal of
Immumology $165(2000)$ pp. $3599-3605$. 
[18] Verschuuren, J.I. F. Spaons, M.H. De Baets, "Single-fiber electromyogrophy in experimental autoimmune myasthenia gravis", Muscle and Nerne 13 (1990) pp. $485-492$.

[19] Lindstrom, J.M. B.L. Einarson, V.A. Lennon, M.E. Seybold, "Pathological mechantsms in experimental autommune myasthenia gravis. I. Immunogenicity of syngeneic muscle acetylcholine receptor and quantitative extraction of receptor and antibody-recepton complexes from muscles of rats with experimental automimmune myasthenia gravis", Journal of Experimental Medicine 144 (1976) pp. 726-738.

[20] Verschuuren, J.T., Y.M. Graus, R.O. Theumissen, T. Yamamoto, A. Vincent, P.J. van Breda Vriesman, M.H. De Baets, "Role of acetylcholine receptor antibady complexes in muscle in experimental autoimmune myasthenio gravis" , foumal of Neurommumology 36 (1992) pp. $117-125$.

[21] Tzartos, S.T. D. Sophianos, A. Efthimiadis, "Role of the moin immunogenic region of acetylcholine receptor in myasthenia grovis. An Fab monoclonal antibody protects against antigenic modulation by human sera", foumal of Jmmunology 134 (1985) pp. 2343-2349.

[22] Graus, Y.F., M.H. de Baets, P.W. Parren, S. Berrih-Aknin, I. Wokke, P.J. van Breda Vriesman, D.R. Burton, "Human anti-nicotinic acetylcholine receptor recombinant Fab fragments isolated from thymus-derived phage display libraries from myasthenia gravis patients reflect predominant specificities in serum and block the action of pathogenic serum antibodies", Journal of Immunology 158 (1997) pp. 1919-1929. 


\section{Chapter 3}

\section{Expression of a human anti-acetylcholine receptor $F_{a b}$ in Pichia pastoris}

Maurice H.W. Stassen, Stephan Hellwig, Stefan Schillberg, Rainer Fischer \& Marc H. De Baets 


\section{Abstract}

The human anti-acetylcholine receptor (anti-AChR) antigen-binding fragment $\left(\mathrm{F}_{a \mathrm{a}}\right) 637$ blocks the binding of anti-AChR autoantibodies of myasthenia gravis patients, thereby preventing the autoantibody-mediated increased degradation of AChRs in vitro. To produce large amounts of $\mathrm{F}_{\text {ais }} 637$ for in wivo protection studies, we assessed the possibility to express $F_{w i j} 637$ in Pichia pastoris. Plasmids containing the coding sequences of the light chain and the heavy-chain fragment $\left(\mathrm{F}_{d}\right)$ of $\mathrm{F}_{a b} 637$, under the control of the alcohol oxidase 1 promoter, were electroporated into $P$. pastoris. The light chain was secreted into the culture medium, but the $F_{d}$ was not produced, although its MRNA was transcribed. A single-chain variable fragment $\left(s c F_{v}\right)$ variant of $F_{a b b} 637$ was also not produced, indicating that failure of expression might be based on the sequence of the heavy-chain variable domain $\left(V_{H}\right)$. 


\section{Introduction}

The major autoantigen in myasthenia gravis (MG) is the muscular nicotinic acetylcholine receptor $(\mathrm{AChR})$, an ion channel at the neuromuscular junction (NMI). Autoantibodies directed to the AChR cause disturbed neurotransmission, either by hindrance of acetylcholine binding or by decrease of the number of functional AChRs. Two mechanisms that lead to this loss of $A C h R$ are anti-AChR-activated complement reaction, leading to focal lysis of the muscle membrane, and cross-linking of receptors by antibodies that are capable of binding to two AChRs simultaneously, resulting in an increased rate of intemalization and degradation of the receptor (antigenic modulation) [reviewed in 1].

The human antigen-binding fragment $\left(F_{a b}\right) 637$, which is highly specific for the human main immunogenic region (MIR) of the $A C h R$, is a potential in vivo protective agent against pathogenic $M G$ autoantibodies [2]. Its monovalent binding capacity and lack of the crystallizable fragment $\left(F_{c}\right)$ prevent antigenic modulation and complement activation, respectively. In vitro experiments have shown that $\mathrm{F}_{\mathrm{abb}} 637$ blocks antigenic modulation by MG patient sera, without interfering with ion channel function. $F_{w s} 637$ shows only cross-reactivity with primate AChRs. For in vivo protective studies in monkeys, large amounts of $\mathrm{F}_{\mathrm{ob}} 637$ are needed. The current bacterial expression system, used to select anti- $A C h R F_{a b} s$ from phagedisplay libraries derived from MG patients' thymuses, is inefficient for producing large quantities of $\mathrm{F}_{\mathrm{abb}} 637$. Cultures of the original $\mathrm{F}_{\mathrm{atb}} 637$ producing Escherichia coli strain have a yield of a few $\mu \mathrm{g} / \mathrm{l}$ in a shake flask, while large-scale fermentation had even lower yields [unpublished data].

Yeast is a popular host for heterologous and recombinant protein production, because of its eukaryotic post-translational modification mechanisms, ease of manipulation, and inexpensive culturing. The methylotrophic yeast Pichia pastoris has shown to be a suitable host for large-scale production of functional single-chain variable fragments ( $\mathrm{CF}_{\mathrm{v}} \mathrm{s}$ ), diabodies, $\mathrm{SCF}_{\mathrm{w}} \mathbb{E}$ fusion proteins, $\mathrm{F}_{i \mathrm{~b}}$ and full-size antibodies [3-10]. The yield of purified antibody fragments in $P$. pastoris have been reported to be as high as $250 \mathrm{mg} / \mathrm{l}[6]$. We tried to produce $\mathrm{F}_{\mathrm{at}} 637$ in P. pastoris by similar methods, using the methanol-inducible promoter of the alcohol oxidase 1 gene $(A O X 1)$ [reviewed in 11,12 ].

\section{Materials and methods}

\section{Construction of expression plasmids}

The coding sequences of the heavy-chain fragment $\left(\mathrm{F}_{6} 637\right)$ and the $\lambda$ light chain ( 2637 ) of $F_{\text {: }} 637$ were PCR cloned from its original pComb3H plasmid [2]. Primers used for cloning $F_{d} 637$ (annealing sequences underlined): $5^{\prime}$-gcg gaa ttc gga gac ttg gtc aag cct gga gg-3' and $5^{\prime}-\mathrm{cgc}$ aag ctt atc tag acc ttit gtc aca aga ttt ggg-3'. Primers used for cloning $2637: 5^{\prime}$-gcg gaa ttc cac tct gtg tcg gag tct ccg gg-3' and $5^{\prime}-g c g$ aag ctt cgc ggc cgc tta tga aca ttc tgt 
agg-3". Amplicons were subcloned into pUC18 (Pharmacia Biotech) with EcoRI and HindIII, and verified by sequencing. Subsequently, $F_{d} 637$ was cloned into pPICZa (Invitrogen, Breda, The Netherlands) by EcoRI and Xbal (pPICZa-F 637 ), and 7637 into pPIC9K (Invitrogen) with EcoRI and NotI (pPIC9K- 2637 ). A plasmid containing both antibody chain expression cassettes, pPICF 637 , was constructed by fusion of pPICZ $6-F_{i j} 637$ and pPIC9K- $\lambda 637$ by Bglll cloning.

a. PPICZOF 637

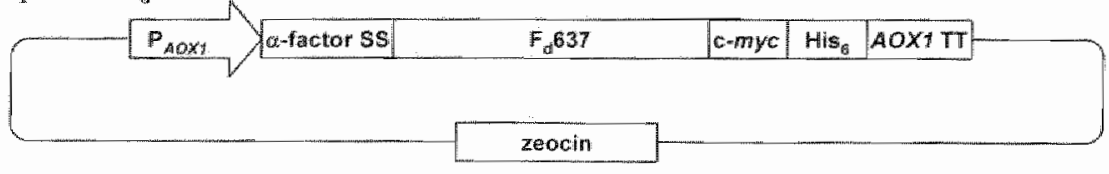

b. $\mathrm{pPIC9K} \times 637$

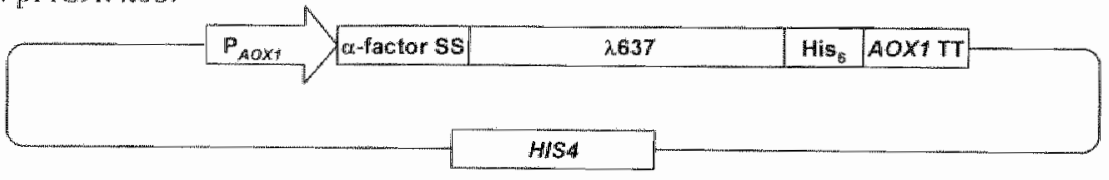

c. $\mathrm{PP} / \mathrm{CF}, 637$

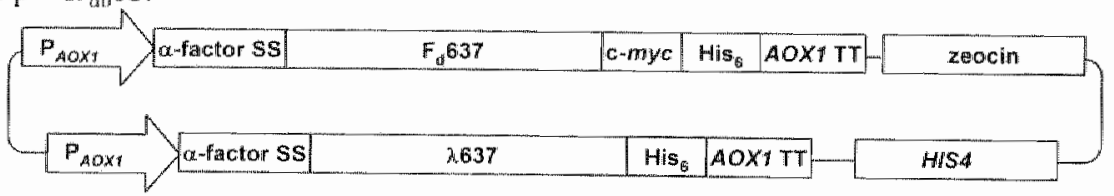

d. $\mathrm{PPICF}_{\text {ilb }} 637 \mathrm{KEX} 2$

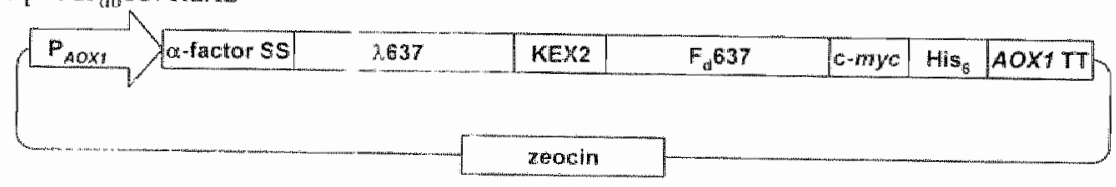

Vigure 1

Expression coustructs for antibody chain production in $P$. pastoris. The coding

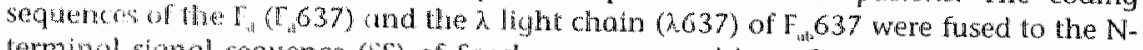
termimal signal sequence ( 55 ) of Sachoromyces cerevisiae a-factor and placed under the control of the AOXI promoter ( $\mathbb{P}_{A(s)}$ ) and AOXI transcription termination (IT), either separately $(a-c)$ or tigether in one cassette $(d), F, 637$ was also fused to a $C$ -

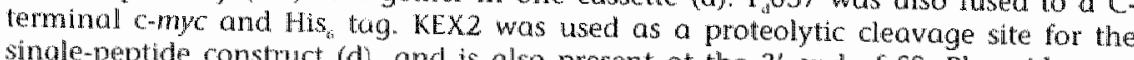
single-peptide construct (d), and is also present at the 3 ' end of S\$. Plasmids were based ether on pPICZa, critaining the zeocin selection marker $(a, d)$, on pPIC9K, containing the HIS4 selection marker (b) or fusion of both (c)

The two chains are encoded as a single peptide in the plasmid pPICF 637KEX2. During or after translation, the chains should be separated by $\mathrm{KEX} 2$, whose proteolytic cleavage site is introduced between the two chains $[13]$. Therefore, $\lambda 637$ was PCR cloned from its original plasmid using the backward primer 5'-gcg aag ctt cgc ggc cgc tga aca ttc 
tgt agg ggc- $3^{\prime}$, eliminating the original stop codon, and $F_{x 1} 637$ by the forward primer 5'.g gaa ttc gcg gcc gca cga alg gat aaa agg gag gct gga gac ttg gtc aag cct gga gg-3' (KEX2 site double underlined, Glu-Ala repeat dotted underlined), introducing the KEX2 cleavage site upstream of $F_{d} 637$, and subsequently cloned into pPICZa.

A plasmid ( $\mathrm{pPICscF}$ 637) expressing a single-chain variable fragment $\left(s \mathrm{~F}_{\mathrm{v}}\right.$ ) variant of $\mathrm{F}_{\mathrm{ab}} 637$ was constructed by subcloning the variable domains from the original pComb3H in pHEN4II for introducing a linker between them. Primers used for $V_{k i}$ and $V_{1}$ cloning, respectively: $5^{\prime}$-cat gcc atg gcc gaa ttc gga gac ttg gtc aag cct gga gg-3', $5^{\prime}-\mathrm{cgc}$ aag ctt ggt gac cca cga tga gac agt gac cag ggt gc-3', 5'-gcg gaa ttc ggc gog cet cac tct gtg tcg gag tct ccg gg- $3^{\prime}$ and $5^{\prime}-g c g$ aag ctt cgc ggc cgc tac gac ggt cag ctt ggt ccc tc- $3^{\prime}$. Subsequently, the scF, 637 cistron was cloned in PPICZ a by EcoRI and NotI.

\section{Transformation of $P$. pastoris}

Prior to transformation, $10 \mu \mathrm{g}$ plasmid was linearized with either Sacl, which favors the integration into the aox l locus, or Sall, which favors the integration into the histidinol dehydrogenase locus (his4) of $P$. pastoris. The HIS4 deficient $P$. pastoris strain GS115 was electroporated, according to the manual of the EasySelect Pichia Expression Kit (Invitrogen), with linearized DNA and plated on YPD (1\% (w/v) yeast extract, $2 \%(\mathrm{w} / \mathrm{v})$ peptone, $2 \%$ $(w / v)$ dextrose) $+500 \mu \mathrm{g} / \mathrm{ml}$ zeocin (Invitrogen)) or histidine-free $\mathrm{MM}$ $\left(1.34 \%(\mathrm{w} / \mathrm{v})\right.$ yeast nitrogen base, $4 \times 10^{-5} \%(\mathrm{w} / \mathrm{v})$ biotin, $0.5 \%(\mathrm{v} / \mathrm{v})$ methanol)) selection plates at $30^{\circ} \mathrm{C}$.

\section{Screening of transformants}

Antibody chain production was induced by methanol on replica plates. A nitrocellulose membrane was placed on top of the colonies during first $24 \mathrm{~h}$ of expression. Membrane was incubated with biotin-conjugated goat antihuman $\lambda$ light chain (Sigma-Aldrich, Steinheim, Germany), biotinconjugated goat anti-human $y$ heavy chain (Sigma-Aldrich) or sheep antihuman $F_{a t}$ (The Binding Site, Birmingham, UK), subsequently with alkaline phosphatase (AP)-streptavidin or AP-conjugated rabbit anti-sheep $F_{\text {, }}$ (Jackson ImmunoResearch Laboratories, West Grove, PA, USA) and stained with 1-Step NBT/BCIP (Pierce, Rockford, IL, USA).

\section{Small-scale expression}

Individual colonies were inoculated in $10 \mathrm{ml}$ BMGY medium $(1 \%(w / v)$ yeast extract, $2 \%(\mathrm{w} / \mathrm{v})$ peptone, $1.34 \%(\mathrm{w} / \mathrm{v})$ yeast nitrogen base, $4 \times 10 \%$ $(\mathrm{w} / \mathrm{v})$ biotin, $1 \%(\mathrm{v} / \mathrm{v})$ glycerol, $100 \mathrm{mM}$ potassium phosphate $\mathrm{pH} 6.0)$ in a $50-\mathrm{ml}$ Falcon tube. After incubation at $30^{\circ} \mathrm{C}, 250 \mathrm{rpm}$ for $24 \mathrm{~h}$, the cells were collected by centrifugation $(2,000 \mathrm{~g}, 5 \mathrm{~min}, \mathrm{RT})$ and resuspended in 5 ml BMMY medium (BMGY with $4 \%(\mathrm{v} / \mathrm{v})$ methanol replacing glycerol). The cells were incubated at $30^{\circ} \mathrm{C}, 250 \mathrm{rpm}$ for $24 \mathrm{~h}$ and the culture supernatant was separated from the cells by centrifugation. Expression levels were determined by SDS-PAGE and western blotting, using the aforementioned staining. 


\section{Northern blotting}

For the detection of $\mathrm{F}_{d} 637$ mRNA in transfected cells, total RNA was blotted on Hybond $\mathrm{N}+$ membrane (Amersham Pharmacia Biotech, Roosendaal, The Netherlands) after electrophoresis. A probe was synthesized, using pPICZa-F 637 as template, and labeled using the PCR DIG Probe Synthesis Kit (Roche, Almere, The Netherlands) according to the manufacturer's manual. The membrane was blocked and washed using the Dig Wash and Block Buffer Set (Roche) and probe detected with an anti-digoxigenin HRP conjugate (Roche) according to the manufacturer's protocol.

\section{Results}

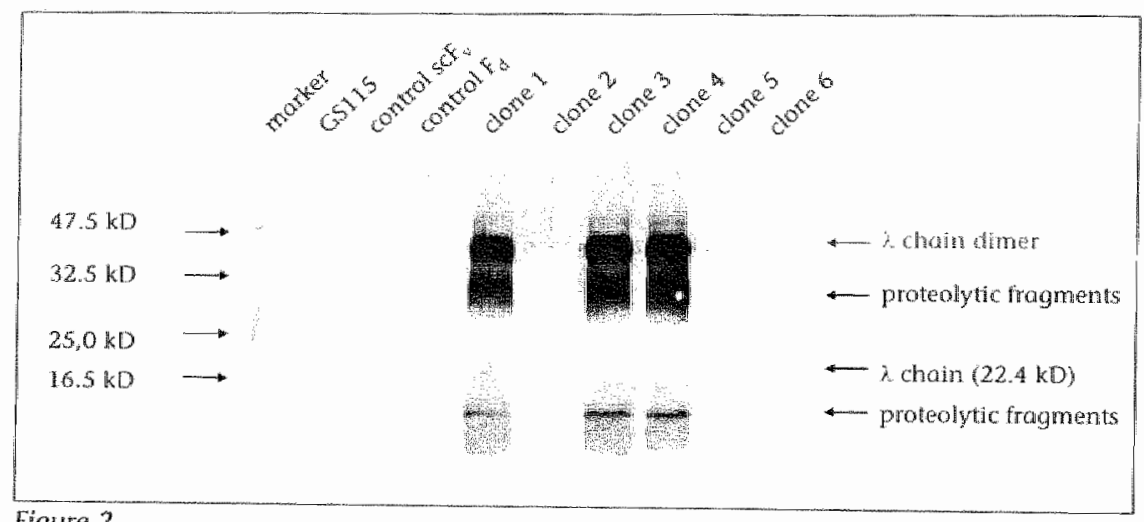

\section{Figure 2}

Analysis of $F_{\text {aiv }} 637$ accumulation in Pichia pastoris. $30 \mu$ of culture supermatant from different $p$. pastoris clones were separated by SDS-PACE and analysed by immunoblot. Expression of the $\lambda$ light chain of anti-hAChR $F_{\text {st }} 637$ was detected with anti-human $\lambda$ light chain antibody. Yeast clones $1-6$ are transformed with the light chain 637 expression cassette and are HIS4; clones 1,3 and 4 show expression of light chain 637, mainly as a dimer or proteolitic fragment of a dimer (monomer is not visible). Untransfomed $P$. pastoris strain GS115 and transgenic clones with a control single-chain variable fragment ( $\mathrm{sCF}$ ) or $\mathbb{F}_{4} 637$ were used as negative controls.

The coding sequences of the heavy-chain fragment $\left(F_{d}\right)$ and the $\lambda$ light chain $(\lambda)$ of $F_{\text {als }} 637$ were placed separately into two expression cassettes, containing the zeocin ( $\mathrm{PPICZ} \alpha$ ) or HIS4 selection marker (pPIC9K), respectively (Figure $1 a$ and b). Expression of both chains was placed under control of the AOX1 promoter, directed to the secretion pathway by the $\alpha$ factor signal sequence. In addition, the $F_{4} 637$ in pPICZa contained a $C$ terminal His, and c-myctag for detection and purification.

P. pastoris strain GS115 (HIS4 deficient) was transformed with pPIC9K$\lambda 637$ (Figure 1b). Integration into the host genome was directed either into the aox 1 or his 4 locus, resulting in transformation efficiencies of $3 \%$ and $75 \%$, respectively. In both cases, $\lambda 637$ was secreted mainly as a light-chain homodimer (Figure 2). This corresponds to the human in vivo situation, 
where overproduced light chains form Bence Jones proteins. The secretion of $\lambda 637$ was effective, since no product could be found in cell lysate. The expression level in shake flask was $10 \mu \mathrm{g} / \mathrm{ml}$.

Subsequently, a 2637-producing clone was transformed with pPICZ $\alpha$ F637 (Figure 1a), directed to aox 1 integration. The transformation efficiency was low, only a few zeocin-resistant clones were generated. After induction, all clones produced $\lambda 637$ but accumulation of $\mathrm{F}_{4} 637$ was below the detection limit of the immunoblot, using anti-Fis ${ }_{6,}$ anti-c- $m y c_{\text {, }}$ anti- $\gamma$ chain and anti- $\lambda$ chain antibodies for detection (data not shown).

To increase the number of transfected clones, $P$. pastoris was transformed with pPICF 637 (Figure 1c) and integrated in the host's his4 locus. Although a high number of zeocin-resitant clones was obtained which all produced $\lambda .637, \mathrm{~F}_{6} 637$ production could not be detected in any of these clones. However, northern blot analysis revealed that the mRNA of $\mathrm{F}_{i} 637$ was transcribed in these clones (Figure 3), indicating the functionality of the $\mathrm{F}_{\mathrm{at}} 637$ expression cassette.

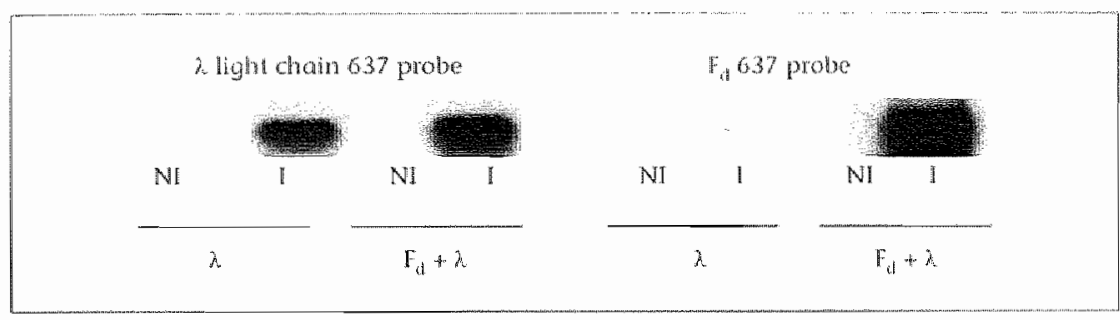

Figure 3

Northern blot analysis of anti-AChR $F_{n b} 637$ expression in Pichia pastoris. Steady state transcript levels of induced (I) and non induced (NI) P. pastoris clones, transformed with the expression cassettes of only the $\lambda$ light chain $(\lambda)$ or both chains of $F_{\text {ut }} 637$ $\left(\mathrm{Fd}+\lambda_{\text {) }}\right.$ were analyzed. After a 48-hours induction period, total RNA was isolated from the cells and blotted. The blots were probed with labeled DNA rom the full. length sequences of the chains.

Finally we transformed $P$. pastoris with the expression construct pPICF $_{\text {an }} 637$ KEX2 (Figure 1d), encoding the two antibody chains as a single peptide. $\lambda 637$ was produced while $F_{6} 637$ was not detectable, indicating that pre-pro- $\lambda 637-F_{6} 637$ was at least partially translated (data not shown).

To further support the hypothesis of a post-transcriptional expression problem of the $F_{a}$ expression studies with a plasmid encoding for a scF. variant of $\mathrm{F}_{\text {wit }} 637, \mathrm{SCF}_{v} 637$ [14], were performed. Accumulation of $\mathrm{scF}_{v} 637$ in $P$. pastoris was not detectable by immunoblot, using anti-c-myc and $-\mathrm{His}_{6}$ antibodies for detection. This result suggests that the heavy-chain variable domain $\left(\mathrm{V}_{\mathrm{H}}\right)$ and not constant domain $1\left(\mathrm{C}_{\mathrm{H}} 1\right)$ of $\mathrm{F}_{\mathrm{d}} 637$ is responsible for the nonexistence of the heavy-chain fragment. 


\section{Discussion}

The $\mathrm{F}_{i j} 637$ coding sequences were cloned into different expression plasmids for production of $\mathrm{F}_{\text {at }}$ in P. pastoris. The production of its light chain $\lambda 637$ by P. pastoris $(100 \mu \mathrm{g} / \mathrm{ml})$ was higher than in the original bacterial expression systems $(60 \mathrm{\mu g} / \mathrm{l})$. We assume that the expression could be further improved, e.g. by multi-copy insertions in the host's genome and optimizing nutritional and physical culturing parameters [12]. In contrast to 2637 , no detectable levels of $F_{b} 637$ were found, although its mRNA was transcribed.

$\mathrm{F}_{\mathrm{d}} 637$ as well as the $\mathrm{ScF}_{\mathrm{v}}$ derivate of $\mathrm{F}_{a b} 637$ [14], were not produced in $P$. pastoris, although they are produced by $E$. coli and $F_{a 1} 637$ genetically fused to the human $\gamma 1 F_{c}$ is expressed by chinese hamster ovary cells, with a yield of $55 \mathrm{mg} / \mathrm{l}$ purified IgG1 [15]. Recently, Lange et al. [9] showed that functional $F_{w i}$ (atrazine specific) can be produced in $P$. pastoris with a yield of $40 \mathrm{mg} / \mathrm{l}$ pure $F_{0, b^{*}}$. They also used a single pPICZa-based plasmid with the expression of each chain controlled by a separate AOXI promoter, indicating that this setup can be successfully used for $\mathrm{F}_{a b}$ expression in $P$. pastoris. But, Lange et al. only C-terminally fused a $\mathrm{His}_{6}$ tag to the heavy

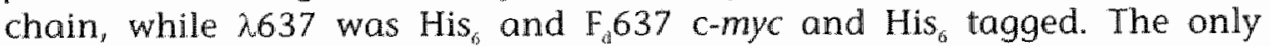
differences between our anti-AChR $F_{u b}$ and the atrazine-specific $F_{a b}$ are the $V_{\mathrm{H}} \mathrm{s}$ and the $c-m y c t a g$. Therefore, the expression problem is either caused by the sequence of $\mathrm{V}_{46} 637$ or the c-myc tag. In recombinant antibodies, the c$m y c$ tag is frequently used, also for the successful production in P. pastoris $[16,17]$. Sequence-depending levels of expression are found with the production of $\mathrm{scF}_{\mathrm{s}} \mathrm{s}$, both in $P$. pastoris [unpublished results] and in $E$. coli [18]. The $\mathrm{F}_{i 1} 637$ nucleotide or amino acid sequence could have caused translationall or proteolytic problems.

In future experiments we will perform modification of the $F_{4} 637$ sequence. This includes the adaptation of the codon usage to P. pastoris and the exchange of certain amino acids of the framework regions that are responsible for the stability of the $F_{i t}$ fragment. The generated data will provide new insights on the correlation between recombinant protein sequence and accumulation.

\section{Acknowledgements}

We would like to thank Nicole Raven for her help and fruitful discussions. This work was supported by a grant from L'Association Française contre les Myopathies.

\section{References}

[1] De Baets, M., M.H. Stassen, "The rolle of antibodies in myasthenia gravis", Journal of the Neurological sciences 202 (2002) pp. 5-11. 
[2] Crous, Y.E. M.H. de Baets, P.W. Parren, S. Berrih-Aknin, Y. Wokke, P.l. van Breda Vriesman, D.R. Burton. "Human anti-nicotinic acetylcholine receptor recombinant Fab fragments isolated from thymus-derived phage display libraries from myasthenia gravis patients reflect predominant specificties in serum and block the action of pathogenic serum antibodies", Joumal of Immunology 158 (1997) pp. 1919-1929.

[3] Ridder, R., R. Schmitz, F. Legay, H. Gram, "Generation of rabbit monoclonal antibody fragments from a combinatorial phage display library and their production in the yeast Pichia pastoris", Bio/Technology 13 (1995) pp. 255-260.

[4] FitzGerald, K., P. Holliger, G. Winter, "Improved tumour targeting by disulphide stabilized diabodies expressed in Pichia pastoris", Protein Engineering 10 (1997) pp. 1221-1225.

[5] Luo, D. M. Geng. A.A. Noujaim, R. Madiyalakan. "An engineered bivalent single-chain antibody fragment that increases antigen binding activity", Joumal of Biochemistry 121 (1997) pp. 831-834.

16] Eldin, P., M.E. Pauza, Y. Hieda, G. Lin, M.P. Murtaugh, P.R. Pentel, C.A. Pennell, "Highlevel secretion of two antibody single choin Fv fragments by Pichia pastoris", Jaumal of Immunological Methods 201 (1997) pp. 67-75.

17] Ogunjimi, A.A., I.M. Chandler, C.M. Gooding, A.I. Recinos, P.V. Choudary, "High-lewel secretory expression of immunologically active intact antibody from the yeast: Pichia pastoris" , Biotechnology Letters 21 (1999) pp. 561-567.

[8\ Hellwig, S, F. Emde, N.P. Raven, M. Henke, P. van Der Logt, R. Fischer, "Analysis of single-chain antibody production in Pichia pasitoris using on-line methanol control in fed-batch and mixed-feed fermentotions", Biotechnology and Bioengineering 74 (2001) $\mathrm{pp}$. $344-352$.

[9] Lange, S., J. Schmitt, R.D. Schmid "High-yield expression of the recombinant, atrazinespecific Fab fragment $\mathrm{K} 411 \mathrm{~B}$ by the methylotrophic yeast Pichia pastoris", foumal of Immunological Methods 255 (2001) pp. 103-114.

[10] Powers, D.B., P. Amersdorfer, M. Poul, U.B. Nielsen, M.R. Shalaby, G.P. Adams, L.M. Weiner, I.D. Marks, "Expression of single-chain Fv-Fc fusions in Pichia pastoris", Jousnal of Immunological Methods 251 (2001) pp. 123-1.35.

[11] Fischer, R., I. Drossard, N. Emans, U. Commandeur, S. Hellwig, "Towards molecular farming in the future: pichia pastoris-based production of single-chain antibody fragments", Biotechnology and Applied Biochemistry 30 ( Pt 2) (1999) pp. 117-120.

[12] Cereghino, J'L., I.M. Cregg, "Heterologous protein expression in the methylotrophic yeast Pichia pastoris", FEMS Microbialogy Reviews 24 (2000) pp. 45-66.

[13] Berry, M.J., P.J. Davis, C.P. van der Logt, G.C. Whitelam, Production in yeast of stable antibody fragments. In: U.S. Patent $5,863,765$, Quest International B.V., Naarden, The Netherlands, United States, 1999.

[14] Meng, F., M.H. Stassen, S. Schillberg, R. Fischer, M.H. De Baets, "Construction and characterization of a single-chain antibody fragment derived from thyrims of a patient with myasthenia gravis", Autoimmunity 35 (2002) pp. 125-133.

[15] Stassen, M.H., B.M. Machiels, E. Fostieri 5 . Tzartos, S. Berrih-Aknin, E. Bosmans, P.W. Parren, M.H. De Baets, "Characterization of a fully human IgGl reconstructed from an anti-AChR Fab". Annals of the New York Academy of Sciences 998 (2003) pp. 399-400.

[16] Boado, R.J., A. [i, W.M. Pardridge, "Cloning and expression in Pichia pastoris of a genetically engineered single chain antibody against the rat transferrin receplor", Joumad of Drug Targeting 8 (2000) pp. $403-412$.

[17] Luo, D., M. Geng, B. Schultes, I. Ma, D.Z. Xu, N. Hamza, W. Qi, A.A. Noujaim, R. Madiyalakan, "Expression of a fusion protein of sclvabiotin mimetic peptide for immunoassay" Journal of Biotechnology $65(1998)$ pp. 225-228.

[18] Hoet, R.M., M. Pieffers, M.H. Stassen; ]. Raats, R. de Wildt, G.J. Pruin, F, van den Hoogen, W.J. van Venrooil, "The importance of the light chain for the epitope specificity of human anti-UI small nuclear RNA autoantibadies present in systemic lupus erythematosus patients", foumal of Immunology 163 (1999) pp. 3304-3312. 


\title{
Chapter 4
}

\section{Construction and characterization of a single-chain antibody fragment derived from thymus of a patient with myasthenia gravis}

Fanping Meng, Maurice H.W. Stassen, Stefan Schillberg, Rainer Fischer \& Marc H. De Baets

\author{
published in \\ Autoimmunity 35 (2002) pp. 125-133
}




\section{Abstract}

Pathogenic anti-acetylcholine receptor $(\mathrm{ACh})$ antibodies in myasthenia gravis (MG) and the corresponding animal model, experimental autoimmune myasthenia gravis (EAMG), principally recognize the main immunogenic region (MIR) of the $A C h R$. Bivalent anti-MIR antibodies binding to the a-subunits of AChR result in AChR loss by antigenic modulation and complement activation. Monovalent $F_{\text {ab }}$ and single-chain variable fragments $\left(\mathrm{SCF}_{\mathrm{v}}\right.$ ) of pathogenic anti-AChR antibodies can interfere with AChR binding of the pathogenic antibodies. In the present study, scF 637 was constructed from its parental $F_{w a} 637$, previously isolated from a thymus-derived phage display library with specificity toward anti-MIR of human AChR (hAChR), by PCR amplification. Bacterial produced scF 637 was able to bind to $h A C h R$ in standard precipitation radioimmunoassay (RIA). SCF,637 also bound to monkey AChR in situ on monkey neuromuscular junctions as showed in immunohistochemical staining. Furthermore, $\mathrm{scF}, 637$ was capable of inhibiting the binding of its intact IgG637 and anti-MIR mAb35 binding to hAChR up to $32.9 \%$ and $73.0 \%$ respectively demonstrated in a competitive ELISA, and of MG patient sera from up to $45.5 \%$ in a competitive RIA. Therefore, SCF, 637, easier for manipulation in improvement of affinity and stability compared with its parental $\mathbb{F}_{a 16} 637$, may serve as an altemative candidate for specific immunotherapy in MG. 


\section{Introduction}

In the prototype autoimmune anti-receptor disease, myasthenia gravis $(M G)$, the binding of autoantibodies to the acetylcholine receptor ( $A C h R$ ) results in AChR loss and leads to fatigue and weakness of skeletal muscle [1-3]. Experimental autoimmune myasthenia gravis (EAMG), an animal model that closely resembles human $\mathrm{MG}$, can be induced by active immunization with purified AChR or by passive transfer of polyclonal or monoclonal antibodies (mAbs) against AChR [4-6], which $a$ is well characterized autoantigen [7]. Muscle-type AChR in neuromuscular junction is a complex transmembrane glycoprotein and consists of five subunits: $\alpha_{2} \beta \gamma \delta$ [8-10]. The $\mathrm{AChR}$ contains a characteristic region, termed the main immunogenic region (MIR) on the $\alpha$ subunit at residues 67.76 [11-13], which is easily accessible to antibodies in vivo.

More than half of the autoantibodies in $M G$ patients or EAMG rats were found to be directed against the MIR [14-16] and pathogenic mAbs were found exclusively among mAbs against MIR $[6,17,18]$. Anti-MIR antibodies are especially effective in antigenic modulation, a mechanism in which the binding of anti-AChR antibodies to AChR by cross-linking of adjacent AChR molecules results in accelerated AChR internalization [19]. Furthermore, the binding of anti-MIR antibodies to $A C h \mathbb{R}$ can also trigger the complement cascade leading to focal lysis of postsynaptic membrane [6].

The ideal immunosuppressive therapies for $M G$ would be to eliminate the autoimmune response to $\mathrm{AChR}$ without affecting the immune response to other antigens. Several specific immunosuppressive therapies have been tested in EAMG based on the pathogenesis of $M G$, including anti-idiotypic antibodies [20] and administration of AChR orally [21-23] or nasally [2426]. Meanwhile, the development of a bioimmunological agent for specific treatment of MG patients has been the focus of MG research. $\mathbb{F}_{\text {ith }}$ and singlechain variable fragment ( $\mathrm{SCF}_{v}$ ) of antibodies derived from anti-MIR antibodies can bind to $\mathrm{AChR}$, blocking the binding of anti-MIR antibodies to $\mathrm{AChR}$, but do not have the activity to induce antigenic modulation or the complement reaction. $F_{\text {aid }}$ isolated from $M G$ patient thymus $[27,28]$ and from rat anti-MIR mAbs $[29,30]$ or scF constructed from rat anti-MIR mAbs [31-33] prevent anti-MIR MAbs or MG patient sera from binding to AChR or from inducing antigenic modulation in a cultured TE671. cell line.

In this study, a human scF 637 directed against the MIR of human AChR (hAChR) was constructed from its parental $\mathrm{F}_{\text {wht }} 637$, isolated from thymus-derived phage display library of a $M G$ patient earlier in our laboratory [27]. SCF 637 will not possess immunogenicity for application in MG patients, considering its human origin, and easily undergoes genetic manipulation to improve its stability and affinity. 
Construction of sCF, 637

$V_{H}$ CDNA of scF 637 was amplified from pComb3H-F 637 [27] by PCR using $V_{H}$ upstream primer 5 'a tctaga ccatg gcc gag gtg cag ctg ctg gag tct ggg 3' (the sequences underlined are the recognition sites of endonucleases $X b a l$ and $N$ col, respectively) encoding the first 8 amino acids of the $V_{m}$, and $V_{H}$ downstream primer $5^{\prime}$ at gaattc ctcga gga tga gac agt gac cag gg 3" (underlined are EcoRI and Xhol sites, respectively) complementary to the nucleotides of amino acids 107-113. The $V_{2}$ CDNA of scF 637 was amplified using $V_{1}$, upstream primer $5^{\prime}$ aa tctaga gtgca cce gag ctc act cag coc $3^{\prime}$ (underllined are $X$ bal and ApaLl sites, respectively) encoding the first 7 amino acids of the $\mathrm{V}_{\mathrm{L}}$, and $\mathrm{V}_{\mathrm{s}}$ downstream primer $5^{\prime}$ at gaattc gcggccgc tag gac ggt cag ctt gg '3' (underlined are EcoRI and NotI sites, respectively) complementary to the gene of amino acids 102-107. The PCR was performed for 35 cycles with denaturation at $95^{\circ} \mathrm{C}$ for $1 \mathrm{~min}$, annealing at $50{ }^{\circ} \mathrm{C}$ for $1 \mathrm{~min}$ and extension at $72{ }^{\circ} \mathrm{C}$ for 2 min using high fidelity enzyme mix (Roche Diagnostics GmbH, Mannheim, Germany).

The $V_{i 1}$ and $V_{i}$ cDNA fragments were purified with QlAquick PCR Purification Kit (Qiagen GmbH, Hilden, Germany). The purified $\mathrm{V}_{\mathrm{H}}$ CDNA fragments were digested with $\mathrm{Ncol}$ and $\mathrm{Xhol}$, and $1 \%$ agarose gel-purified with Geneclean Kit II (Bio 101 Inc, La Jolla, CA, USA), and cloned into the NCoI and Xhol site of vector pHEN2 ( $a$ generous gift of Dr G. Winter, Center for Protein Engineering, MRC Center, University of Cambridge, UK). The recombinant phagemid was transformed into competent $E$. coli $\mathrm{DH} 5 \alpha$ and isolated and purified with Wizard Plus SV Minipreps (Promega, USA). Subsequently, the purified $V_{L}$ cDNA fragments were digested with ApaLI/NotI, and cloned into the pHEN2-VH as above to construct a complete scF, 637 gene segment.

\section{Production of soluble scF,637}

E. coli HB2151 transformed with pHEN2-ScF 637 were grown from a single colony overnight at $37^{\circ} \mathrm{C}$ in a $5 \mathrm{ml} 2 \mathrm{x}$ TY medium containing $100 \mu \mathrm{g} / \mathrm{ml}$ ampicillin and $1 \%$ glucose, and subsequently diluted in $500 \mathrm{ml} 2 \times$ TY medium with $100 \mu \mathrm{g} / \mathrm{ml}$ ampicillin and $0.1 \%$ glucose. The culture was further incubated at $37{ }^{\circ} \mathrm{C}$ to an $\mathrm{OD}_{\text {tomans }}$ of 0.6 . ScF, 637 expression was induced by addition of isopropyl- $\beta$-D-thiogalactopyranoside (IPTG) at final concentration of $1 \mathrm{mM}$. After an additional $3 \mathrm{~h}$ of incubation at $30^{\circ} \mathrm{C}$ with shaking, the bacteria were harvested by centrifugation at $10000 \times \mathrm{g}$ for 10 min at $4{ }^{\circ} \mathrm{C}$.

The periplasmic fraction containing $\mathrm{ScF}_{\mathrm{w}} 637$ was prepared with sodium borate [34]. The bacterial pellet was resuspended in $5 \mathrm{ml}$ ice-cold sodium borate solution ( $200 \mathrm{mM}$ sodium borate, $160 \mathrm{mM} \mathrm{NaCl}, 1 \mathrm{mM}$ EDTA, pH 8.0). After incubation on ice for $20 \mathrm{~min}$, the bacterial suspension was centrifuged at $15000 \times \mathrm{g}$ for $10 \mathrm{~min}$ at $4{ }^{\circ} \mathrm{C}$. The supernatant represented 
the periplasmic fraction. E. coli HB2151 which do not bear pHEN2-scF, 637 or bear pHEN2 only were used as control.

\section{Detection of SCF 637}

The production of soluble ScF 637 was detected with nitrocellulose dot blot [35]. $5 \mathrm{\mu l}$ of periplasmic fraction or culture supernatant of ScF 637 was loaded on nitrocellulose fillter $\left(0.45 \mu \mathrm{m}\right.$, Bio-Rad Laboratories, Hercules, $\mathrm{CA}_{\text {, }}$ USA). Non-specific binding sites on the filter were blocked for $1 \mathrm{~h}$ at room temperature in PBS containing $2 \%$ dried skimmed milk, and subsequently incubated with $300 \mathrm{ng} / \mathrm{ml}$ of mouse anti-c-myc mAb (ATCC clone number CRL-1729) for $1 \mathrm{~h}$ at room temperature with gentle shaking. After washing 3 times with PBS containing $0.05 \%$ Tween 20 and 2 times with PBS alone, the binding of the anti-c-myc $\mathrm{MAb}$ to SCF 637 was detected by adding rabbit anti-mouse IgG conjugated with HRP (1/2000, Pierce, Rockford, $\|$ L, USA). The HRP activity was visualized with DAB.

\section{Purification of $\mathrm{SCF}, 637$}

The purification of $\mathrm{SCF}, 637$ was performed with immobilized metal affinity chromatography (IMAC) using Ni-NTA agarose (Qiagen GmbH, Hilden, Germany). Periplasmic fraction of $E$. coli HB2151 was dialysed against lysis buffer ( $50 \mathrm{mM} \mathrm{NaH} \mathrm{PO}_{4}, 300 \mathrm{mM} \mathrm{NaCl}, 3 \mathrm{mM}$ imidazole, $\mathrm{pH} 8.0$ ), and loaded on Ni-NTA resin column. After washing with wash buffer $(50 \mathrm{mM}$ $\mathrm{NaH}_{2} \mathrm{PO}_{4}, 300 \mathrm{mM} \mathrm{NaCl}, 20 \mathrm{mM}$ imidazole, $\mathrm{pH} 8.0$ ), the column was eluted with elution buffer $\left(50 \mathrm{mM} \mathrm{NaH} \mathrm{PO}_{4}, 300 \mathrm{mM} \mathrm{NaCl}, 250 \mathrm{mM}\right.$ imidazole, $\mathrm{pH}$ 8.0). The collected elution fractions were analysed by $12 \%$ SDS-PAGE. Protein bands were detected by Coomassie staining and $\mathrm{ScF}_{v} 637$ by western blotting using mouse anti-c-myc mAb.

\section{Determination of $S C F, 637$ specificity}

The specificity of $\mathrm{scF} 637$ binding to $\mathrm{AChR}$ was determined with precipitation RIA using crude hAChR extract, isolated from TE671 cells [36], as antigen. Briefly, $200 \mu \mathrm{l}$ of periplasmic fraction of scF 637 were incubated overnight at $4{ }^{\circ} \mathrm{C}$ with $200 \mu$ of crude hAChR extract $(0.3 \mathrm{nM}$, preincubated with 2 pmol ${ }^{125} \mathrm{I}-\alpha-\mathrm{BT} / \mathrm{pmol} \mathrm{AChR}$ for $4 \mathrm{~h}$ at $4{ }^{\circ} \mathrm{C}$ ), and further incubated with $100 \mu \mathrm{l}$ mouse anti-c-myc mAb $(10 \mu \mathrm{g} / \mathrm{ml})$ for additional $2 \mathrm{~h}$ at $4{ }^{\circ} \mathrm{C}$. The complex of hAChR-scF 637 -anti-mouse $\mathrm{c}$-myc mAb was precipitated by addition of goat anti-mouse $\lg G$ and bound activity was counted in $\gamma$ counter.

The cross-reactions of SCF.637 to rat AChR (rAChR) or Torpedo AChR (tAChR) were also tested by RIA using $200 \mu \mathrm{l}$ of crude rAChR extracted from rat muscle or $200 \mu \mathrm{l}$ of purified tAChR (10 pM) isolated from the electric organ of Torpedo californica (Pacific Biomarine, California, USA).

\section{Immunohistochemical staining of SCF 637}

Binding of $s c F 637$ to $\mathrm{AChR}$ in situ at the neuromuscular junction was verified by immunohistochemical staining on monkey Macaca fascicularis intercostal muscle section (a kind gift from Dr M. Jonker "Biomedical 
Primate Research Center, Rijswijk, The Netherlands). Slides, fixed with cold acetone for $10 \mathrm{~min}$ at $4{ }^{\circ} \mathrm{C}$, were preincubated with PBS containing $2 \%$ $B S A$, and subsequently incubated with $1 / 10$ diluted periplasmic fraction of bacteria for $1 \mathrm{~h}$ at room temperature. After washing 3 times with PBS with 5 min for each time, slides were incubated with mouse anti-c-myc mAb together with rhodamine-labeled $\alpha-B T\left(\alpha-B T^{\text {Bh }}\right.$, Molecular Probes Europe BV, Leiden, The Netherlands) for $1 \mathrm{~h}$ at room temperature. The binding activity was visualized by addition of goat anti-mouse IgC conjugated with FITC.

\section{Protection of hAChR from binding of anti-MIR antibodies and MG patient sera}

The protective ability to $\mathrm{hAChR}$ was measured in a competitive ELISA between $s C \mathbb{F}_{4}, 637$ and IgG637 (recombinant full-size IgG1 variant of $\mathbb{F}_{a b} 637$ ) and rat anti-MIR mAb35 [37], and in a competitive RIA between scF 637 and MG patient sera. ELISA plates were coated with $50 \mu \mathrm{lmAb153}$ (1.5 $\mu \mathrm{g} / \mathrm{ml}$ ), a rat anti-AChK mAb directed against a cytoplasmic epitope [38], for $1 \mathrm{~h}$ at $37^{\circ} \mathrm{C}$, then blocked with PBS containing $3 \% \mathrm{BSA}$ and $0.05 \%$ Tween 20. The plates were incubated overnight at $4{ }^{\circ} \mathrm{C}$ with $50 \mu \mathrm{l} h \mathrm{AChR}$ $(0.3 \mathrm{nM})$ extracted from TE671 cells, and after washing, further incubated with periplasmic fraction of $\mathrm{scF}_{4} 637(0.0032-50 \mu \mathrm{l})$ overnight at $4{ }^{\circ} \mathrm{C}$. For inhibition of $\mathrm{mAb} 35,50 \mu \mathrm{lmAb} 35$ conjugated with $\mathrm{HRP}\left(\mathrm{IC}_{\mathrm{so}}=0.9 \mu \mathrm{g} / \mathrm{ml}\right.$, predetermined in ELISA) was added and incubated for $1 \mathrm{~h}$ at $37^{\circ} \mathrm{C}$ without washing, and HRP reaction was developed using TMB (Sigma, St. Louis, $\mathrm{MO}$, USA). For inhibition of IgG637, $50 \mu \mathrm{IgG637}\left(\mathrm{IC}_{50}=80 \mathrm{ng} / \mathrm{ml}\right.$, predetermined in ELISA) was added and incubated for $1 \mathrm{~h}$ at $37^{\circ} \mathrm{C}$ without washing. Subsequently $50 \mu \mathrm{l}$ goat anti-human IgG ( $F_{c}$ specific) coupled with alkaline phosphatase (dilution $1 / 250$, preabsorbed with $1 \%$ normal rat serum at $37^{\circ} \mathrm{C}$ for $1 \mathrm{~h}$ ) was added and incubated for $1 \mathrm{~h}$ at $37^{\circ} \mathrm{C}$, and the color reaction was visualized with pNPP. In RIA, $50 \mu \mathrm{l}$ hAChR $(0.3 \mathrm{nM})$ labeled with ${ }^{125} \mathrm{I}-\alpha-\mathrm{BT}$ at $4{ }^{\circ} \mathrm{C}$ for $4 \mathrm{~h}$ was pre-incubated with $250 \mu \mathrm{l}$ of periplasmic fraction of $\mathrm{sCF} 637$ overnight at $4^{\circ} \mathrm{C}$, subsequently $10 \mu \mathrm{l}$ of $\mathrm{MG}$ patient sera ( $70 \%$ of the maximum binding to $\mathrm{hAChR}$ ) was added. After an aditional $3 \mathrm{~h}$ incubation at $4{ }^{\circ} \mathrm{C}$, the complex was precipitated by addition of goat anti-human immunoglobulin serum, and the radioactivity was counted. The result was expressed as percentage of inhibition of binding of anti-MIR antibodies or MG patient sera.

\section{Results}

Construction of $\mathrm{SCF}_{4} 637$

$V_{H}$ and $V_{b}$ CDNAs of SCF, 637 were PCR amplified from its parental $F_{6 t h} 637$, isolated from thymus-derived phage display library of a MG patient, and subsequently cloned into vector pHEN2. The generated scF 637 is 762 bp long and its $V_{13}$ and $V_{1}$ sequences are identical to those of $F_{a b} 637$ at amino sequences of the $V_{18}$ (Figure 1). The original nucleotide sequences of $F_{a b} 637$
were described earlier [27]. 


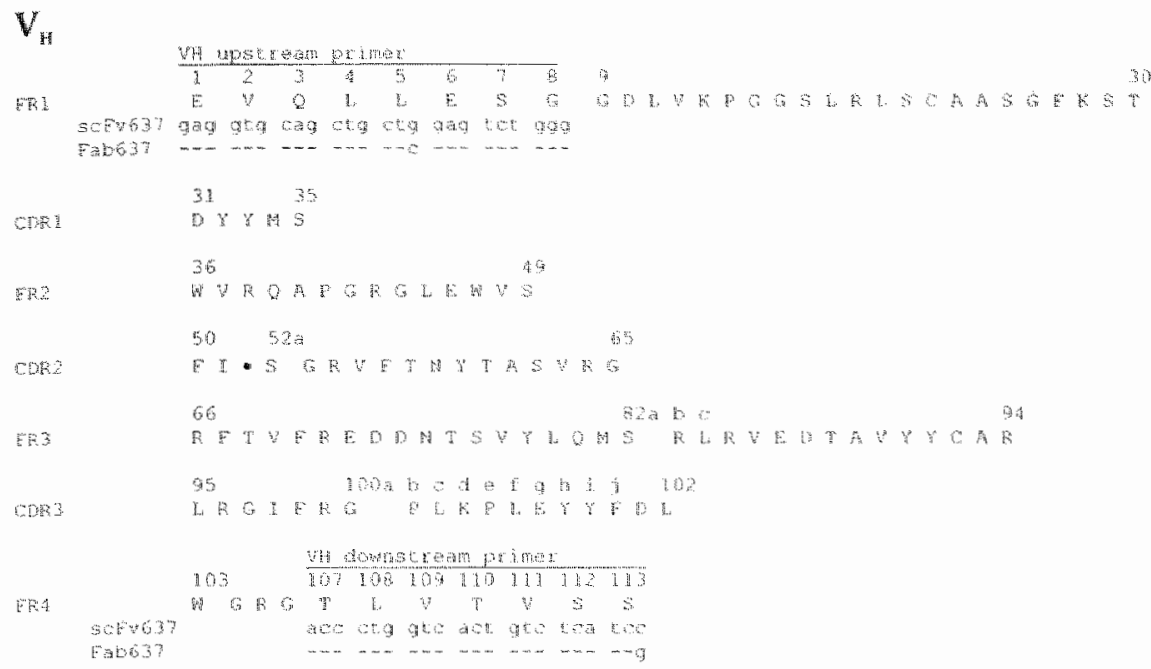

\section{Linker}

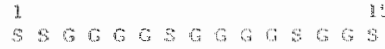

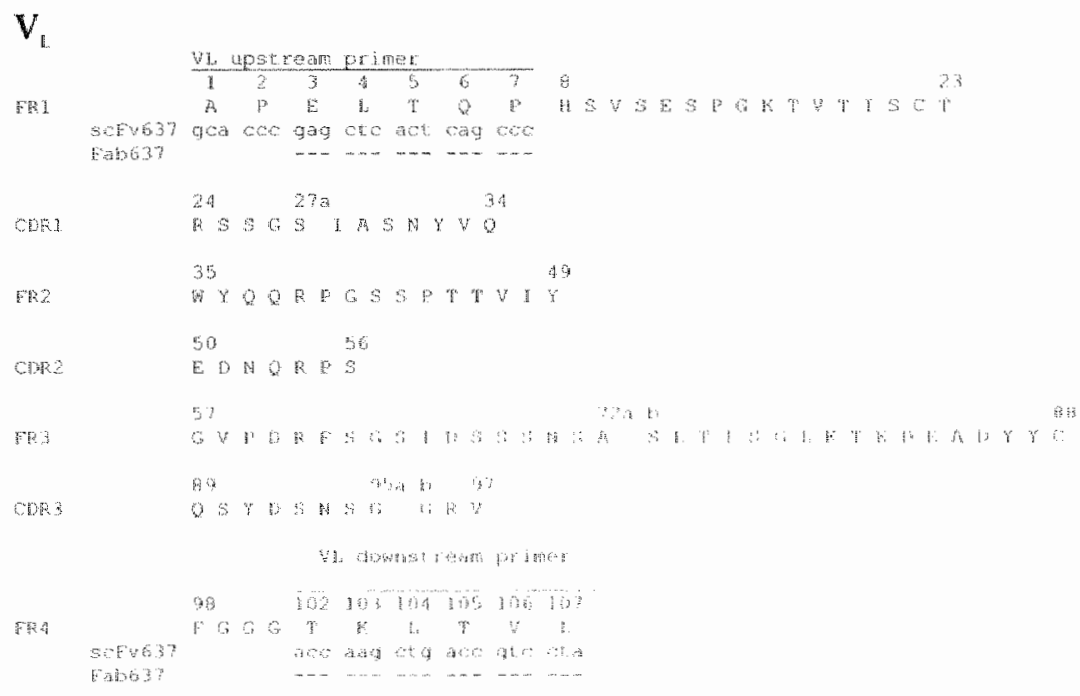

Figure 1

Amino acid sequences of heavy $(\mathrm{H})$ and light $(\mathrm{L})$ chains of $5 \mathrm{CF}, 637$. The primers used both in PCR amplification of $V_{11}$ and $V_{1}$ genes and for sequencing of scF 637 are also indicated as nucleotide sequences, and compared with its parental $F_{s i n} 637$. The codon "ctc" at amino acid position 5 in the $V_{14}$ of $F_{\text {vit }} 637$ was changed into "ctg" in scF 637 to remove Xhol recognition site (ctcgag) without alterations of the corresponding amino acids. The codon change "tcg" $\rightarrow$ "tcc" from $\mathbb{F}_{\text {in }} 637$ to $\mathrm{scF} 637$ at amino acid position 113 of the $V_{n}$ was created in $V_{4}$ downstream primer to match the Xhol restriction sequence without intraduction of an extro amino acid between the $V_{n}$ and the linker. The sequence identity of $F_{4 t h} 637$ with scF, 637 in primers is indicated by dashes. The amino acid position is numbered according to Kabal et al. [39]. RR: framework region; CDR: complementarity determining region; : missing amino acid. 
Expression and purification of soluble scF 637

The phagemid pHEN2-scF,637 construct was transformed into nonsuppressor E. coll HB2151 for production of soluble scFv637. The soluble $\mathrm{scF}_{v} 637$ accumulated in the bacterial periplasm but not in culture medium of bacteria after induction of $\mathbb{P} T \mathrm{TG}$ for $3 \mathrm{~h}$ at $30^{\circ} \mathrm{C}$. However, no scF, production was detectable in either periplasm or culture supernatant of control bacteria or bacteria without IPTG induction by nitrocellulose dot blot assay with anti-c-myc antibody (result not shown).

SDS-PAGE and western blotting analysis of fractions from IMAC purification showed that the apparent molecular weight of SCF. 637 was approximately $36 \mathrm{kDa}$ although it was calculated to be $30.4 \mathrm{kDa}$ from the amino acid sequence (Figure 2).

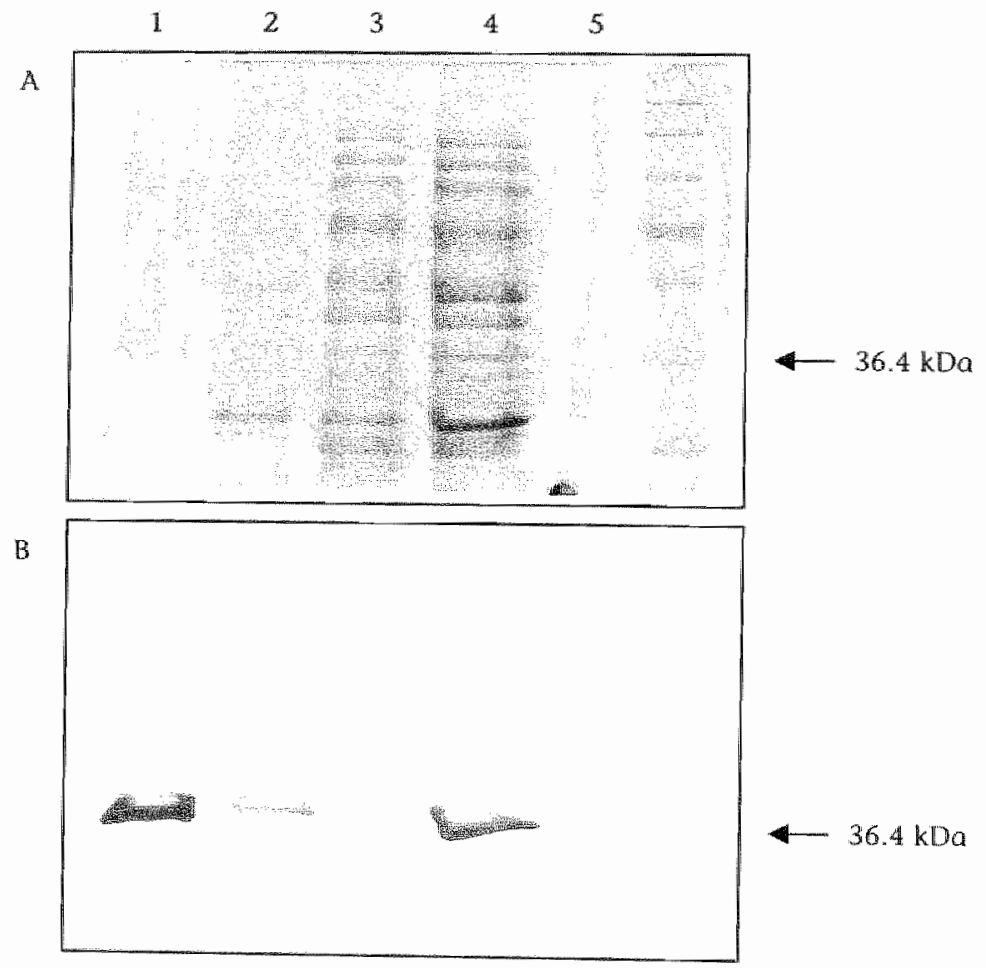

\section{Figure 2}

SOS-PACE and westem blotting analysis of fractions from IMAC purification of 8C, 637 corrying C-myc and His, tags. Two identical gels were run in parallel. Protein bands were detected by Coomassie staining (A) and the scF 637 by western blotting using mouse anti-cmyc $\mathrm{mAb}$ and followed by rabbit anti-mouse $\lg \mathrm{G}$ conjugated with HIR and substrate DAB (B). Lanes: 1, eluate with $250 \mathrm{mM}$ imidazole; 2 , washing fraction with $20 \mathrm{mM}$ imidazole; 3 , flow-through; 4, unpurified periplasmic fraction, 5 , periplasmic fraction from $E$. coli HB21.51 as negative control; 6 , molecular weight marker. 
Antigen binding activity of $S C F, 637$

The binding activity of $\mathrm{SCF}_{v} 637$ to hAChR extracted from TE671 cells was tested using a precipitation RIA. SCF 637 produced in periplasm of different bacterial clones were able to bind hAChR but not $\mathrm{rAChR}$ or $\mathrm{tAChR}$. Whereas, no binding activity was found in bacterial culture medium and in control bacteria, expressing the non-specific scF, $637=80 a$ [unpublished data], which lacks the first eight amino acids of framework 1 of $V_{H}$ and $V_{L}$ (Figure 3).

$\mathrm{ScF}_{v} 637$ cross-reacted with primate $\mathrm{AChR}$ at neuromuscular junction of monkey intercostal muscle section. $\mathrm{SCF}_{*} 637$ bound to endplate regions (Figure 4, A and C) which were colocalized in the same slides with $\alpha-B T^{\text {Eh }}$ (Figure $4, \mathrm{~B}$ and D), demonstrating the in situ binding capacity of SCF 637 .

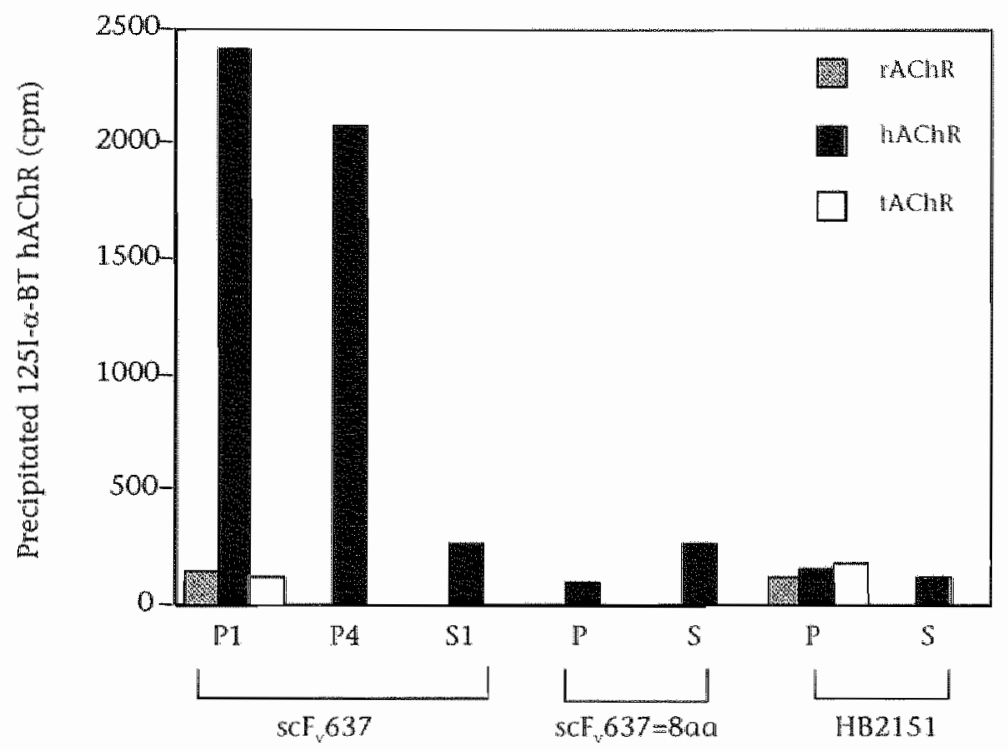

Figure 3

Binding activities of ScF.637 to AChRs. "1-a-BT-AChR-scF 637 complex was precipitated by addition of mouse anti-c-myc $\mathrm{MAb}$ and goat antimouse $\mathrm{IgG}$ in standard precipitation RIA. hAChR: human AChR; rAChR: rat AChR: TAChR: Torpedo AChR; P: periplasmic fraction; S: culture supernatant; $s \mathrm{CF}, 637=80 \mathrm{aa:}: 5 \mathrm{C}, 637$ without the first 8 amino acids of $\mathrm{V}_{19}$ and $\mathrm{V}_{8}$, resulting in loss of specificity; $4 B 2151$ : E. coll HB2151 control; numbers represent different bacterial colonies.

Protective capacity of SCF 637 to hAChR

The inhibition of $\mathrm{SCF}_{v} 637$ to anti-MIR antibodies or MG patient sera for binding to hAChR was determined in a competitive ELISA and RIA, SCl 637 expressed in the periplasmic fraction of E. coli HB2151 inhibited the binding of anti-MIR mAb35 to hAChR up to $73.0 \%$ and that of $\operatorname{IgG637}$ up to $32.9 \%$, due to the affinity difference between the two $\mathrm{F}_{4 \mathrm{~m}} 637$ variants (Figure 5A). It also inhibited the binding of MG patient sera to hAChR from 
up to $45.5 \%$ (Figure $5 \mathrm{~B}$ ), indicating its protective capacity towards a broad range of polyclonal anti-AChR antibodies.
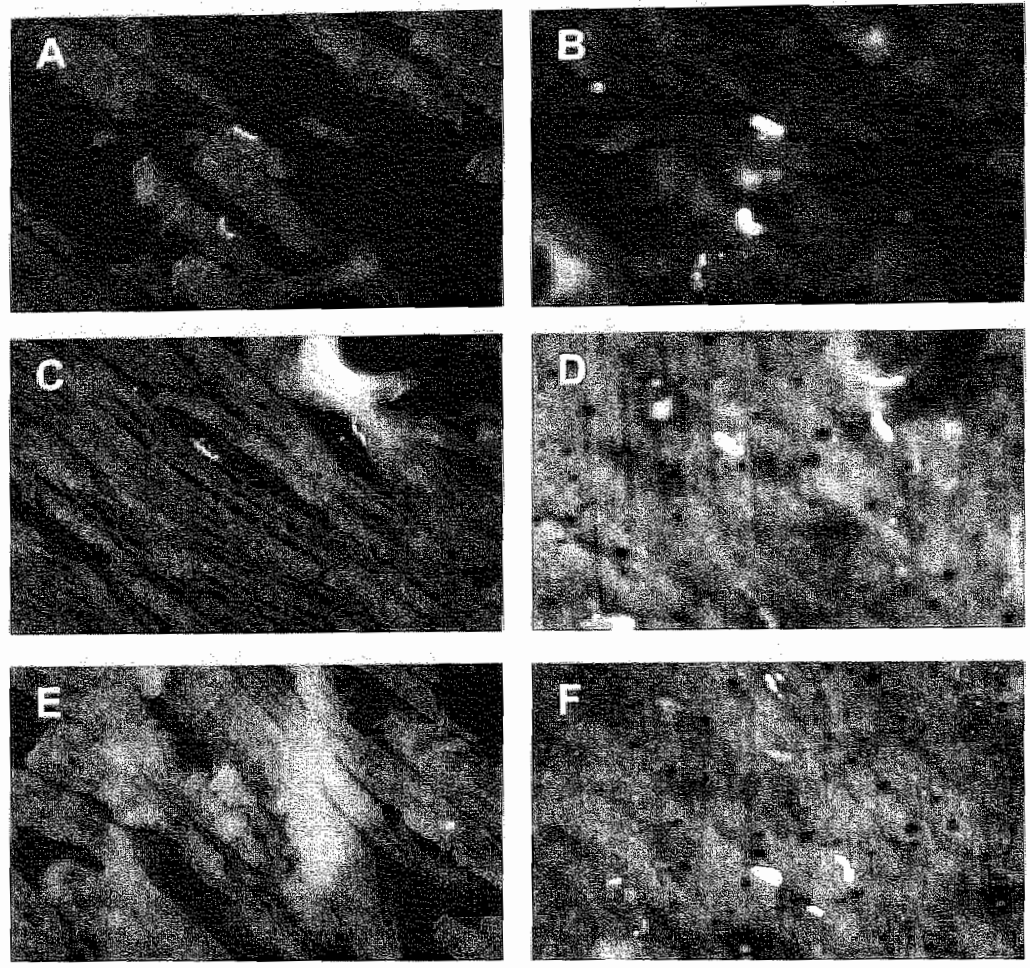

Figure 4

In situ binding of $s \mathrm{CF}_{\mathrm{v}} 637$ to $\mathrm{AChR}$ at neuromuscular junction of monkey intercostal muscle section. The binding of sCF,637 to AChR at endplate was demonstrated by immunohistochemical staining. Mouse anti-c-myc mAb and goat anti-mouse IgG conjugated with FTC were used for visualization. Rhodamire-labeled $\alpha-B T\left(\alpha-B T^{\text {shl }}\right)$ was used to colocalize the same endplates. A and $\mathrm{C}$ scF 637 from colonies 1 and 4 bound to AChR at endplates; $B$ and D: colocalization of AChR in the same endplates as in $A$ and $C$ respectively; $E$ : scF 637 without the tirst 8 amino acids of $V_{31}$ and $V_{1}$

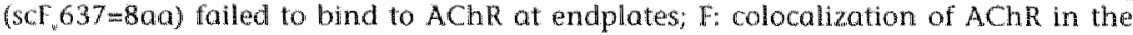
same endplates as in E. Magnification: $x 200$.

\section{Discussion}

Pathogenic anti-AChR antibodies are mainly those that are directed against the MIR and make up most part of the total anti-AChR antibodies in both MG and EAMG. However, $F_{\text {at }}$ or ScF fragments can not themselves cross-link AChR to cause antigenic modulation, since they are monovalent, and can not activate the complement cascade to cause focal lysis of postsynaptic membrane, since they lack the $\mathrm{F}_{c}$. $\mathrm{F}_{\mathrm{abb}}$ or scF derived from antiMIR antibodies could block the binding of $\mathrm{MG}$ patient sera or their 
parental anti-MIR antibodies to $A C h R[27,33]$, and protect the $A C h R$ from antigenic modulation induced by $M G$ patient sera or anti-MIR mAbs in cultured TE671 cells $[27,29,31,32]$.

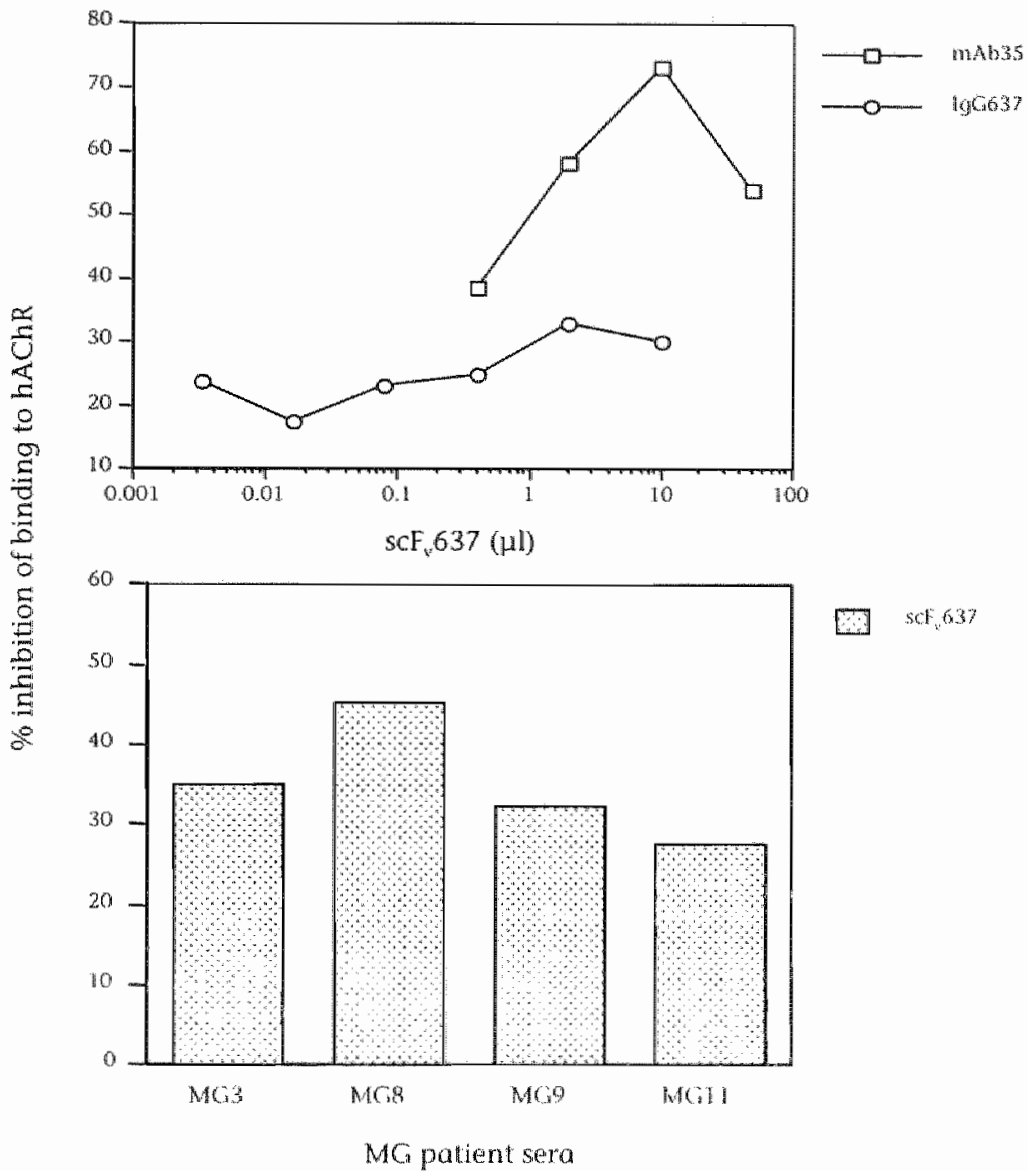

Figure 5

Inhibition of binding of anti-MLR antibodies and MG patient sena to $\mathrm{ACC} R$ by scFv637. A: scFv637 was tested for the ability to inhibit the binding of its intact IgG637 and rat anti-MIR MAb35 to hAChR by ELISA. hAChR was captured by bound mAb153 and incubated with various amounts of periplasmic fractions of sciv637. The competition was determined at $50 \%$ of the maximum binding of 196637 or mAb35 to hAChR. B: capacity of SCF 637 to protect hAChR from binding of MG patient sera was tested in a RIA. hAChR labeled with ${ }^{12} 1$ a-BT was preincubated with $250 \mu \mathrm{H}$ of Ni-NTA-purified periplasmic haction of scFv637, then incubated with MG patient serum (70\% of the maximum binding to hAChR) and precipitated with goat anti-human immunoglobulin serum. The result was expressed as percentage of inhibition of binding of anti-MIR antibodies or MG patient sera to hAChR. 
$\mathbb{F}_{03} 637$ is a $\mathrm{MG}$ thymus-derived anti-MIR antibody fragment [27]. It prevents $M G$ serum from binding to $h A C h R$ and protects $A C h R$ from loss induced by $M G$ serum. Since $F_{\text {aib }} 637$ can bind monkey $A C h R$ in situ on monkey intercostal muscle section, it is ideal to test its in vivo protective ability in monkey before clinical application in MG patient (a large-scale production of $\mathrm{F}_{a \mathrm{ab}} 637$ by transfecting it into chinese hamster ovary cells for mammalian expression is in progress). We have constructed a scF $\mathrm{serived}_{\mathrm{v}}$ from $F_{v i j} 637$. The aim of this study is to try an alternative possibility using antibody fragment for the specific immunosuppressive therapy of $\mathrm{MG}$. Since a $\mathrm{SCF}_{v}$ is smaller then a $\mathrm{F}_{\mathrm{ab}}$, it could penetrate the target area better. The change in biodistribution compared to the half-life difference between $s c F_{v}$ and $F_{d i b}$ could be beneficial. Furthermore, the $V_{H}$ and $V_{L} C D N A s$ of $s c F_{v}$ are located in the same cistron, this property makes it easier for manipulation of genetic improvement in its affinity and stability.

$\mathrm{ScF}_{v} 637$ was constructed from $V_{14}$ and $V_{L}$ CDNAs of $F_{s, 6} 637$ by PCR amplification and cloning into the vector pHEN2, which contains GS (Gly and Ser) rich linker and $\mathrm{c}-\mathrm{myc}$ and $\mathrm{His}_{6}$ tags for specific detection and efficient purification. The $V_{H}$ upstream primer was designed according to the first 8 codons of $F_{a i b} 637^{\prime} s V_{k b}$. However, the first 6 codons used in $F_{a b} 637$ was artificially designed in vector pComb3 $\mathrm{H}$, and codons 5 and 6 (ctc gag) was used as Xhol restriction site for original cloning of $\mathrm{V}_{\mathrm{H}}$. Since vector pHEN2 contains the same Xhol restriction site for cloning and we prefer the $\mathrm{V}_{\mathrm{it}}$-linker- $\mathrm{V}_{\mathrm{l}}$ orientation construct of $\mathrm{scF}_{w}$, therefore, "ctc" in codon 5 was changed into " $\mathrm{ctg}$ " to remove the Xhol restriction site without substitution of amino acid. Similarly, codon " $\mathrm{tcg}^{\prime} \rightarrow$ " $\mathrm{tcc}$ " from $\mathrm{F}_{\mathrm{ab}} 637$ to $\mathrm{scF}$, at amino acid position 113 of $\mathrm{V}_{\mathrm{H}}$ was created in $\mathrm{V}_{\mathrm{H}}$ downstream primer to match the Xhol site without introduction of an extra amino acid between $V_{H}$ and linker. For the $\mathrm{V}_{\mathrm{L}}$ cloning, codon " $\mathrm{gca}$ " (encoding Ala) in ApaLI restriction sequence was designed in $\mathrm{V}_{\mathrm{L}}$ upstream primer as first codon of $\mathrm{V}_{\mathrm{L}}$ of $\mathrm{scF}_{v} 637$ and "ccc" (encoding Pro) as second codon to match both ApaLI restriction site and annealing to template in pComb3H.

The specificity of bacterial produced $\mathrm{scF}, 637$ binding to hAChR was determined in RIA in which scF 637 first bound to AChR and then to the Cmyc tag in the complex of scF 637 .AChR was recognized by mouse anti-cmyc mAb. However, interestingly, when a solid-phase RIA (SPRIA) in which the c-myc lag of $\operatorname{scF}_{2} 637$ was captured first by fixed mouse anti-c-myc mAb was utilized to determine the specificity of $\mathrm{SCF} 637$ binding to $\mathrm{hAChR}$, no binding activity of $\mathrm{hAChR}$ to the $\mathrm{SCF}_{*} 637-\mathrm{mAb}$ complex could be found (data not shown). In contrast, its parental $\mathrm{F}_{\text {aib }} 637$ could bind AChR in SPRIA suggesting that the binding of anti-c-myc mAb to the C-terminal c-myctag of $\mathrm{scF}_{v} 637$ may interfere with the binding of $\mathrm{scF}_{v} 637$ to AChR. A similar result was described in a previous study of Goel et al. [40], who found that the C-terminal position of $\mathrm{His}_{6}$ tag partially covered the antigen-binding site and affected the binding properties of $\mathrm{scF}_{\text {in }}$ in SPRIA. Although several studies showed that the affinity tags of different types had no significant effects on the activity of native proteins [41-48], it will be helpful to determine the effects of an $\mathrm{N}$-terminal c-myctag on scF 637 specificity since 
the effects of affinity tags on SCF, specificity depend on the primary sequences and conformation of the $\mathrm{ScF}_{\mathrm{v}}$. It was also reported that $\mathrm{scF}$. exhibited higher cross-reactivity with analogs of the antigen originally used for production of its parental mAb [49]. Nevertheless, $\mathrm{SCF} 637$, just like $\mathrm{F}_{\mathrm{ab}} 637$, could specifically bind to $\mathrm{AChR}$ in situ at monkey neuromuscular junction but did not cross-react with $\mathrm{rAChR}$ or tAChR.

Interestingly, scF $637=8 \mathrm{aa}$, which lacks the first eight amino acids of framework regions (FRs) $I$ of $V_{H}$ and $V_{L}$ compared to $\operatorname{scF}_{v} 637$, is a good negative control, since it has no specificity towards AChR (Figures 3 and 4). Li et al. [50] found that sequence changes at the N-terminus of both $\mathrm{V}$ domains introduced by PCR may seriously affect antigen binding. Several other groups noted the same phenomena [51-54]. Since the N-terminus of both $\mathrm{V}$ domains can be contiguous with the complementarity determining region (CDR) surface [55] they would influence the structure of the combining site and the antigen binding characteristics of antibodies.

Competition experiment showed that scF,637 was able to protect $h A C h R$ from the binding of anti-MIR antibodies and MG patient sera, which makes it an alternative candidate for specific immunosuppressive therapy compared with its parental $\mathrm{F}_{\mathrm{itb}} 637$. Presently, we are trying to prepare a conjugate by linking the $\mathrm{scF}_{v}$, without tags, with human serum albumin (HSA) or polyethylenoglycol (PEG) to increase its half-life and alter its biodistribution.

\section{Acknowledgements}

We would like to thank Drs G. Winter, M. Jonker and S. Tzartos for kindly supplying pHEN2, monkey muscle, mAb35, and mAb153. We are also grateful to Dr B. Machiels for excellent laboratory assistance and helpful discussion. This work was supported by grants from Prinses Beatrix Fonds (to Dr M. De Baets) and National Foundation for Natural Science of China (to F. Meng).

\section{References}

[1] Lindstrom, I., D. Shelton, X. Fuil, "Myasthenia gravis", Advances in Immunology 42 (1988) pp. 233-284.

[2] Grous, Y.M., M.H. De Baets, "Myasthenia gravis: an autoimmune response against the acetylcholine receptor", Immunologic Research 12 (1993) pp. 78.100.

[3] Drachman, D.B., "Myasthenia gravis", New England foumal of Medicine 330 (1994) pp. $1797-1810$.

[4] Lindstrom, J.M., V.M. Lennon, M.E. Seybold, S. Whittingham, "Experimental autommune myasthenia gravis and myasthenia gravis: biochemical and immunochemical aspects", Annals of the New York Academy of Sciences 274 (1976) pp. $254-274$.

[5] Toyka, K.V., D.B. Drachman, A. Pestronk, I. Koo, "Myasthenia gravis: passive transfer from man to mouse". Science 190 (1975) pp. 397-399.

[6] Tzartos, S. S. Hochschwender, P. Vasquez, J. Lindstrom, "Passive transfer of experimental autoimmune myasthenia gravis by monoclonal antibodies to the main immunogenic region of the acetylcholine receptor", Joumal of Neuroimmunology $15(1987)$ pp. 185-194. 
[7] Conti-Tronconi, B.M., K.E. McLane, M.A. Raftery, S.A. Grando, M.P. Protti, "The nicotinic acerylcholine receptor: structure and autommune pathology", Critical Reviews in Biochemistry and Molecular Biology 29 (1994) pp. 69-123.

(8) Lindstrom, 1., J. Merlie, G. Yogeeswaran, "Biochemical properties of acteylcholine receptor subunits from Torpedo califormica", Biochemistry 18 (1979) pp. 4465-4470.

[9] Raftery, M.A., M.W. Hunkapiller, C.D. Strader, L.E. Hood, "Acetylcholine receptor: complex of homologous subunits", Science 208 (1980) pp. 1454-1456.

[10] Kuballek, E, S. Ralston, I. Lindstrom, N. Unwin, "Location of subunits within the acetylcholline receptor by electron image analysis of rubular crystals from Torpedo mamotata", Journal of Cell Biology 105 (1987) pp. 9.18.

(11) Barkas, T., A. Mauron, B. Roth, C. Alliod, S.I. Tzartos, M. Ballivet, "Mapping the main immunogeric region and toxin-binding site of the nicotinic acetylcholine receptor", Sicience 235 (1987) pp. $77-80$.

[12] Barkas, T., J.M. Gabriel, A. Mauron, G.]. Hughes, B. Roth, C. Alliod, S.]. Tzartos, M. Bollivet, "Monoclonal antibodies to the main immunogenic region of the nicotinic acetylcholine receptor bind to residues 61-76 of the alpha subunit" "foumal of Biological Chemistry 263 (1988) pp. 5916.5920.

[13] Tzartos, S.J., A. Kokla, S.L. Walgrave, B.M. Conti-Tronconi, "Localization of the main immunogenic region of human muscle acetylcholine receptor to residues $67-76$ of the alpha subunit", Proceedings of the National Academy of Sciences of the United States of America 85 (1988) pp. 2899-2903.

[14] Tzartos, S.f., I.M. Lindstrom, "Monoclonal antibodies used to probe acetylcholine receptor structure: localization of the main immunogenic region and detection of similarities between subunits" Procedings of the National Academy of Sciences of the United States of America $77(1980)$ pp. $755-759$.

[15] Tzartos, S.I., M.E. Seybold, I.M. Lindstrom, "Specificities of antibodies to acetylcholine receptors in sera from myasthenia gravis patients measured by monoclonal antibodies". Proceedings of the National Academy of Sciences of the United States of America 79 (1982) pp. $188 \times 192$.

[16] Tzartas, S.J., T. Barkas, M.T. Cung, A. Mamalaki, M. Marraud P. Orlewski, D. Papanastasiou, C. Sakarellos, M. Sakarellos-Daitsiotis, P. Tsantili, V. Tsikaris, "Anatomy of the antigenic structure of a large membrane autoantigen, the muscle-type nicotinic acetylcholine receptor", Immunological Reviews 163 (1998) pp. 89-120.

[17. Lennon, V.A., E.H. Lambert, "Myasthenia gravis induced by monoclonal antibodies to acetylcholine receptors", Nature 285 (1980) pp. 238-240.

[18] Graus, Y., F. Meng, A. Vincent, P. van Breda Vriesman, M. de Baets, "Sequence analysis of anti-AChR antibodies in experimental autoimmune myasthenia gravis", Jounal of Immunology 1.54 (1995) pp. 6382-6396.

[19] Tzartos, S.1. A Starzinski-Powitz, "Decrease in acetylcholine-receptor content of human myotube cultures mediated by monoclonal antibodies to alpha, beta and gamma subunits", FEBS Letters 196 (1986) pp. $91-95$.

[20] Souroujon, M.C. A.R. Pachner, S. Fuchs, "The treatment of passively transterred experimental myasthenia with anti-idiotypic antibodies", Neurology 36 (1986) pp. 622 -
625 .

[21] Wang, Z.Y. I. Qlao, H. Link, "Suppression of experimental autoimmune myasthenia gravis by oral administration of acetylcholine receptor". Joumal of Neuroimmunology 44 (1993) pp. 209-214.

[22] Wang, Z.Y. 1. Qiao, A. Melms, H. Link, "T cell reactivity to acetylcholine receptor in rats orally tolerized against experimental autoimmune myasthenia gravis", Cellular Immunology $152(1993)$ pp. $394-404$.

[23] Wang, Z.Y, J. Huang, T. Olsson, B. He, H. Link, "B cell responses to acetylcholine receptor in rats orally tolerized against experimental autoimmune myasthenia gravis", Journal of the Neurological Sciences $128(1995)$ pp. $167-174$.

124] karachunski, P.I., N.S. Ostlie, D.K. Okita, B.M. Conti-Fine, "Prevention of experimental myasthenia gravis by nasal administration of synthetic acetylcholine receptor $\mathrm{I}$ epitope sequences", lournal of Cinical Investigation $100(1997)$ pp. $3027-3035$.

[25] Barchan, D., M.C. Souroujon, S.H. Im, C. Antozzi, S. Fuchs, "Antigen-specific modulation of experimental myasthenia gravis; nasal tolerization with recombinant fragments of the 
human acetylcholine receptor alpha-subunit" Procedings of the National Academy of sciences of the United States of America $96(1999)$ pp. 8086-8091.

[26] Shi, F.D. H. Li, H. Wang, X. Bai, P.H. van der Meide, H. Link, H.G. Ljunggren, "Mechanisms of nasal tolerance induction in experimental autoimmune myasthenia gravis: identification of regulatory cells" Joumal of Immunology $162(1999)$ pp. 5757.5763 .

[27] Grous, Y.F., M.H. de Baets, P.W. Parten, S. Bernih-Aknin, I. Wokke, P.I. van Breda Wriesman, D.R. Burton, "Human anti-nicotinic acetylcholine receptor recombinant Fab fragments isolated from thymus-derived phage display libraries from myasthenia gravis patients reflect predominant specificities in serum and block the action of pathogenic serum antibodies", youmal of Immunology 158 (1997) pp. 1919-1929.

[28] Farrar, I., S. Portolano, N. Willcox, A. Vincent, L. Jacobson, I. Newsom-Dovis, B. Ropoport, S.M. McLachlan, "Diverse Fab specific for acetylcholine receptor epitopes from a myasthenia gravis thymus combinatorial library", Intemational immunology 9 (1997) pp. 1311-131.8.

[29] Sophianos, D., S.J. Tzartos, "Fab fragments of monoclonal antibodies protect the buman acetylcholine receptor against antigenic modulation caused by myasthenic sera", Journal of Autoimmurity 2 (1989) pp. $777-789$.

[30] Papanastasiou, D., K. Poulas, A. Kokla, S.J. Tzartos, "Prevention of passively transferred experimental autoimmune myasthenia gravis by fab fragments af monoclonal antibodies directed against the main immunogenic region of the acetylcholine receptor", Joumal of Neurommunology 104 (2000) pp. 124-132.

[31] Papanastasiou, D., A. Mamalaki, E. Eliopoulos, K. Poulas, C. Liolitsas, S.I. Tzartos, "Construction and characterization of a humanized single chain fv antibody fragment against the main immunogenic region of the acetylcholine receptor", foumal of Neuroimmunology 94 (1999) pp. 182-195.

[32] Mamalaki, A., N. Trakas, S.J. Tzartos, "Bacterial expression of a single-chain Fv frogment which efficiently protects the acetylcholine receptor against antigenic modnlation coused. by myasthenic antibodies", European Jounal of Immunology 23 (1993) pp. 1839-1845.

[33] Tsantili, P., S.I. Tzartos, A. Mamalaki, "High affinity single-chain. Fv antibody fragments protecting the human nicotinic acetylcholine receptor", Journal of Neuroimmunology 94 (1999) pp. 15-27.

(34] de Wildt, R.M., R. Finnern, W.H. Ouwehond, A.D. Griffiths, W.I. van Venrooij, R.M. Hoet, "Characterization of human variable domain antibody fragments against the U1 RNAassociated A protein, selected from a synthetic and patient-derived combinatorial $V$ gene library", European loumal of Immunology 26 (1996) pp. 629-639.

[35. Hoet, R.M., I. Koornmeef, D.]. de Rooij, L.B. van de Putte, W.J. van Venrooij, "Changes in anti-U1 RNA antibody levels correlate with disease activity in patients with systemic lupus erythematosus overlap syndrome", Arthritis and Rheumatism 35 (1992) pp. 1202 1210

[36] Luther, M.A. R. Schoepfer, P. Whiting, B. Casey, Y. Blatt, M.S. Montal, M. Montal, I. Linstrom, "A muscle acetylcholine receptor is expressed in the human cerebellar medulloblastoma cell tine TE67 1", foumal of Neuroscience 9 (1989) pp. 1082-1096.

[37] Kordossi, A.A., S.I. Tzartos, Monoclonal antibodies against the main immunogenic region of the acetylcholine receptor. Mapping on the intact molecule", Joumal of Neuroimmunology $23(1989)$ pp. $35-40$.

[38] Tzartos, S.I. M.S. Remoundos, "Precise epitope mapping of monoclonal antibodies to the cytoplasmic side of the acetylcholine receptor alpha subunit. Dissecting a potentially myasthenogenic epitope", European Journal or Biochemistry $207(1992)$ pp. 915.922.

[39] Kabat, E. T. Wu, H. Perry, K. Gottesman, C. Foeller, Sequences of proteins of immunological interest, Nationall Institute of Health, Bathesda, MD, 1991.

[40] Goel, A. D. Colcher, I.S. Koo, B.I. Booth, G. Pavlinkova, S.K. Batra, "RGlative position of the hexahistidine tag effects binding properties of a tumor-associated single-chain $\mathrm{Fv}$ construct", Biochimica et Biophysica Acta 1523 (2000) pp. 13-20.

[41] Xu, B., J. Kriongkum, L.P. Nagata, R.E. Fulton, M.R. Suresh, "A single chain Fv specific against Western equine encephalitis vinus", Hybridoma 18 (1999) pp. 31.5-323

[42] Alcocer, M.]., C. Doyen, H.A. Lee, M.R. Morgan, "Properties of polyclonal, monoclonal, and recombinant antibodies recognizing the organophosphorus pesticide chlorpyrifosethyl", Joumal of Agricultural and Food Chemistry 48 (2000) pp. 4053-4059. 
(43) Hashimoto, w. T. Tkenaga, K. Tanigawa, T. Ueda, I. Ezak, T. Imoto, "Expression and characterization of human theumatoid factor single-chain $F v^{\mathrm{m}}$, Bological and Pharmaceutical Bulletin $23(2000)$ pp. 941.945.

[44] Kuderova, A., J. Tanha, 1.5. Lee, "Characterization of four nucleic acid-binding singlechain Fv fragments by direct and competitive solid-phase radiommunoassays", Joumal of Biological Chemistry 269 (1994) pp. 32957.32962.

[45] Casey. IL., P.A. Keep, K.A. Chester, L. Robson, R.E. Hawkins, R.H. Begent, "Purification of bactertally expressed single chain Fv antibodies for clinical applications using metal chelate chromatography", joumal of Immunological Methods 179 (1995) pp. 105-116.

[46] Long, M.C., S. Jager, D.C. Mah, L. Jebailey, M.A. Mah, S.A. Masri, L.P. Nagata, "Construction and characterization of a novel recombinant single-chain variable fragment antibody against Western equine encephalitis wirus" Hybridoma 19 (2000) pp. $1-13$.

[47] Brown, 1.C., B. Brown, 2nd, Y. Li, C.C. Hardin, Construction and characterization of a quadruplex. DNA selective single-chain autoantibody from a viable motheaten mouse hybridona with homology to telomeric DNA binding protens", Biochemistry 37 (1998) pp. $16338-16348$.

[48] Berdichewsky, $Y$, E. Ben-Zeev, R. Lamed, I. Benhar, "Phage display of a cellulose binding domain from Clostridium themocellum and its application as a tool for antibody engineering" Joumal of Immunological Methods 228 (1999) pp. 151-162.

[49] Yuan, Q. I.R. Clarke, H.R. Zhou, J.E. Linz, I.J. Pestka, L.P. Hart, "Molecular cloning, expression, and characterization of a functional single-chain $F y$ antibody to the mycotoxin zearalenone" Applied and Environmental Microbiology 63 (1997) pp. 263-269.

[50] $\mathrm{Li}, \mathrm{I}, \mathrm{Y}$. Wang, $Z$. Wang, $Z$. Dong, "Infuences of amino acid sequences in FR1 region on binding activity of the SCFv and Fab of an antibody to human gastric cancer cells", Immunology Letters 71 (2000) pp. 157-165.

[51] Benhar, 1., 1. Pastan, "Identification of residues that stabilize the single-chain Fv of monoclonal antibodies B3", Journal of Biological Chemistry 270 (1995) pp. 23373-23380.

[52] Ohtomo, T., M. Tsuchiya, K. Sato, K. Shimizu, S. Moriuchi, Y. Miyao, T. Akimoto, K. Akamatsu, T. Hayakawa, Y. Ohsugi, "Humanization of mouse ONS-M21 antibody with the aid of hybrid variable regions", Molecular Immunology 32 (1995) pp. 407-4.16.

[53] Li, Y., M.B. Spellerberg, F.K. Stevenson, I.D. Copra, K.N. Potter, "The I binding specificity of human $\mathrm{VH}$ 4-34 (VH 4-21) encoded antibodies is determined by both VH framework region 1 and complementarity determining region $3^{31}$, Joumal of Malecular Biology 256 (1996) pp. 577-589.

[54] de Haard, H.J., B. Kazemier, A. van der Bent, P. Oudshoom, P. Boender, B. van Gemen, I.W. Arends, H.R. Hoogenboom, "Absolute conservation of residue 6 of immunoglobulin heavy chain variable regions of class ILA is required for correct folding", Protein Engineering 11 (1998) pp. 1267-1276.

[55] Padlan, E.A., "A possible procedure for reducing the immunogenicity of antibody wariable domains while preserving their ligand-binding properties", Molecular Immunology 28 (1991) pp. 489.498. 


\section{Chapter 5}

\section{Characterization of a human IgG1 reconstructed from an anti-acetylcholine receptor $F_{a b}$}

Maurice H.W. Stassen, Barbie M. Machiels, Bert A. 't Hart, Herbert P.M. Brok, Jan J.G.M. Verschuuren, Gert van Dijk, Anja Roos, Mohamed R. Daha, Efrosini Fostieri, Socrates J. Tzartos, Sonia Berrih-Aknin, Eugène Bosmans, Paul W.H.I. Parren \& Marc H. De Baets 


\section{Abstract}

In myasthenia gravis ( $M G$ ), autoantibodies against the acetylcholine receptor $(A C h R)$ lower the number of $A C h R s$, leading to an impaired neuromuscular signal transmission. Previously, we have cloned an anti$A C h R F_{a j:}, F_{a b} 637$, from an $M G$ patient's thymus. $F_{a b} 637$ protects against loss of AChRs by blocking the binding of pathogenic MG autoantibodies in vitro. In order to test the primate-specific anti-AChR $\mathrm{F}_{a b} 637$ in vivo, large amounts of this $F_{\text {iti }}$ are needed in a monkey experimental autoimmune MG (EAMG) model. But, the current bacterial expression system has a low yield. Therefore, we genetically fused the $F_{a b} 637$ 's $F_{d}$ to the $F_{c}$ of human IgG1 and transfected chinese hamster ovary $(\mathrm{CHO})$ cells with a plasmid encoding for IgG1-637. CHO cells produced $55 \mathrm{mg} / \mathrm{l}$ protein G-purified IgG1-637. IgG1637 specifically recognized the human al subunit of $A C h R$ in its native conformation, like its parental $F_{\mathrm{ab}}$. Three daily doses of 1.7 or $5 \mathrm{mg}$ IgGl637 per $\mathrm{kg}$ body weight induced muscle weakness in rhesus monkeys, indicating the reconstruction of a myasthenia gravis autoantibody. IgG1637 could be used for the enzymatic production of the potential therapeutic $F_{a b} 637$ or could be used as the genetic basis of a therapeutic IgG-like molecule, which has an increased serum half-life compared to $F_{a b}$. 
In myasthenia gravis (MG), binding of autoantibodies to the acetylcholine receptor $(A C h R)$ at the neuromuscular junction leads to fatigable weakness of skeletal muscles. The nicotinic, muscle type $A C h R$ is an ion channel, formed by five subunits: $\alpha 1, y$ (replaced by $\varepsilon$ in adult), $\alpha 1, \delta$ and $\beta 1$. The extracellular domain of the al subunit contains the acetylcholine (ACh)binding site and a main immunogenic region (MIR), to which a major part of the pathogenic $M G$ antibodies is directed $[1,2]$. Anti-AChR antibodies cause impaired neuromuscular transmission by lowering the number of functional $A C h R s$. Three mechanisms account for the functional $A C h R$ loss. Anti-AChR antibodies can crosslink $A C h R$, leading to an increased internalization and degradation of $\mathrm{AChR}$ (antigenic modulation) $[3,4]$. Antibodies can activate complement upon binding to the $\mathrm{ACh}$, leading to focal lysis of the postsynaptic membrane $[5,6]$. To a lesser extent, the autoantibodies can functionally inhibit the $\mathrm{AChR}$ by interfering with $\mathrm{ACh}$ binding [7] or ion channel function [8]. Anti-MIR antibodies make up more than half of the autoantibodies in $M G$ patients or experimental autoimmune MG (EAMG) rats $[1,9,10]$, and are especially effective in antigenic modulation [11].

Currently, there is no specific immune therapy for MG. Severall specific immunotherapy approaches have been tested, like anti-idiotypic antibodies $[12,13]$, a peptide that competes with a pathogenic mAb for binding with AChR [14], induction of tolerance by administration of AChR [15] or AChR-derived synthetic peptides [16], and elimination of AChRspecific $T$ cells by genetically engineered antigen-presenting cells that act as "guided missiles" [17]. MG and EAMG antibody-derived $F_{\text {at }} s$ have been shown to protect against AChR loss in rodent EAMG models $[18,19] . \mathrm{F}_{\mathrm{ab}} \mathrm{s}$ block the binding of pathogenic antibodies and, because of their monovalent antigen-binding capacity and their lack of $F_{c}$, do not induce $A C h R$ loss themselves. A few human anti-human $A C h R F_{t i t} s$ have been cloned and their ability to block MG serum antibodies explored in the last years [20-23]. But, $\mathrm{F}_{\mathrm{ot}} \mathrm{s}$ are not ideal blockers due to there rapid serum clearance.

An MG patient-derived anti-MIR $F_{t: b}, F_{a t} 637$, protects against loss of $A C h R$ by $M G$ sera in vitro, without interference with ion channel function [21]. To test $\mathrm{F}_{\text {ai }} 637$ in vivo, a monkey EAMG model is essential, because it only shows crossreactivity with primate AChR. To date, only chronic

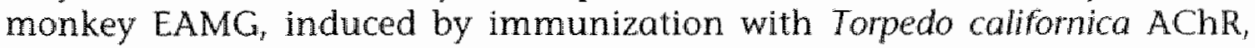
has been reported in the literature [24,25]. But, transfer of $1 \mathrm{~g} / \mathrm{kg}$ purified IgG from $M G$ patients to monkeys, like to mice [26], induces EAMG as well [Heiniger and Toyka, personal communications].

The current bacterial expression system of $\mathbb{F}_{i b} 637$ has a too low yield and production in the yeast Pichia pastoris was not successful [27]. Besides, the serum half-life of $F_{o b}$ is low, requiring even a larger amount of $F_{w i} 637$ for in vivo experiments. Fusing $\mathrm{F}_{a b} \mathrm{~s}$ to polyethylene glycol or albumin only increases their serum half-life by 15-17 times to about 1 day $[28,29]$, while 
IgG1 has a half-life of 21 days [30]. Sanna et al. [31] genetically linked an $F_{d}$ to an $F_{i}$ and expressed the full-size heavy chain (HC) and light chain (LC) in chinese hamster ovary (CHO) cells.

In this study, we reconstructed a fully human $\gamma 1$ immunoglobulin variant of $F_{d b} 637$ (IgG1-637) by genetically fusing its $F_{d}$ to an $F_{c}$. The specificity of IgG1-637 was compared to its parental $F_{a b}$ and its predicted pathogenicity was tested in rhesus monkeys. As an alternative to shielding the AChR with enzymatically produced $\mathrm{F}_{a b} 637$ from IgG1-637, we designed a recombinant IgG1-637 with monovalent AChR specificity and no complement-activating capacity, because of its expected higher serum halflife. The $\mathrm{K} 322 \mathrm{~A}$ mutation in the $\mathrm{Clq}$-binding site has been reported to abolish or at least reduce complement-dependent cytotoxicity (CDC) of human IgG1 and -3 [32-34]. Besides mutations in amino acid residues, changes in the glycosylation affect complement activation. Production of a chimeric mouse-human IgGI in the cell line CHO-Lec1 results in an antibody with truncated glycosylation, which abolishes CDC [35]. Potential non-complement-activating variants of $\operatorname{lgG1-637}$ were tested in vitro.

\section{Methods}

\section{Cloning}

The mammalian expression plasmid of the IgG1 isotype of $F_{a b} 637$, plgG1637, was constructed by Xba I and Sac I cloning of the LC and Xho I and BstE II cloning of the $F_{d}$ from the bacterial expression plasmid of $F_{a n} 637, a$ pComb3 plasmid [21], into the same pIgG1 vector. In pIgG1-637, the expression of each chain was regulated by $q$ human cytomegalovirus promoter/enhancer (hCMV P/E) element, the secretion of the HC by a mouse HC leader peptide, the secretion of the LC by a mouse $\kappa$ leader peptide and $F_{d} 637$ was fused to the human $\gamma 1 F_{\varepsilon}$.

The $\mathrm{K} 322 \mathrm{~A}$ mutation was introduced using the oligonucleotide $\mathrm{G} \mathrm{GAG}$ TAC AAG TGC GCG GTC TCC AAC AAA GCC C and the oligonucleotide with the complementary sequence with the QuickChange XL Site-directed Mutagenesis Kit (Stratagene, La Iolla, CA, USA), according to the manufacturer's manual. The sequence PLKP in the complementary determining region (CDR) 3 of the $H C$ was deleted using the oligonucleotide GGA ATT ITT CGA GGG CTA GAG TAC TAC TIC G and the oligonucleotide with the complementary sequence.

\section{Cell culture}

CHO-K1 (ATCC Number CCL-61) was cultured in HAM's F12 (Gibco/Invitrogen, Breda, The Netherlands) and the Nacetylglucosaminyltransferase I-deficient CHO-Lec1 (ATCC Number CRL1735) in MEM Eagle, alpha modification (Sigma-Aldrich, Zwijndrecht, The Netherlands), both supplemented with $10 \%$ fetal bovine serum (Bodinco, Alkmaar, The Netherlands). Cells were transfected with Lipofectin (Gibco/Invitrogen, Breda, The Netherlands), according to the 
manufacturer's manual. Transfected cells were adapted to suspension culture.

\section{Radioimmunoassay}

The specificity of CHO-produced antibody was determined by RIA [36], using human (prepared from the human TE671 rhabdomyosarcoma cell line [37]), Torpedo (prepared from Torpedo californica) or hybrid (human $\alpha 1$ subunit and Torpedo $\beta, \gamma$ and $\delta$ subunits [38]) AChR, marked with ${ }^{125} \mathrm{I}$ labeled $\alpha$-bungarotoxin. For anti-human AChR titer measurements, the Acetylcholine Receptor Autoantibody RRA Kit (IBL, Hamburg, Germany) was used.

\section{Flow cytometry analysis}

The recombinant antibodies were tested for there binding of AChR expressed on TE671 or M[TC cells [39]. Trypsinized cells were incubated with sample antibody and subsequently with FITC-conjugated goat antihuman Ig. Signal was amplified by EAS Kit (Flow-Amp Systems, Cleveland, $\mathrm{OH}$, USA). Paraformaldehyde solution (2\%) was added to the cell. suspension to permeabilize cells for cytoplasmic AChR detection. Flow cytometry was performed on a FACSCalibur apparatus (Becton Dickinson. Immunocytometry Systems, Mountain View, CA, USA).

\section{Complement binding}

Functional activation of the classical pathway by the recombinant antibodies was assessed by ELISA [40]. The human antibodies were coated in Nunc Maxisorb plates (Nunc, Roskilde, Denmark) in $100 \mu \mathrm{l}$ coating buffer (100 $\mathrm{mM} \mathrm{Na}_{2} \mathrm{CO}_{3} / \mathrm{NaHCO}_{3}$ pH 9.6) for $2 \mathrm{~h}$ at $37^{\circ} \mathrm{C}$. Residual binding sites were blocked by incubation with PBS containg $1 \%$ BSA for $1 \mathrm{~h}$ at $37^{\circ} \mathrm{C}$. Normal human serum (diluted $1 / 50$ or $1 / 100$ ) was used as the source of complement. Complement binding was assessed using dig-conjugated antihuman $\mathrm{C1q}$ ( $\mathrm{mAb} 2214$ ) and anti-human C3 (RFK22), followed by detection of $\mathrm{mAb}$ binding using HRP-conjugated sheep anti-dig $\mathrm{F}_{\mathrm{ab}}$ (Roche Molecular Biochemicals, Mannheim, Germany).

\section{EAMG in monkey}

EAMG was induced in monkeys by passive transfer of IgG from $M G$ patient plasma. Pooled plasma was clotted by $25 \mathrm{mM} \mathrm{CaCl}$ and supernatant diluted with 1 volume of phosphate buffered saline (PBS). IgG was precipitated by adding drop-wise 1 volume of saturated ammonium sulphate (SAS) $\mathrm{pH} \mathrm{7,} \mathrm{resuspended} \mathrm{in} \mathrm{water} \mathrm{and} \mathrm{dialyzed} \mathrm{against} \mathrm{PBS.}$ Solution of $10 \mathrm{~g} / \mathrm{IgG}$ contained $78 \mathrm{nM}$ anti-human AChR IgG. EAMG was induced in monkeys by 3 daily injections of $0.8 \mathrm{~g} \mathrm{IgG}$ per $\mathrm{kg}$ body weight. Animal experiments were performed at the Biomedical Primate Research Center (Rijswijk, The Netherlands) with permission of the Committee on Animal Welfare (DEC), according to Dutch governmental rules. 


\section{Electromyography}

Decrement of compound muscle action potential (CMAP) was measured in the flexi digiti quinti. Monkeys were anesthetized with ketamine. For stimulation and recording, two small monopolar needle electrodes were placed subcutaneously. To detect a decremental response, 10 repetitive stimuli of $0.2 \mathrm{~ms}$ were given at 3,5 and $10 \mathrm{~Hz}$ with an EMG system (Nicolet Biomedical Inc, Madison, WI, USA). The test was considered positive when the average of three consecutive measurements of the same muscle showed a decrement of at least $10 \%$ of both the amplitude and the area of the negative (upward) peak op the CMAP.

\section{Results}

\section{Construction of expression plasmids}

In order to produce a full-size human IgGil variant of the previously cloned $F_{i i j} 637$, its $F_{i j}$ and $\mathbb{L C}$ coding sequences were cloned into the mammalian expression plasmid pIgG1. The $F_{10} 637$ was genetically fused to the human $\gamma 1 \mathrm{~F}_{\text {" }}$ resulting in a full-size human heavy chain $(\mathrm{HC})$ cistron. So, pIgG1637 contained both the $\mathrm{HC}$ and LC cistron, each under the control of an hCMV P/E element.

To produce an IgG1-637 variant that does not activate complement, a mutation was introduced in the $\mathrm{Clq}$ binding site. Lysine 322 was mutated to alanine by site-directed mutagenesis of its codon, resulting in plgG1$637 / \mathrm{K} 322 \mathrm{~A}$. Interestingly, by chance also another mutant was created, pIgG1-637AC1q, which had six insertions of the K322A oligonucleotides downstream the mutated codon, resulting in a tandem of seven repeats.

In order to produce a non-specific antibody that has the same LC as IgG1-637, the CDR3 of the HC was mutated. The amino acid sequence PLKP in the CDR3 was deleted by site-directed mutagenesis, resulting in plgG1-637/CDR3APLKP.

\section{Antibody production by $\mathrm{CHO}$ cells}

In order to produce large amounts of $1 \mathrm{gG} 1-637$, CHO cells were transfected with plgG1-637 by lipofectin. Monoclonal stable transfected cells were obtained by limiting dilution and auxotroph-based sellection. The highest producer, as determined by human Ig-specific ELISA (data not shown), was selected for large-scale production. A 10-liter hollow fiber culture yielded $558 \mathrm{mg}$ protein G-purified IgG1-637.

lgG1-637 $\triangle \mathrm{Clq}$ was similarly produced in CHO-K1. A 10-liter culture of a monoclonal plgG1-637 $\mathrm{C} 1 \mathrm{q}$-transfected $\mathrm{CHO}-\mathrm{K} 1$ cell line yielded $135 \mathrm{mg}$ protein G-purified IgG1-637 $\Delta \mathrm{Clq}$. To create an alternative to IgG1$637 \triangle \mathrm{Clq}$ and IgG1-637/K322A, for abolishing the complement-activating capacity of IgG1-637, the glycosylation of IgG1-637 was changed. CHOLec1 cells were transfected with plgG1-637 and IgG1-637/Lec1 was isolated from culture by protein G. IgG1-637/CDR3 $\triangle$ PLKP was produced by CHO-K1 in culture flasks and not purified. 


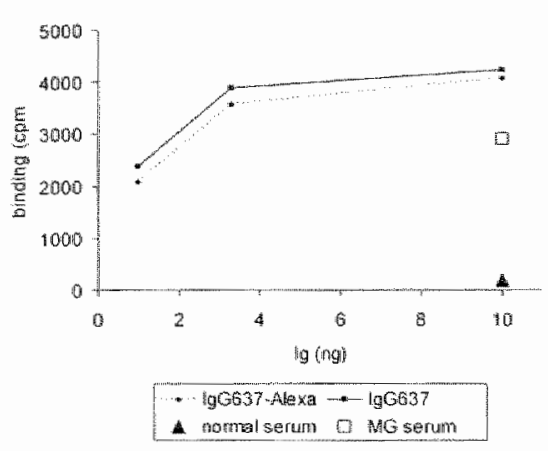

hum an-Torpedo hybrid receptior

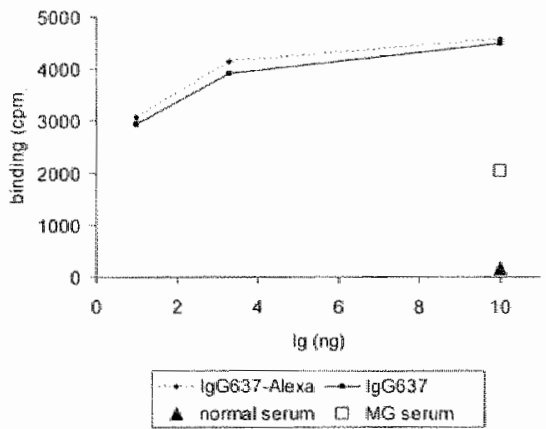

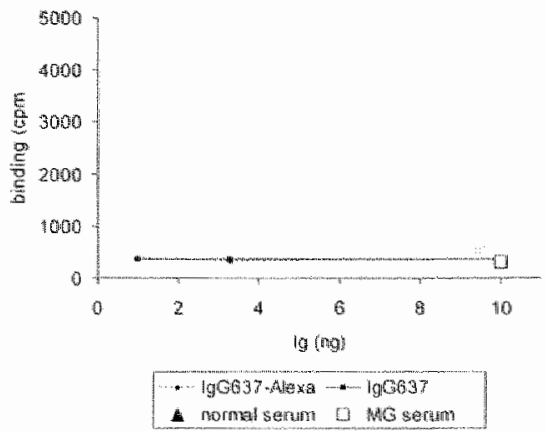

human alphat -210 peptide

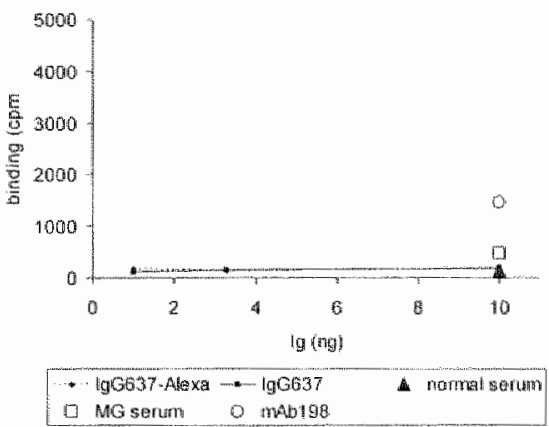

Figure 1

Specificities of the human anti-AChR mAb IgG1-637. Specificities of non- and Alexa488-conjugated $\lg 61.637$ were determined by RIA with extracts of human muscle AChR-expressing cell lines TE671 and CN21, by RIA with purified Torpedo AChR, by RIA with a hybrid receptor of human $\alpha \perp$ and Torpedo $\beta, \gamma$ and $\delta$ subunits, and by ELISA with extracellular domain peptide human a 1-210.

\section{IgG1-637 specifically binds the human AChR a1 subunit}

To determine if the epitope specificity of IgG1-637 was the same as its parental $F_{016} 637$, several RLAs were performed (Figure 1). IgG1-637 was able to precipitate human $\mathrm{AChR}$ and a human-Torpedo hybrid receptor, which contained the human $\alpha 1$ subunit and the Torpedo $\beta, \gamma$ and $\delta$ subunits, while Torpedo AChR was not precipitated. In contrast, IgG1-637/CDR3APLKP did not precipitate human $A C h R$, indicating the necessity of PLKP in the CDR3 for the specificity (data not shown). The human a1-210 peptide was not bound by IgG1-637, indicating the specificity of the recombinant Ab for the native conformation of the $a 1$ subunit. The anti-human AChR Ab titer, as

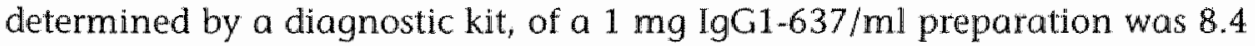
$\mathrm{mmol}$, calculated with the kit's standard of pooled MG patient antibodies. These data indicated that the specificity was maintained after reconstruction, i.e. IgG1-637 specifically bound the native human $A C h R \alpha 1$ subunit. 

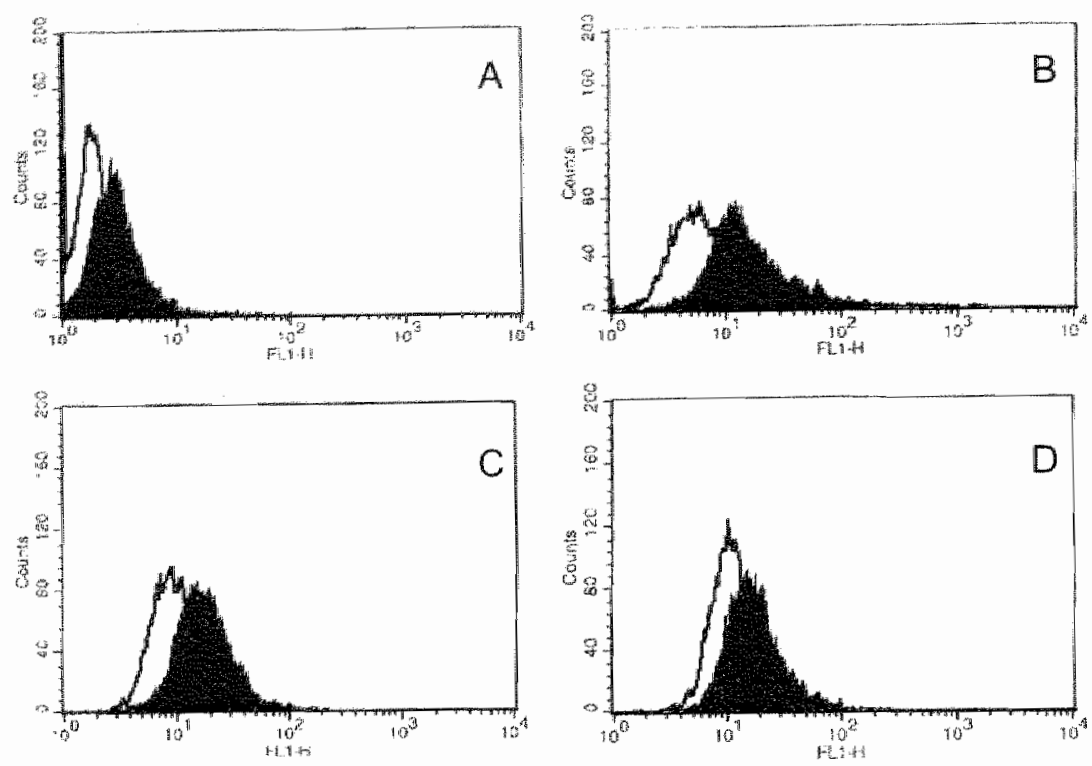

figure 2

FACS analysis of human anti-AChR IgG1-637. The human fetal muscle AChRexpressing cell line TE671 was incubated with IgG1-637 and stained with goat antihuman $\mathrm{Ig}$ (A) and signal amplified (B) or cells permeablized (C). The human fetal and odult muscle AChR-expressing cell line MITC was incubated with IgG1-637 and stained with goat onti-human ${ }^{\text {inc }} \mathrm{lg}(\mathrm{D})$.

\section{IgG1-637 FACS analysis}

FACS analysis of IgG1-637 on TE671 cells gave a half log-scale shift after amplification (Figure 2). This indicates that IgG1-637 is able to bind the membrane-bound human AChR.

IgG1-637 $\mathrm{AC} 1 \mathrm{q}$ does not activate complement

To measure the complement activation capacities of IgG1-637 and its variants IgG1-637 $\mathrm{Clq}$ and IgG1-637/Lec1, their $\mathrm{Clq}$ and $\mathrm{C} 3$ binding were measured. IgG1-637 bound $\mathrm{Clq}$ and $\mathrm{C} 3$ in a concentration depended way (Figure 3), as predicted considering its IgG1 isoptype. But, IgG1-637/Lec1 also bound $\mathrm{Clq}$ and $\mathrm{C} 3$, indicating that the changed glycosylation only slightly influenced the complement activation. Interestingly, IgG1-637 $\Delta \mathrm{Clq}$ did not bind Clq or C3.

\section{$19 G 1-637$ is pathogenic}

The transfer of $0.8 \mathrm{~g} / \mathrm{kg} \mathrm{MG} \mathrm{IgG} \mathrm{per} \mathrm{dose} \mathrm{in} \mathrm{two} \mathrm{monkeys} \mathrm{resulted} \mathrm{in}$ clinical signs in one monkey, while both monkeys showed decrement of the CMAP (Table 1). To determine if IgG1-637 is pathogenic, five monkeys were injected with three daily doses of $0.5,1,1.7$ or $5 \mathrm{mg} / \mathrm{kg}$. The monkeys which received the doses of 1.7 and $5 \mathrm{mg} / \mathrm{kg}$ showed clinical signs of EAMG, indicating the pathogenic characteristic of IgG1-637. 


\section{C1q binding}

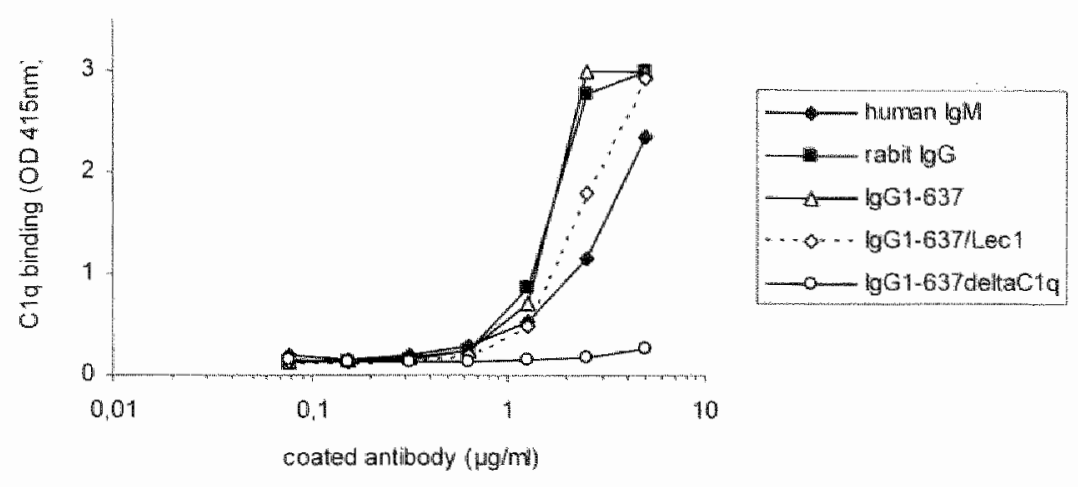

C.3 binding
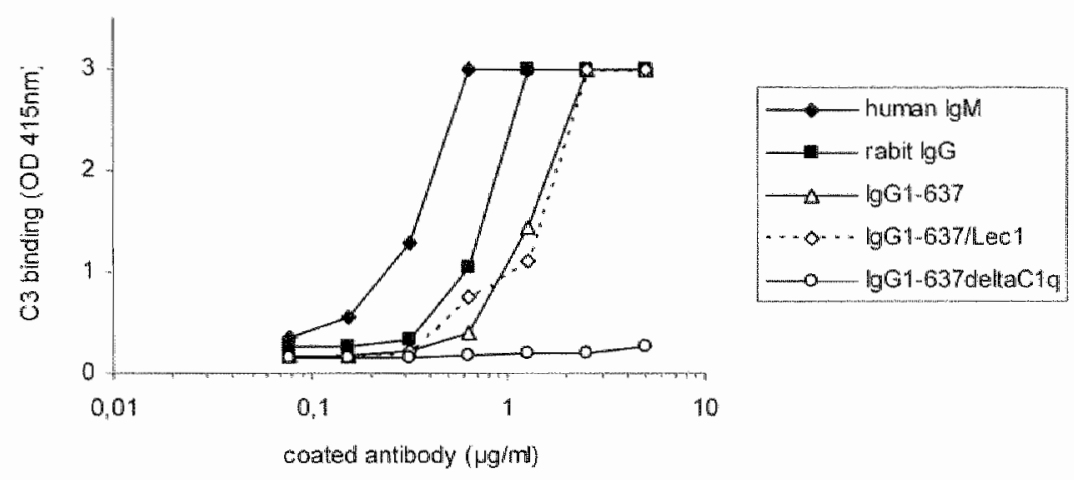

Figure 3

Complement binding by $19 G 1-637$ and its variants. The complement binding characteristics of $\operatorname{lgG1-637}$ and its variants lgG1-637/Lecl, with truncated glycosylation, and IgC1-637 $\triangle \mathrm{Clq}$, with altered Clq-binding site, were determatned by ELISAS.

\section{Discussion}

In order to produce a completely human, full-size IgG1 isotype, the MG thymus-derived anti-AChR $\mathrm{F}_{\text {at }} 637$ was genetically fused to the $\mathrm{F}_{\mathrm{c}}$ of human IgG1. The $F_{i d}$ and LC coding sequences of $F_{i b} 637$ were cloned into expression plasmid plgG1, creating two hCMV promoter-driven, full-length chain cistrons. CHO cells transfected with pIgG1-637 yielded $56 \mathrm{mg} / 1$ of protein $\mathrm{G}$ purified IgG1-637. RIA, FACS and immunohistochemistry dato showed that IgG1-637 specifically bound the native primate $\alpha 1$ subunit, indicating the maintained specificity of $F_{a b} 637$. The pathogenicity of $\lg G 1-637$ was shown 
in a monkey EAMG model, confirming the reconstruction of an $M G$ antibody. IgG1-637/CDR3APLKP was shown to be non-specific for AChR, while IgG1-637 $\triangle \mathrm{Cl} q$ did not activate complement.

Table 1: Passive transfer EAMC in morikeys

\begin{tabular}{|c|c|c|}
\hline $\begin{array}{c}\text { monkey } \\
\text { [amount/kg/day] }\end{array}$ & clinical signs of EAMC & decrement of CMAP \\
\hline $0.5 \mathrm{mg} \lg 61637$ & 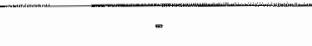 & - \\
\hline $1.0 \mathrm{mg} \lg G 1.637$ & - & + \\
\hline $1.7 \mathrm{mg} \mathrm{lgGi-637}$ & + & + \\
\hline $1.7 \mathrm{mg} \lg 61-637$ & + & + \\
\hline $5.0 \mathrm{mg} \lg \mathrm{Cl} 1-637$ & + & + \\
\hline $0.8 \mathrm{gMG} \lg \mathrm{C}$ & - & + \\
\hline $0.8 \mathrm{gMG} \mathrm{Ig} G$ & * & + \\
\hline
\end{tabular}

Rhesus monkeys were intravenously injected for three successive doys with on amount of $19 \mathrm{G}$ per $\mathrm{kg}$ body weight. Clinical signs (muscle weakness) were seen within one week after the first injection $(+)$ or not at all. $(-)$, and decrement of the compound muscle action potential (CMAP) was determined $(+$, at least $10 \%$ decrement).

In an earlier study, the $\mathrm{V}_{\mathrm{H}}$ and $\mathrm{V}_{\mathrm{t}}$ of $\mathrm{F}_{\mathrm{ab}} 637$ were cloned in a $\mathrm{scF}_{\mathrm{v}}$ expression plasmid [41]. The bacterial produced $\mathrm{scF}_{\mathrm{v}} 637$ binds specifically to primate $A C h R$, like the parentally $F_{o b} 637$ and IgG1-637. Only a few human monoclonal anti-AChR antibodies have been cloned by hybridoma technology before the reconstructed IgG1-637 [42-45]. IgG1-637 recognized the membrane-bound $A C h R$, which is consistent with other FACS data we obtained in a different set-up earlier [46]. CHO-produced IgG1-637 had a high yield, compared to the bacterial production yields of $F_{a b} 637$ and SCF,637. Moreover, the IgG1-637 yield was higher than similar IgGI or $F_{\text {ah }}$ production in $\mathrm{CHO}$ by others [31,47-49]. The high yield makes plgG1-637transfected $\mathrm{CHO}$ a good source for a standard monoclonal human $\mathrm{MG}$ antibody, which could be used as a reference in diagnostic assays. Production could be further increased by, e.g. supertransfection of the clone by plgGi-637.

IgG1-637 is pathogenic itself, but it could serve as a source of enzymatic $F_{b i b} 637$ production. The therapeutic effect of $F_{0 b} 637$ could then be tested in the passive transfer monkey EAMG model. But considering the low serum half-life of $F_{a b}$, an IgG1-637-based molecule could be a alternative. Such a therapeutic antibody should not be able to activate complement and should be monovalent for AChR. IgG1-637 $\mathrm{CC} 1 \mathrm{q}$ does not activate complement, which is required for the establishment of clinical signs $[6,50,51]$. Deletion of four amino acids (PLKP) in the CDR3 of the HC makes IgG1-637 non-specific. A "bispecific" immunoglobulin (bslg) with one anti-AChR arm, one non-specific arm and both $F_{\varepsilon} s$ with a disrupted Clq-binding site could be a potential therapeutic design (Figure 4). 
The pathogenic reconstructed MG antibody $\mathbb{I g G 1 - 6 3 7}$ could serve as a reference human monoclonal antibody in diagnostic assays, as a source for the enzymatic production of $\mathrm{F}_{a b} 637$, which is protective in vitro, or could serve as the genetic basis of a therapeutic bsig.

\section{Figure 4}

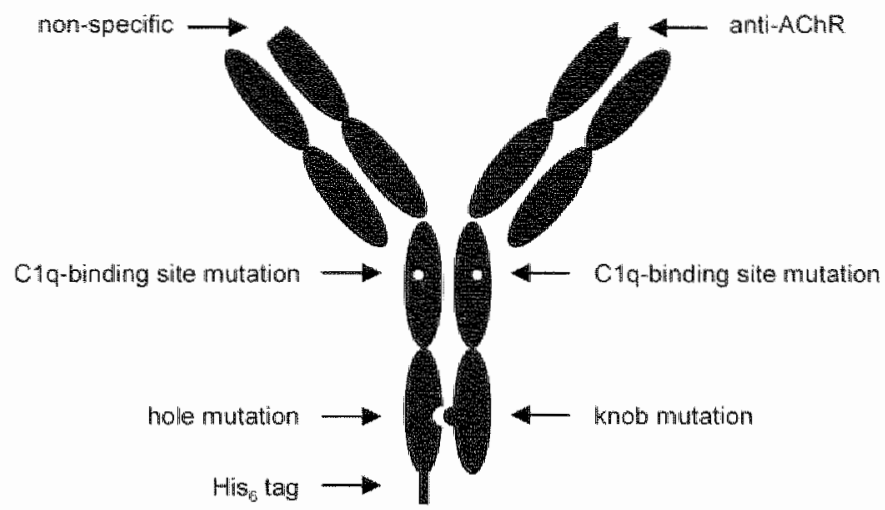

Design of a potential therapeutic, "bispecific" immunoglobulin derived from $19 G 1$ 637. bslgG637. One antibody arm is specific for the MIR of the human AChR, while the other arm is non-specific, thereby shielding the AChR without causing antigenic modulation. The Clq-binding sites are mutated to prevent focal lysis of the postsymaptic membrane. "Knobs-into-holes" engineering [52] fovors the formation of bsig over homomeric byproducts. The His $\mathrm{H}_{6}$ tag can be used for purification and detection.

\section{Acknowledgements}

We would like to thank Ms M. Pilar Martínez-Martínez for her discussions. This work was supported by grants from the Quality of Life Program of the European Union, Prinses Beatrix Fonds and L'Association Française contre les Myopathies.

\section{References}

[1] Tzartos, S.J., I.M. Lindstrom, "Monoclonal antibodies used to probe acetylcholine receptor structure: localization of the main immunogentc region and detection of similarittes between subunits", Proceedings of the National Academy of Sciences of the United States of America $77(1980)$ pp. 755-759.

(2) Tzartos, S.J., A. Kokla, S.L. Walgrave, B.M. Conti-Tronconi, "Localization of the main immunogenic region of human muscle acetylcholine receptor to residues $67-76$ of the alpha subunit", Proceedings of the National Academy of Sciences of the United States of America 85 (1988) pp. 2899-2903.

[3] Kao, I., D.B. Drachman, "Myasthenic immunoglobulin accelerates acetylcholine receptor degradation", Science 196 (1977) pp. 527-529.

14] Heimemann, S., S. Bevan, R. Kulberg. 1. Lindstrom, I. Rice, "Modulation of acetylcholine receptor by antibody against the receptor", Proceedings of the National Academy of Sciences of the United States of America 74 (1977) pp. 3090-3094. 
(5) Engel, A.G., E.H. Lambert, F.M. Howard, "Immune complexes (gG and C3) at the notor end-plate in myasthenia gravis: ultrastructural and light microscopic localization and electrophysiologic correlations", Mayo Clinic Proceedings 52 (1977) pp. 267-280.

[6] Lennon, V.A., M.E. Seybold, I.M. Lindstrom, C. Cochrane, R. Ulevitch, "Role of complement in the pathogenesis of experimental autoimmune myasthenia gravis" foumal of Experimental Medicine 147 (1978) pp. 973-983.

[7] Almon, RR. C.G. Andrew, S.H. Appel, "Senum globulin in myasthenia graws: inhibition of alpha-bungarotoxin binding to acetylcholine receptors", Science 186 (1974) pp. 55-57.

[8] Lang, B., G. Richardson, ]. Rees, A. Vincent, 1. Newsom-Davis" "Plasma from myasthenia gravis patients reduces acetylcholine receptor agonist-induced $\mathrm{Na}+$ flux into TE671 cell linels, foumal of Neuroimmunology 19 (1988) pp. 141-148.

[9] Tzartos, S.I. M.E. Seybold, I.M. Lindstrom, "Specificities of antibodies to acetylcholine receptors in sera from myasthenia gravis patients measured by monoclonal antibadies", Proceedings of the National Academy of Sciences of the United States of America 79 (1982) pp. $188-192$.

[10] Tzartos, S.J., T. Barkas, M.T. Cung, A. Mamalaki, M. Marraud, P. Orlewski, D. Papanastasiou, C. Sakarellos, M. Sakarellos-Daitsiotis, P. Tsantili V. Tsikaris, "Anatomy of the antigenic structure of a large membrane autoantigen, the muscle-type nicotinic acetylcholine receptor", Immunological Reviews 163 (1998) pp. 89-120.

[11] Tzartos, S.I., A. Starzinski-Powitz, "Decrease in acetylcholine-receptor content of human myotube cultures mediated by monoclonal antibodies to alpha, beta and gamma subunits", FEBS Letters 196 (1986) pp. $91-95$.

[12] Souroujion, M.C. A.R. Pachner, S. Fuchs, "The treatment of passively transierred experimental myasthenia with anti-idiotypic antibodies", Neurology 36 (1986) pp. 622. 625.

[13] Verschuuren. 1. ., Y.M. Graus, S.J. Tzartos, P.]. van Breda Vriesman, M.H. De Baets, "Paratope- and framework-related cross-reactive idiotopes on anti-acetylcholine receptor antibodies". Joumal of Immunology 146 (1991) pp. $941-948$.

[14] Luo, G.X., K. Victor, K. Chong, P. McNeeley, D. Ramirez, J. Preclaro, M.D. Linnik, M.A. Campbell, "Identification of a peptide that protects the human acetylcholine receptor against antigenic modulation", Journal of Immunological Methods 251 (2001) pp. 177-186.

[15] Wang, Z.Y., I. Qiao, H. Link, "Suppression of experimental autoimmume myasthenia gravis by orall administration of acetylcholine receptor", Joumal of Neuroimmunology 44 (1993) pp. 209-214.

[16] Im, S.H., D. Barchan, S. Fuchs, M.C. Souroujon, "Suppression of ongoing experimental myasthenia by oral treatment with an acetylcholine receptor recombinant fragment" foumal of Cinical Investigation $104(1999)$ pp. 1723-1730.

[17] Wu, J.M., B. Wu A. Miagkov, R.N. Adams, D.B. Drachman, "Specific immunotherapy of experimental myasthenia gravis in vitro: the "guided missile" strategy" Cellular Irmmunology 208 (2001) pp. 137-147.

[18] Toyka, K. $V_{n}, B$. Lowenadler, K. Heininger, U.A. Besinger ${ }_{n}$ K.I.. Birnberger, A. FatehMoghadam, E. Hellbronn, "Passively transferred myasthenia gravis: protection of mouse endplates by fab fragments from human myasthenic $\mathrm{IgG}^{\prime}$, joumal of Newrology, Newrosurgery and Psychiatry $43(1980)$ pp. 836.840

[19] Papanastasiou, D., K. Poulas, A. Kokla, S.]. Tzartos, "Prevention of passively transferred experimental autoimmune myasthenia gravis by Fab fragments of monoclonal antibodies directed against the main immunogenic region of the acetylcholine receptor", foumal of Neuroimmunology 104 (2000) pp. 124-132.

[20] Zeidel, M., E. Rey, I. Tami, M. Fischbach, I. Sanz, "Genetic and functional characterization of human autoantibodies using combinatorial phage display libraries", Anmals of the New York Acadeny of Siciences 764 (1995) pp. 559-564.

21] Graus, Y.F., M.H. de Baets, P.W. Parren, S. Berrih-Aknin, 1. Wokke, P.J. van Breda Vriesman, D.R. Burton. "Human anti-nicotinic acetylcholine receptor recombinant Fab fragments isolated from thymus-derived phage display libraries from myasthenia grovis patients reflect predominant specificities in serum and block the action of pathogenic serum antibodies", Joumal of Immunology 158 (1997) pp. 1919-1929.

[22] Farrar, I., S. Portolano, N. Willcox, A Vincent, L. Jacobson, I. Newsom-Dawis, B. Rapoport, S.M. Mclachlan, "Diverse Fab specific for acetylcholine receptor epitopes from 
a myasthenia gravis thymus combinatorial library", International Immunology 9 (1997) pp. 1311-1318.

[23] Rey, E. M. Zeide], C. Rhine, I. Tami, K. Krolick, M. Fischbach, 1. Sanz, "Characterizotion of human anti-acetylcholine receptor monoclonal autoantibodies from the peripheral blood of a myasthenia gravis patient using combinatonal libraries", Clinical Immunology 96 (2000) pp. 269-279.

[24] Tarrab-Hazdai, R., A. Aharonov, I. Silman, S. Fuchs, O. Abramsky, "Experimental autoimmune myasthenia induced in monkeys by purified acetylcholine receptor" "Nature $256(1975)$ pp. 128-130.

[25] Toro-Goyco, E., E.M. Cora, M.J. Kessler, M. Martinez-Carrion, "Induction of experimental myasthenia gravis in rhesus monkeys: a model for the study of the human disease.", Puerto Rico Health Sciences foumal 5 (1986) pp. 13-18.

[26] Toyka, K.V., D.B. Drachman, A. Pestronk, I. Kao, "Myasthenia gravis: passive transfer from man to mouse", Science 190 (1975) pp. 397-399.

[27] Stassen, M.H., S. Hellwig, S. Schillberg, R. Fischer, M. De Baets, "Expression of an antiacetylcholine receptor Fab in Pichia pastoris", in preparation

[28] Trakas, $N_{\text {., }} S_{n}$. T. Tzartos, "Conjugation of acetylcholine receptor-protecting Fab fragments with polyethylene glycol results in a prolonged half-life in the circulation and reduced immunogenicity", Journal of Neuroimmunology 120 (2001) pp. 42-49.

[29] Smith, B.1. A. Popplewell, D. Athwal, A.P. Chapman, S. Heywood, S.M. West, B. Carrington, A. Nesbitt, A.D. Lowson, P. Antoniw, A. Eddelston, A. Suitters, "Prolonged in vivo residence times of antibody fragments associated with albumin", Bioconjugate Chemistry 12 (2001) pp. 750-756.

[30] Waldmann, T.A., W. Strober, "Metabolism of immunoglobulins", Progress in Allergy $\mathbb{1} 3$ (1969) pp. 1-110.

[31] Sarna, P.P., M.E. Samson, J.S. Moon, R. Rozenshteyn, A. De Logu, R.A. Williamson, D.R. Burton, "pFab-CMV, a single vector system for the rapid conversion of recombinant Fabs into whole IgGI antibodies", Immunotechnology 4 (1999) pp. 185-188.

[32] Idusogie, E.E., L.G. Presta, H. GazzanomSantoro, K. Totpal, P.... Wong, M. Ultsch, Y.G. Meng, M.G. Mulkerrin, "Mapping of the C1q binding sitte on rituxan, a chimeric antibody with a human IgG1 $\mathrm{FC}^{\prime \prime}$, Joumal of Immunology $164(2000) \mathrm{pp} .4178-4184$.

[33] Hezareh, M., A.]. Hessell, R.C. Jensen, J.G. van de Winkel, P.W. Parren, "Effector function activities of a panel of mutants of a broadly neutralizing antibody against human immunodeficiency virus type 1", Joumal or Virology 75 (2001) pp. 12161-12168.

[34] Thommesen, I.E., T.E. Michaelsen, G.A. Loset, I. Sandlie, O.H. Brekke, "Lysine 322 in the human $\operatorname{IgG} 3 \mathrm{C}(\mathrm{H}) 2$ domain is crucial for antibody dependent complement activation", Molecular Immunology 37 (2000) pp. 995-1004.

[35] Wright, A., S.L. Morrison, "Effect of alkered CH2-associated carbohydrate structure on the functional properties and in vivo fate of chimeric mouse human immunoglobulin GI", Joumal of Experimental Medicine 180 (1994) pp. $1087-1096$.

[36] Lindstrom, 1., B. Einarson, S. Tzartos, "Production and assay of antibodies to acefylcholine receptors", Methods in Enzymology 74 Pt C (1981) pp. $432-460$.

[37] Luther, M.A., R. Schoepfer, P. Whiting, B. Casey, Y. Blatt, M.S. Montal, M. Montal, I. Linstrom, "A muscle acelylcholine receptor is expressed in the human cerebellan medulloblastoma cell line TE671", Journal of Neurosicience 9 (1989) pp. 1082-1096.

[38] Loutrari, H., A. Kokla, N. Trakas, S.]. Tzartos, "Expression of human-Torpedo hybrid acetylcholine receptor $(A C h B)$ for analysing the subunit specificity of antibodies in sera from patients with myasthenia gravis (MG)", Climical and Experimental Immunology 109 (1997) pp. 538-546.

[39] Wakkach, A. S. Poea, E. Chastre, C. Gespach, F. Lecerf, S. De La Porte, S. Tzartos, A. Coulombe, S. Berrih-Aknin, "Establishment of a human thymic myoid cell line. Phenotypic and functional characteristics", American Joumal of Pathology 155 (1999) pp. $1229-1240$.

[40] Roos, A. L.H. Bouwman, I. Munoz, T. Zuiverloon, M.C. Faber-Krol, E.C. Fallaux-van den Houten, N. Klar-Mohamad, C.E. Hack, M.G. Tilanus, M.R Datha, "Functional characterization of the lectin pathway of complement in human serum", Molecular Immunology 39 (2003) pp. 655-668. 
[41] Meng. F, MH. Stassen, S. Schillberg, R. Fischer, M.H. De Baets, "Construction and charactetization of a single-chain antibody fragment derived from thymus of a patient with myasthenia grawis", Autoimmunity 35 (2002) pp. 125-133.

[42] Victor, K.D., V. Pascual, A.K. Lefvert, I.D. Capra, "Human anti-acetylcholine receptor antibodies use variable gene segments analogous to those used in autoantibodies of various specificities" Molecular Immunalogy 29 (1992) pp. 1.501-1506.

[43] Cardona, A., H.I. Garchon, B. Vernet-der-Garabedian, E. Morel, P. Gajdos, I.F. Bach, "Human IgG monaclonal autoantibodies against muscle acetylcholine receptor: direct evidence for clonal heterogeneity of the antiself humoral response in myasthenia gravis" Journal of Neuroimmunology 53 (1994) pp. 9-16.

[44] Serrano, M.P. A. Cardona, B. Vernet der Garabedian, J.F. Bach, J.M. Pleaus, "Nucleotide sequences of variable regions of an human anti-acetylcholine receptor autoantibody derived from a myasthenic patient", Molecular Immunology 31 (1994) pp. 413-417.

[45] Cardona, A., O. Pritsch, G. Dumas, I.F. Bach, G. Dighiero, "Evidence for an antigendriven selection process in human autoantibodies against acetylcholine receptor", Molecular Immumology 32 (1995) pp. 1215-11223.

[46] Stassen, M.H., E. Meng, E. Melgert, B.M. Machiels, S.H. Im, S. Fuchs, A.F. Gerritsen, M.A. van Dijk, I.G. van de Winkel, M.H. De Baets, "Experimental autoimmune myasthenia gravis in mice expressing human immunoglobulin loci", Iournal of Neuroimmunology 135 (2003) pp. 56-61.

[47] Bender, E., I.M. Woof, J.D. Atkin, M.D. Barker, C.R. Bebbington, D.R. Burton, "Recombinant human antibodies: linkage of an Fab ragment from a combinatorial library to an Fc fragment for expression in mammalian cell cullture ${ }^{\mathrm{n}}$, Hituan Antibodies and Hybridomas 4 (1993) pp. 74-79.

[48] Ames, R.S., M.A. Tometta, K. Deen, C.S. Jones, A.M. Swift, S. Ganguly, "Conversion of murine Fabs isolated from a combinatorial phage display لibrary to full length immunoglobulins", Journal of Immunological Methods 184 (1995) pp. 177.186.

[49] Henderikx, P., N. Coolen-wan Neer, A. Jacobs, E. van der Linden, J.W. Arends, J. Mullberg, H.R. Hoogenboom, "A human immunoglobulin G1 antibody originating from an in vitro-selected Fab phage antibody binds avidly to tumor-associated MUCI and is efficiently internalized", American Journal of Pathology 160 (2002) pp. 1597-1608.

[50] Christadoss, P., "C5 gene influences the development of murine myasthenia gravis", Journal of Immunology $140(1988)$ pp. 2589-2592.

[51] Tuzun, E., B.G. Scott, E. Goluszko, S. Higgs, P. Christadoss, "Genetic evidence for involvement of classical complement pathway in induction of experimental autoimmune myasthenia gravis", Journal of Immunology 171 (2003) pp. 3847-3854.

[52] Ridgway, I.B., L.G. Presta, P. Carter, "Knobs-into-holles' engineering of antibody CH3 domains for heavy chain heterodimerization", Protein Engineering 9 (1996) pp. 617-621. 


\section{Chapter 6}

\section{Overexpression of rapsyn in muscles prevents experimental autoimmune myasthenia gravis}

Maurice H.W. Stassen, Mario Losen, Barbie M. Machiels, Henk Veldman, John H.J. Wokke, Frank Spaans \& Marc H. De Baets 


\section{Abstract}

The target organ of myasthenia gravis (MG) is the postsynaptic membrane of the neuromuscular junction (NM)) with the acetylcholine receptor (AChR) as the primary autoantigen. Susceptibility to experimental autoimmune MG (EAMG) decreases with age in Brown Norway (BN) and Lewis rats due to an intrinsic resistance of the postsynaptic membrane of old animals to the antibody-mediated loss of AChR at the NMJ. Previously, we found that the level of rapsyn, an AChR clustering and anchoring protein, at the NMJ is higher in old BN rats. In the present study, we investigated effects of rapsyn overexpression in EAMG susceptible rats. Gene transfer of rapsyn into rat muscles by means of in vivo electroporation resulted in rapsyn overexpression. Transfected muscle fibers had extrasynaptic membrane rapsyn clusters. The level of AChR was increased in muscles two weeks after electroporation. In EAMG rats, rapsynoverexpressing muscles showed no loss of $\mathrm{AChR}$, in contrast to control muscles. Repetitive nerve stimulation showed no decrement of the compound muscle action potential of the rapsyn-overexpressing muscles, in contrast to sham-treated muscles of the same EAMG animals. Electron microscopic examination showed that endplates of rapsyn-overexpressing muscles of EAMG rats had a normal morphology of the postsynaptic folds, while endplates of sham-treated muscles of the same animals had damaged folds. These data suggest an important role for rapsyn in the susceptibility to EAMG. 


\section{Introduction}

In myasthenia gravis (MG) the target organ is the postsynaptic membrane of the neuromuscular junction (NMJ). The muscular nicotinic acetylcholine receptor $(A C h R)$ is the primary autoantigen in eight out of ten $M G$ patients, while in anti-AChR antibody-negative patients the muscle-specific kinase (MUSK) has recently been found to be an important antigen [1]. Anti-AChR antibodies cause functional loss of $A C h R$ at the motor endplate, either by: crosslinking the receptors, leading to increased internalization (antigenic modulation); activation of complement, leading to focal lysis of the postsynaptic membrane, which also reduces the folding of this membrane; or by inhibiting the AChR's ion channel function [reviewed in 2]. Functional AChR loss impairs neuromuscular signal transmission, resulting in skeletal muscle weakness.

Rapsyn, a 43-kD cytoplasmic protein, clusters and anchors AChRs and is essential for the formation of the postsynaptic apparatus at the NMJ. In innervated muscle fibers, $A C h \mathbb{R}$ and rapsyn are clustered in high density at the motor endplate. Pre-assembled AChR-rapsyn complexes, which are already present in post-Golgi vesicles [3], are linked to the cytoskeleton and are clustered upon induction by agrin, a neuronal released synaptogenic protein of which the receptor complex includes MuSK [4,5]. In MG patients, point mutations in the rapsyn gene (RAPSN), which hinder the recruitment of AChR, and mutations in the RAPSN promoter, which decrease the level of rapsyn expression, lead to congenital myasthenic syndromes (CMS) $[6,7]$. Mice deficient in rapsyn die at birth because the postsynaptic specialization of the NM], including its cytoskeleton, has failed to develop [8]. Agrininduced clustering of AChRs can be restored in cultured rapsyn-deficient myotubes by introducing a rapsyn expression plasmid [9]. Overexpression of rapsyn in in vitro models, however, reduces the size of AChR clusters dramatically, independent of agrin treatment, and alters the intracellular trafficking of AChR [9-11]. In cell lines, cotransfection of rapsyn and AChR expression plasmids increases the half-life of AChR $[12,13]$. Rapsyn also reduces antigenic modulation in transfected fibroblasts when incubated with the anti-AChR monodonal antibody (mAb) 35 [12].

Experimental autoimmune MG (EAMG) is an animal model which closely resembles clinical $M G$. EAMG can be induced passively by transfer of MG patient sera or anti-AChR mAbs, or can be induced actively by immunization with $A C h R$. Brown Norway (BN) rats have an age-related resistance to the induction of passive and chronic EAMG [1.4]. In contrast to young $B N$ rats, transfer of anti-AChR antibodies does not result in $A C h R$ loss or muscular weakness in aged $B N$ rats. This resistance could not be explained by age differences in the immune response including macrophage infiltration, antibodies and complement activation or by compensatory mechanisms such as increased AChR expression [15-17]. The postsynaptic NM] membrane is intrinsically resistant to antibody-mediated degradation in aged animals [18]. Rapsyn, as well as S-laminin, is found to 
be upregulated in aged $B N$ rats as compared to young $B N$ rats, suggesting a role for rapsyn in making the MG target organ resistant [18].

In the present study, the effects of rapsyn overexpression on $A C h R$ level and on EAMG induction in EAMG susceptible Lewis rats were examined. To achieve this, we transfected the tibjalis anterior muscle fibers of rats with a rapsyn expression plasmid. Gene transfer into the muscles was performed by in vivo electroporation (electropermeabilization), an efficient, non-viral technique [19].

\section{Methods}

Construction of expression plasmid

The mouse rapsyn CDNA [13] was cloned into the CMV promoter-driven mammalian expression vector pCDNA1.1/Amp (Invitrogen, Breda, The Netherlands) by EcoR I digestion and ligation, resulting in the plasmid pCDNA-rapsyn. The pcDNA-rapsyn plasmid was prepared for electropermeabilization with the Qiagen Midiprep kit, according to the manufacturer's manual, and finally dissolved in $0.9 \% \mathrm{NaCl}$ at a concentration of $2 \mu \mathrm{g}$ DNA/ $\mu \mathrm{l}$.

\section{Animals}

11-week-old female Lewis rats were obtained from the Department of Experimental Animal Services, University of Maastricht, The Netherlands, with permission of the Committee on Animal Welfare (DEC), according to Dutch governmental rules.

\section{Electropermeabilization}

Prior to electropermeabilization, rats were anesthetized with inhalational Halothane and hind legs were shaved. One tibialis anterior was injected with $75 \mu \mathrm{l}$ pcDNA-rapsyn solution and the other with $75 \mu \mathrm{l} 0.9 \% \mathrm{NaCl} .5$ min after the injection, the leg was placed between caliper electrodes (BTX, San Diego, CA, USA) with conductive gel and 8 pulses of $200 \mathrm{~V} / \mathrm{cm}, 20 \mathrm{~ms}$, $1 \mathrm{~Hz}$ (reversal of pollarity after first 4 pulses) were given by an Electro Square Porator ECM 830 (BTX, San Diego, CA, USA) [19].

\section{Induction of EAMG}

Rats were intraperitoneally injected with 20 pmol mAb35 per $100 \mathrm{~g}$ body weight [15] at 2 weeks after electropermeabilization with pcDNA-rapsyn. After another 48 hours, the rats were clinically scored.

\section{Clinical scoring}

The severity of clinical signs of disease in EAMG was scored by measuring muscular weakness. The animals muscle strength was assessed by their ability to grasp and lift repeatedly a $300 \mathrm{~g}$ rack from the table, while suspended manually by the base of the tail for 30 seconds. Clinical scoring was based on the presence of tremor, hunched posture, muscle strength 
and fatigability. Disease severity was expressed as: 0 , no obvious abnormalities; +, no abnormalities before testing, but reduced strength at the end; ++ , clinical signs present before testing, i.e. tremor, head down, hunched posture, weak grip; +++ , severe clinical signs present before testing, no grip, moribund $[20,21]$.

\section{Histochemical staining}

Isolated tibialis anterior was frozen in melting isopentane and cryosectioned. Rapsyn was stained by incubating with mouse anti-rapsyn mAb 1234 (dilution 1/1000; a kind gift of Prof. Dr S.C. Froehner) in phosphate-buffered saline with $2 \%$ bovine serum albumin (PBSA) for 45 min and subsequently washed and incubated with Alexa488-conjugated goat anti-mouse Ig (dilution 1/100; Molecular Probes, Leiden, The Netherlands) in PBSA for $45 \mathrm{~min}$. AChR was visualized by incubating with Alexa594-conjugated $\alpha$-bungarotoxin (dilution 1/300; Molecular Probes, Leiden, The Netherlands) in PBSA for $45 \mathrm{~min}$.

\section{Measurement of AChR level}

The AChR concentrations of isolated tibialis anterior muscles were performed as described previously $[22,23]$, with the following modifications. Muscles were minced and homogenized with an ultra-turrax

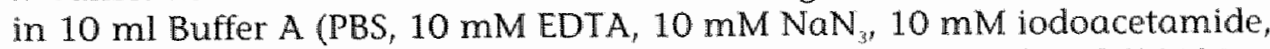
$1 \mathrm{mM}$ PMSF) for 3 times $30 \mathrm{~s}$ at $4^{\circ} \mathrm{C}$. Homogenate was centrifuged (22100 $\mathrm{g}$, $30 \mathrm{~min}$ ) and the resulting pellet resuspended in $2.5 \mathrm{ml}$ Buffer $B$ (Buffer A with additional $0.5 \%$ Triton X-100). Extraction was performed for $1 \mathrm{~h}$ at $4^{\circ} \mathrm{C}$ on a platform shaker. After centrifugation $(22100 \mathrm{~g}, 30 \mathrm{~min})$, alliquots of $1 \mathrm{ml}$ were labeled with $1 \mu \mathrm{l}\left[{ }^{125} \mathrm{I}-\mathrm{Ty} r^{54}\right] \alpha$-bungarotoxin $(74 \mathrm{TBq} / \mathrm{mmol}$, Amersham Pharmacia Biotech Benelux, The Netherlands) with or without $1 \mathrm{mM}$ acetylcholine and neostigmine bromide overnight at $4^{\circ} \mathrm{C}$. Immunoprecipated triplets were counted in a $\gamma$-counter.

\section{Electromyography (EMG)}

Decrement of compound muscle action potential (CMAP) was measured in the tibialis anterior muscle 48 hours after mAb35 transfer. Rats were anesthetized with $60 \mathrm{mg} / \mathrm{kg}$ sodium pentobarbital. For stimulation, two small monopolar needle electrodes were used. The cathode was inserted near the peroneal nerve at the level of the knee and the anode more proximal and lateral at a distance of 3 to $4 \mathrm{~mm}$. For recording, a third monopolar needle electrode was inserted subcutaneously over the tibialis anterior muscle. A ring electrode distally around the relevant hind leg served as a reference and the animal was grounded by a ring electrode around the tail. Stimulation and recording were performed with the EMG system Viking IV (Nicolet Biomedical Inc., Madison, WI, USA). To detect a decremental response, series of 8 supramaximal stimuli were given at $3 \mathrm{~Hz}$. Stimulus duration was 0.2 ms. The test was considered positive for decrement when both the amplitude and the area of the negative (upward) peak op the CMAP showed a decrease of at least 10\% [24]. To demonstrate 
reproducibility, at least 3 recordings were made of all investigated muscles. During the measurements, skin temperature was kept between 35 and $37^{\circ} \mathrm{C}$ by means of an infrared heating lamp (DISA, Copenhagen, Denmark). All EMG studies were performed by the same investigator (F.S.).

\section{Electron microscopy (EM)}

Rapsyn-treated and control tibialis anterior muscles from three EAMG rats were fixed isometrically in $2 \%$ glutaraldehyde in $10 \mathrm{mM} \mathrm{CaCl}, 0.1 \mathrm{M}$ cacodylate buffer $\mathrm{pH}=7.3$, postfixed in $1 \%$ osmiumtetroxide in the same buffer, dehydrated through a graded acetone series and embedded in epoxy resin (Glycid ether 100, Serva, Heidelberg, Germany). Endplates were lacated in toluidine blue stained semi-thin sections from the central region of each muscle. Ultra-thin sections from selected areas were contrasted with uranyl acetate and lead citrate and viewed with Jeol 1200 EX electron microscope. All endplates were photographed up to a total of at least two per muscle per animal.
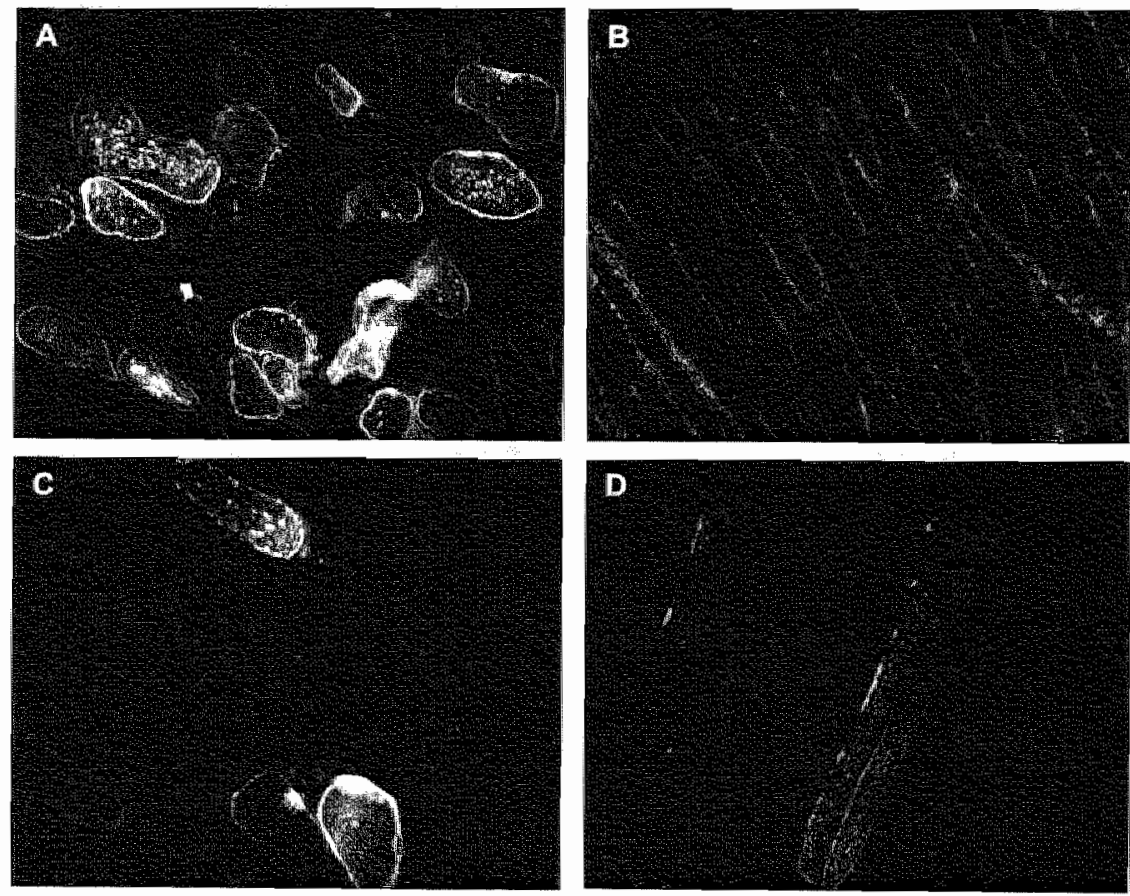

Figure 1

Immunohistochemical staining of rapsyn-treated muscles. Cryosections of muscles were stained with mouse anti-rapsyn $\mathrm{mAb}$ and Alexa488-conjugated gaat antimouse 19 . Rapsyn-treated muscles ( $a, c, d)$ contained rapsyn clusters outside the postsynaptic membrane, in contrast to non-treated muscle (b) were rapsyn was only located at the NMI. (a) A typical staining of rapsyn-treated muscle; (b) non-treated muscle: (c) variable ropsyn expression in transfected fibers; (d) three transfected fibers in a longitudinal section. 


\section{Results}

Electropermeabilization led to rapsyn overexpression in muscle fibers

To overexpress rapsyn in vivo, the left tibialis anterior muscle was electropermeabilized with pCDNA-rapsyn (rapsyn-treated muscle) and the right tibiallis anterior muscle with $0.9 \% \mathrm{NaCl}$ only as internal control. After two weeks, the muscles were isolated and cryosections were double stained for rapsyn and AChR. Rapsyn-treated muscles had transfected fibers containing non-postsynaptic rapsyn clusters (Figure 1a) whereas fibers from control muscles had no detectable rapsyn outside the postsynaptic membrane (Figure 1b). Transfected muscle fibers had variable levels of rapsyn overexpression, with some showing a high level of expression leading to rapsyn-specific staining of the complete cytoplasm (Figure 1c) while others only had a few rapsyn clusters (Figure 1d). Most transfected muscle fibers however, showed a large number of rapsyn clusters equally distributed throughout the muscle fiber (Figure 1a).

\section{Rapsyn overexpression increased AChR level}

In order to analyze the effect of rapsyn overexpression on the level of AChR in muscles, we measured the concentration of AChR using a RIA two weeks after electropermeabilization. The rapsyn-treated muscles $(n=5)$ had a $42 \%$ increase in AChR concentration as compared to control muscles ( $n=5)$ of same animals (Figure 2).

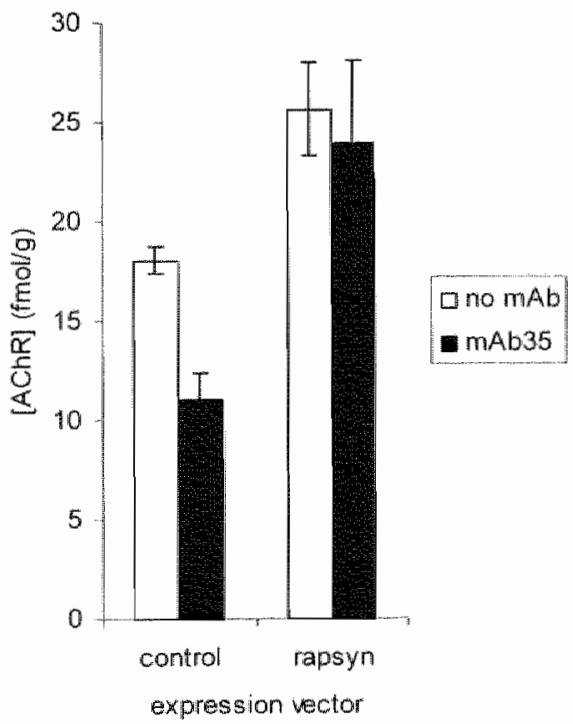

Figure 2

Effect of rapsyn overexpression on $A C h R$ levell in non-EAMG rats and $M A b 35$ induced EAMG rats. The AChR concentration of rapsym-treated and non-treated tibialis anterior muscles of the same rats, with or without mAb35 transfer 14 days after electropermeabilization, were measured by a RIA. 
Rapsyn overexpression protected against AChR loss in EAMG rats

To determine if in vivo rapsyn overexpression conveyed protective effects on the $A C h R$ level in rats suffering from EAMG, we induced EAMG in rats $(n=5)$ two weeks after rapsyn gene transfer. Within 48 hours, all mAb35transferred animals had clear clinical signs of EAMG (score of + or ++ ). The AChR loss in sham-treated muscles of EAMG rats was $39 \%$ while the rapsyn-treated muscles of EAMG rats showed no AChR loss at all (Figure 2).

Rapsyn overexpression prevented decrement of CMAP in EAMG rats

The non-rapsyn-treated legs of EAMG rats, which had a clinical score of ++ , showed a mean amplitude decrement of $19.6 \%$ and a mean area decrement of $17.6 \% \quad(n=5)$, confirming the presence of abnormal neuromuscular transmission (Figure 3). In contrast, the rapsyn-treated legs of the same five EAMG animals showed no decrement, illustrating the protective effect of rapsyn overexpression on EAMG induction.
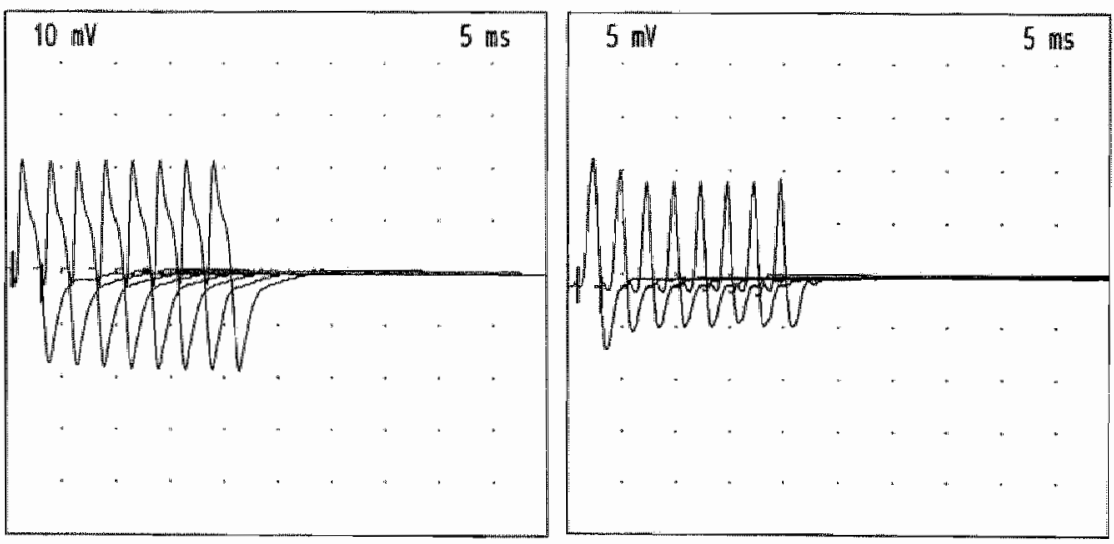

Figure 3

Effect of rapsyn overexpression on decrement of the compound muscle action potential in EAMG rats. Reconding of the rapsyn overexpressing tibialis anterior muscle (left panel) and of the non-electropermeabilized muscle (right ponel) of the same EAMG rat.

Rapsyn overexpression prevented the destruction of postsynaptic folds in EAMG rats

The structure of the motor endplates was examined to determine the effect of rapsyn overexpression on the postsynaptic folds in EAMG rats. In control muscles of EAMG rats $(n=3)$, all examined endplates (14 out of 14 ) had morphological abnormalities. The postsynaptic folds were strongly reduced (Figure $4 \mathrm{~b}, \mathrm{~d}$ ). In rapsyn-treated muscles of the same EAMG animals, only one endplate with an abnormal morphology (1 out of 14) was found (Figure $4 a, c)$. The data suggest a protective effect of rapsyn overexpression on the mAb35-mediated destruction of postsynaptic folds. 

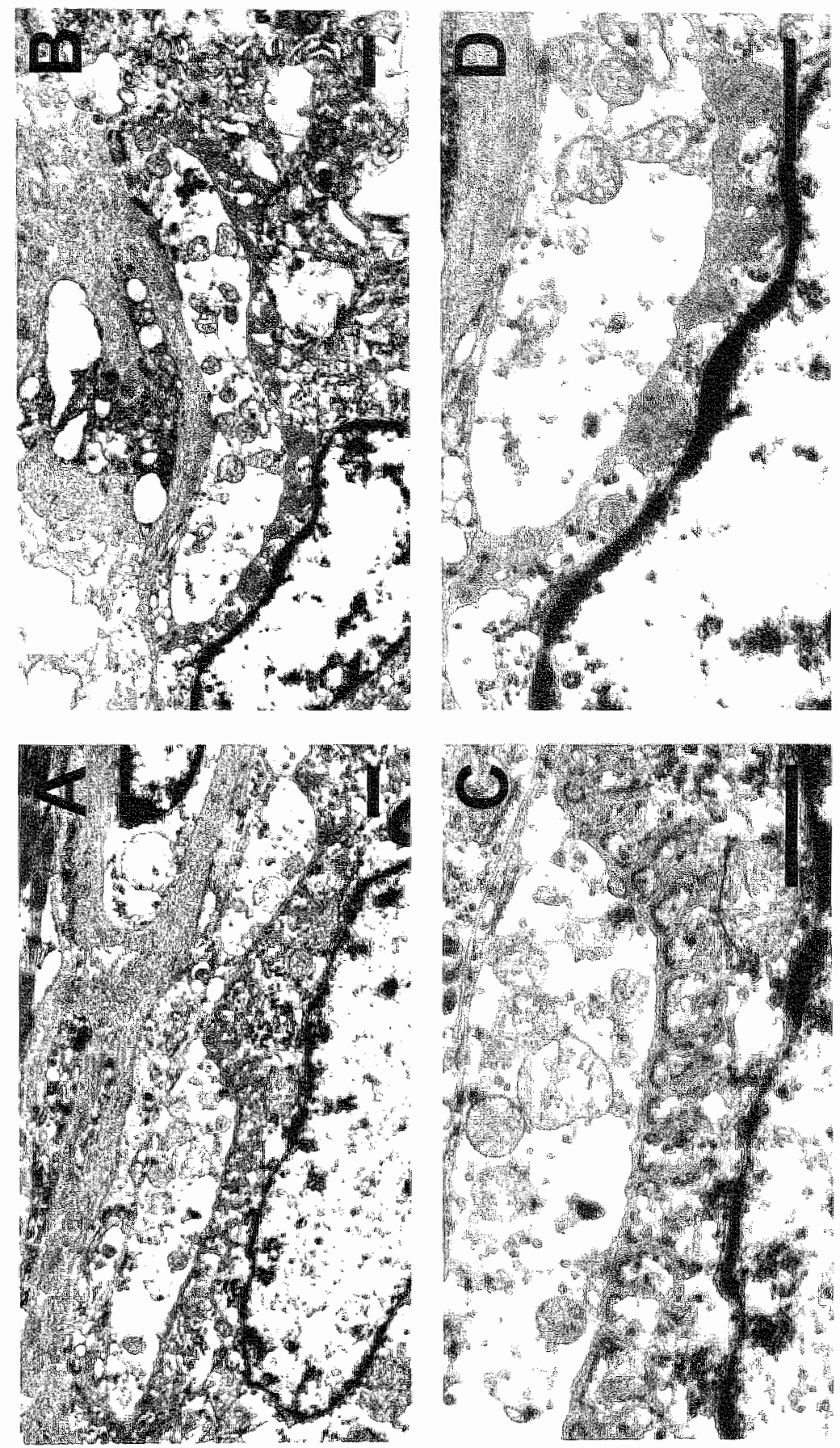

Figure 4

Electron microscopic examination of the postsymaptic folds of motor endplates in EAMG rats. Typical neuromuscular junctions of a rapsyn-treated ( $A$ and enlargement of folds in $C$ ) or a shom-treated muscle (B and enlargement of folds in D). Bars are $1 \mu \mathrm{m}$. 


\section{Discussion}

We have shown that overexpression of rapsyn prevents the induction of EAMG in rat muscles electropermeabilized with rapsyn cDNA. Antigenic modulation, focal lysis of the postsynaptic membrane and decrement of muscle action potential were absent in rapsyn-treated muscles of EAMG rats.

Transfected muscles fibers of the tibialis anterior muscles, which were electropermeabilized with pcDNA-rapsyn, overexpressed rapsyn, as revealed by immunohistochemical staining. The level of rapsyn found in transfected fibers ranged from a few large rapsyn clusters per fiber, located at the non-postsynaptic membrane, to small rapsyn clusters densely distributed throughout a fiber's cytoplasm. The influence of the level of rapsyn expression on rapsyn cluster size, i.e. high expression decreases cluster size, in rapsyn-treated muscles was comparable to the effects of rapsyn overexpression in vitro reported by others $[9,10]$. Differences in level of rapsyn expression were probably due to the variation in number of pcDNA-rapsyn molecules taken up by fibers and variation in their nuclear distribution in a syncytium.

The amount of $A C h R$ in rapsyn-treated muscles was increased by $42 \%$ after two weeks, as measured by RIA of total muscle extracts. Marchand and coworkers [25] found a 50\% increase in AChR at the cell surface when rapsyn was coexpressed in COS-7 cells. The increased AChR concentration we found in rapsyn-treated muscles was likely due to the metabolic stabilizing effects of rapsyn $[12,13]$. The $25 \%$ increased rapsyn level at the NM] in aged BN rats, however, does not coincide with increased $A C h R$ or $\alpha 1$ subunit mRNA levels $[14,18]$. In CMS patients with mutations in the RAPSN promoter, a lower level of rapsyn at the NMJ coincides with a decreased level of AChR [7].

Rapsyn overexpression prevented $A C h R$ loss in EAMG rats. The $A C h R$ concentration of electropermeabilized muscles was not decreased after EAMG induction two weeks after rapsyn treatment, while AChR loss was seen in sham-treated muscles of the same animals. AChR loss is also not seen in aged BN rats subjected to passive transfer of EAMG [14], which have altered levels of several postsynaptic proteins [18]. Apparently, AChR levels can be protected against antigenic modulation by overexpressing rapsyn alone.

Rapsyn treatment prevented muscle weakness in EAMG rats, which was confirmed by electrophysiological measurements. EMG of rapsyn-treated tibialis anterior muscles of rats suffering from EAMG showed no decrement of CMAP, while significant decrement was seen in non-treated muscles of the same animal. The high AChR level of rapsyn-treated muscles apparently restored normal neuromuscular transmission in EAMG rats.

Postsynaptic folds of rapsyn-treated muscles of EAMG rats were not destroyed, as shown by EM studies. The endplates of sham-treated muscles were all damaged, as expected. Engel and coworkers [26,27] found that $96 \%$ of the endplates have an abnormal morphology in the acute phase of 
EAMG. Our data indicated that rapsyn overexpression prevents the antibody-mediated destruction of postsynaptic folds.

In cultured myotubes it has been found that rapsyn overexpression inhibits agrin-induced $A C h R$ clustering [9] and affects the distribution and size of the clusters $[10,11]$, which would have a negative effect on neuromuscular transmission. In the present study, however, at two weeks after the rapsyn treatment, the rats moved normally, showed no EMG decrement and their postsynaptic membrane had a normal morphology. These data indicate that in vivo, rapsyn overexpression does not lead to a dysfunction of neuromuscular transmission. Rapsyn-overexpressing muscle fibers were innervated prior to induction of EAMG, which could explain the difference in the responsiveness to agrin of AChR-rapsyn clustering with cultured myotubes. A functional motor endplate, which already contains large AChR-rapsyn clusters, seems able to maintain these clusters after two weeks of rapsyn overexpression. Rapsyn overexpression impairs the formation of large AChR-rapsyn clusters, but apparently has little effect on their maintenance.

The protective effect of exogenous rapsyn overexpression on the induction of EAMG in Lewis rats is similar to the increased endogenous rapsyn expression in aged $\mathrm{BN}$ rats, indicating that rapsyn is an important factor in age-related EAMG resistance. Changes in endogenous rapsyn expression could determine the susceptibility of $\mathrm{MG}_{\text {, }}$ irrespective of the anti-AChR antibody titer, while slight changes could influence the severity. Rapsyn treatment is potentially therapeutic for the treatment of selected muscles of MG patients, e.g. the eyelid muscles, and individuals with mutations in the rapsyn gene.

\section{Acknowledgements}

We would like to thank Dr J.T. Vilquin (Institut National de la Santé et de la Recherche Médicale U-582 Institut de Myologie, Groupe Hospitalier PitieSalpetriere, 75013 Paris, France) for the helpful discussions concerning electropermeabilization. Furthermore, we wish to thank Ms M. Pilar Martínez-Martínez for her excellent laboratory assistance and discussions. This work was supported by grants from Prinses Beatrix Fonds and L'Association. Française contre les Myopathies.

\section{References}

[1] Hoch, W. I. McConville, S. Helms, I. Newsom-Davis, A. Melms, A. Vincent, "Autoantibodies to the receptor tyrosine kinase MUSK in patients with myasthenia gravis without acetylcholine receptor antibodies", Nature Medicine 7 (2001) pp. 365-368.

[2] De Baets, M., M.H. Stassen. "The role of antibodies in myasthenia gravis", foumal of the Neurological Sciences 202 (2002) pp. 5-11.

[3] Marchand, S., F. Bignami, E. Stetzkowski-Marden, I. Cartaud, "The myristoylated protein rapsyn is cotargeted with the nicotinic acetylcholine receptor to the postsynaptic membrane via the exocytic pathway", Journal of Neurosicience 20 (2000) pp. $521-528$. 
[4] Glass, D. A. D.C. Bowen, T.N. Stitt, C. Radziejewski, I. Bruno, T.E. Ryan, D.R. Gies, S. Shah, K. Mattsson, S.l. Burden, P.S. Distefano, D.M. Valenzuela, T.M. Dechiara, G.D. Yancopoulos, "Agrin acts via a MuSk receptor complex", Cell 85 (1996) pp. 513-523.

[5] Moransard, M. L.S. Borges, R. Willmann, P.A. Marangl, H.R. Brenner, M.J. Ferns, C. Fuhrer, "Agrin regulates rapsyn interaction with surface AChRs which underlies cytoskeletal anchoring and clustering", Joumal of Biological Chemistry (2002) pp.

[6] Ohno, K. A.C. Engel, X.M. Shen, D. Selcen, 1. Brengman, C.M. Harper, A. Tsujino, M. Milone, "Rapsyn Mutations in Humans Cause Endplate Acetylcholine-Receptor Deficiency and Myasthenic Syndrome", American Joumal of Human Genetics 70 (2002) pp. 4.

(7) Ohno, K., M. Sadeh, I. Blatt, J.M. Brengman, A.G. Engel, "E-box mutations in the RA.PSN promoter region in eight cases, with congenital myasthenic syndrome" "Human Molecular Genetics 12 (2003) pp. $739-748$.

[8] Gautam, M., P.G. Noakes, I. Mudd, M. Níchol, G.C. Chu, J.R. Sanes, I.P. Merlie, "Failure of postsynaptic specialization to develop at neuromuscular junctions of rapsyn-deficient mice". Nature 377 (1995) pp. 232 236.

[9] Han, H. P.G. Noakes, W.D. Phillips, "Overexpression of rapsyn imhibits agrin-induced acetylcholine receptor clustering in muscle cells", Journal of Neurocytology 28 (1999) pp. $763-775$

[10] Yoshihara, C.M., ZW. Hall, "Increased expression of the 43-kD protein disnupts acetylcholine receptor clustering in myotubes", Journal of Cell Biology 122 (1993) pp. 169. 179.

[11] Han, H. S.H. Yang, W.D. Phillips, "Overexpression of rapsyn modifies the intracellular trafficking of acetylcholine receptors" foumal of Neuroscience Research 60 (2000) pp. 155 . 163.

[12] Phillips, W.D., D. Vladeta, H. Han, P.G. Noakes, "Rapsyn and agrin slow the metabolic degradation of the acetylcholine receptor", Molecular and Cellular Neurasciences 10 (1997) pp. $16-26$.

[1.3] Wang, Z.Z., A. Mathias, M. Gautam, Z.W. Hall, "Metabolic stabilization of muscle nicotinic acetylcholine receptor by rapsyn", Journal of Neuroscience 19 (1999) pp. 1998. 2007

[14] Graus, X.M., J.J. Verschuuren, F. Spaans, F. Jennekens, P.I. van Breda Vriesman, M.H. De Baels, "Age-rellated resistance to experimental autoimmune myasthenia gravis in rats", Joumal of Immunology 150 (1993) pp. 4093-4103.

[15] Hoedemaekers, A., Y. Graus, L. Beijleveld, P. van Breda Vriesman, M. De Baets, "Macrophage infiltration at the neuromuscular junction does not contribute to $A C h \mathbb{R}$ loss and age-related resistance to EAMG', Journal of Neuroimmumology 75 (1997) pp. 147-155.

[16] Hoedernaekers, A., Y. Grous, P. van Breda Vriesman, M. de Baets, "Age- and sex-related resistance to chronic experimental autoimmune myasthenia gravis (EAMG) in Brown Norway rats", Clinical and Experimental Immunology 107 (1997) pp. 189-197.

[17】 Hoedemaekers, A.C., J.I, Verschuuren, F. Spaans, Y.F. Graus, S. Riemersma, P.]. van Breda Vriesman, M.H. De Baets, "Age-related susceptibility to experimental autoimmune myasthenia gravis: immunological and electrophysiological aspects", Muscle and Nerve 20 $(1997)$ pp. $1091-1101$

[18] Hoedemaekers, A., J.L. Bessereau, Y. Graus, T. Guyon, J.P. Changeux, S. Berrih-Aknin, P. wan Breda Vriesman, M.H. De Baets, "Role of the target ongan in determining susceptibility to experimental autoimmune myasthenia gravis", foumal of Neuroimmunology 89 (1998) pp. 131-141.

[19] Mir, L.M., M.F. Bureau, J. Gehl, R. Rangara, D. Rouy, I.M. Cailland, P. DeJaere, D. Branellec, B. Schwart2, D. Scherman, "High-efficiency gene transfer into skeletal muscle mediated by electric pulses", Proceedings of the National Academy of Sciences of the United States of America 96 (1999) pp. $4262-4267$.

[20] Lemon, V.A., I.M. Lindstrom, M.E. Seybold, "Experimental autoimmune myasthenia: A model of myasthenia gravis in rats and guinea pigs" "foumal of Experimental Medicine 141 (1975) pp. $136.5-1375$.

[21] Verschuuren, J.1. E. Spaans, M.H. De Baets, "Single-fiber electromyography in experimental autoimmune myasthenia gravis", Muscle and Nerve 13 (1990) pp. 485-492.

[22] Lindstrom, I.M. V.A. Lennon, M.E. Seybold, S. Whittingham, "Experimental autoimmune myosthenia gravis and myasthenia gravis: biochemical and immunochemical aspects", Annals of the New York Academy of Sciences 274 (1976) pp. 254-274. 
[23] Verschururen, I.I., Y.M. Graus, R.O. Theunissen, T. Yamomoto, A. Vincent, P.I, van breda Vriesmon, M.H. De Baets, "Role of acetylcholine receptor antibody complexes in muscle in experimental autommune myasthenia gravis", Joumal of Neurommumology 36 (1992) pp. $117-125$.

[24] Kimura, I., Electrodiagnosis in diseases of nerve and muscle: principles and practice, Oxford University Press, Oxford, 2001, 1024 pp.

[25] Marchand, S., A. Devillers-Thiery, S. Pons, 1.P. Changeux, I. Cartaud, "Rapsyn escorts the nicotinic acetylcholine receptor along the exocytic pathway via association with lipid rafts", Joumal of Neuroscience 22 (2002) pp. 8891-8901.

[26] Engel, A.G., M. Tsujihata, I.M. Lindstrom, V.A. Lennon, "The motor end plate in myasthenia gravis and in experimental autommune myasthenia gravis. A quantitative ultrastructural study", Annals of the New York Academy of Sciences 274 (1976) pp. 60-79.

[27] Engel. A.C., M. Tsujhata, E.H. Lambert, I.M. Lindstrom, V.A. Lenmon, Experimental autommune myasthenia gravis: a sequential and quantitative study of the neuromuscular junction ultrastructure and electrophysiologic correlations" , Jounal of Neuropathology and Experimental Neurology 35 (1976) pp. 569.587. 


\section{Summery and general discussion}

Chapter 1 reviews the role of autoantibodies in myasthenia gravis (MG). The majority of $\mathrm{MG}$ patients have autoantibodies against the muscular nicotinic acetylcholine receptor (AChR). Although anti-AChR antibodies are the main $\mathrm{MG}$ antibodies, patients can be seronegative for them or specificities for other muscle autoantigens can coincide. Besides electromyography (EMG) and single-fiber EMG (SFEMG), analysis of the autoantibodies of patient sera can diagnose $\mathrm{MG}$ and can also lead to the early detection of thymoma. The immunopathogenesis of seropositive $\mathrm{MG}$ has been studied in detail. Anti-AChR antibodies lower the number of functional AChRs at the motor endplate by: crosslinking of AChRs, which increases their internalization and degradation (antigenic modulation); complement activation, which causes focal lysis of the postsynaptic membrane; and functional inhibition of the AChR's ion-channel function. AChR loss leads to an impaired neuromuscular signal transmission, explaining the muscle weakness of the MG patients. The etiology of $M G$ is not clear. However, the thymus plays an important role in $M G$, since hyperplastic thymic medullas or thymoma are found in many patients. Experimental autoimmune MG (EAMG) is an animal model that closely resembles $M G$. It can be induced by immunization with $A C h R$ or transfer of MG sera. EAMG is used to study MG and EAMG antibodies, the role of complement and macrophages, the resistance to the induction of the disease, and the treatment of EAMG.

Chapter 2 describes a new EAMG mouse model that generates human anti-AChR antibodies. Mice transgenic for human $\mu, \gamma 1$, and $\kappa$ germ line genes (HuMAb-Mice) were immunized with AChR from Torpedo californica ( $t A C h R)$. Serum titers of anti-tAChR antibodies were in the nanomolar range, and anti-rodent $A C h R$ antibodies were in picomolar range. Some HuMAb-Mice had signs of muscle weakness, clearly indicating their susceptibility to EAMG. Human antibody-mouse AChR complexes were found at the neuromuscular junction, while AChR loss was up to $65 \%$. Spleen and lymph nodes were used for producing hybridomas. Of the antitAChR monoclonal antibody (mAb)-producing hybridomas, $2 \%$ had crossreactivity with rodent $A C h R$ and none with human $A C h R$. Immunization with a fusion protein, Trx-Ha1-210, displaying the human main immunogenic region did not result in EAMG or the generation of human anti-human AChR mAbs.

In Chapter 3, a large-scale production method of the potential therapeutic $\mathbb{F}_{a b} 637$ was assessed. $F_{a b} 637$ protects the $A C h R$ from antigenic modulation in vitro. To test the in wivo effects of $F_{a 15} 637$, which only crossreacts with primate $\mathrm{AChR}$, large quantities of purified $F_{\text {sit }}$ are needed for a monkey EAMG model. But, the current bacterial expression system is inefficient for this purpose. The methylotrophic yeast Pichia pastoris has 
been successfully used by others to produce antibodies and antibody fragments. $P$. pastoris was transfected with plasmids encoding for the $\lambda$ light chain $(2637)$ and the heavy chain of $F_{a s} 637\left(\mathbb{F}_{d} 637\right)$. Stable transfected cells produced about $100 \mathrm{mg} \lambda 637$ per liter, which was secreted as a homodimer. However, co- or supertransfection of $F_{6} 637$ plasmid did not result in the production of $\mathrm{F}_{a t}$ or $\mathrm{F}_{4} 637$. Although $\mathrm{F}_{d} 637$ was not produced in $P$. pastoris, its $m R N A$ was transcribed. A plasmid encoding for a single-chain variable fragment ( $\left(\mathrm{SCF}_{v}\right.$ ) variant of $\mathrm{F}_{w i b} 637$ did not express $\mathrm{SCF}_{v}$ in $P$. pastoris.

In Chapter 4, a scF variant of $\mathrm{F}_{a b} 637, \mathrm{scF}_{v} 637$, was constructed and characterized. Bacterially produced $\mathrm{ScF}, 637$ was able to bind to human and monkey AChR, like its parental $\mathrm{F}_{a b} 637$. Furthermore, $\mathrm{scF}_{v} 637$ was capable of inhibiting the binding of its intact IgG1 isotype variant (IgG1-637) and anti-AChR mAb35 binding to human AChR up to 33 and $73 \%$, respectively, and of MG patient sera up to $46 \%$.

Chapter 5 describes a fully human $\gamma 1$ immunoglobulin that was reconstructed from $F_{a k} 637$, IgG1-637. The coding sequences of $\lambda 637$ and $F_{6} 637$ were cloned in one expression plasmid. The $\mathrm{F}_{d} 637$ was genetically fused to the human $\gamma 1 \mathrm{~F}_{a}$ resulting in a complete IgG1 heavy-chain coding sequence. Monoclonal transfected chinese hamster avary (CHO) cells produced up to $55 \mathrm{mg}$ purified IgG1-637 per liter. IgG1-637 bound human and monkey $A C h R$, indicating a maintained specificity after the reconstruction. The pathogenicity of the reconstructed $M G$ autoantibody was tested in a monkey EAMG model. Three daily injections of 1.7 to $5 \mathrm{mg}$ IgG1-637 per $\mathrm{kg}$ body weight resulted in clinical signs of EAMG in rhesus monkeys.

In Chapter 6, it is shown that overexpression of rapsyn prevents the induction of EAMG. In age-related resistance to EAMG, the postsynaptic membrane of old rats is resistant to antigenic modulation. The AChRclustering and -anchoring protein rapsyn is upregulated in old Brown Norway (BN) rats. In order to test if rapsyn overexpression could transfer the resistance to susceptible rats, muscles were in vivo transfected with a rapsyn expression plasmid. Transfected muscle fibers showed, in contrast to non-transfected fibers, extra-synaptic clusters of rapsyn. The rapsyn overexpression increased the AChR level of the muscles by $42 \%$. Two weeks after transfection, EAMG was passively transferred. Rapsyn overexpressing muscles of EAMG rats had no AChR loss, in contrast to control muscles of the same animals. Moreover, repetitive nerve stimulation of rapsynoverexpressing muscles showed no decrement of the compound muscle action potential, in contrast to control muscles of the same EAMG rats. Electron microscopic examination of the motor endplates of EAMG rats showed a normal morphology of the postsynaptic folds in rapsynoverexpressing muscles, while the folds were damaged in control muscles.

A specific therapy for $M G$ would reduce the side effects of non-specific treatments. The hypothetical immunotherapy with a human anti-AChR antibody-derived protein could help treating patients with an acute MG phase [1]. MG patients can be treated by plasmapheresis during a 
myasthenic crisis, thereby removing the autoantibodies from the circulation [2]. To prolong the remission effect of plasmapheresis, the MG patient's AChRs could be shielded against newly produced autoantibodies by a therapeutic antibody. A recombinant antibody with $F_{a 1} 637$ 's binding characteristic [3] and IgG4's bispecific and none-complement-activating characteristics [4] would combine the advantages of $F_{\text {at }}$ and $\lg G$. The resulting IgG-like molecule could block the AChR for a long period (expected serum half-life of 21 days), compared to scF, 637 and $F_{a t} 637$. IgG1-637 and its mutants IgG1-637 $\triangle \mathrm{Clq}$, which does not activate complement, and IgG1-637/CDR3 $\triangle$ PLKP, which is non-specific, could form the basis for the construction of a therapeutic antibody.

Gene therapy, on the other hand, is a potential long-lasting therapy for $M G$. Although overexpression of rapsyn prevents the induction of EAMG, the effect on ongoing EAMG has to be investigated. After an immune attack, the postsynaptic membrane is focally destroyed by the membrane attack complex. In contrast to the maintenance, formation of new AChR clusters could be impaired by a high overexpression of rapsyn. Considering the impact of slight changes in rapsyn expression in old BN rats [5] and in a subset of congenital myasthenic syndrome (CMS) patients $[6,7]$ versus the rapsyn overexpression in cultured cells [8-10], a more moderate rapsyn expression induced by gene therapy is better for the formation of $A C h R$ clusters. An inducible, tissue-specific promoter in stead of the currently used constitutive CMV promoter is an option to optimize the level of expression. The stability of long-term (overjexpression of rapsyn in muscles has to be determined. The level of expression of luciferase is reported to be stable from day 3 to at least day 270 after electropermeabilization [11]. Also, the long-term effects of rapsyn (over)expression have to be assessed, e.g. a possible anti-rapsyn response. If rapsyn gene therapy has a therapeutic effect, selected muscles could be in vivo electroporated, like the eyelid muscles.

The expression level of rapsyn plays an important role in the susceptibility to myasthenia. Down-regulation causes CMS, while upregulation provides protection against $M G$. Slighter changes in the endogenous level of rapsyn could correlate with the severity of $\mathrm{MG}$. Therefore, it might be interesting to determine the level of rapsyn in different subsets of MG patients.

\section{References}

[1] Toyka, K.V., B. Lowenadler, K. Heininger, U.A. Besinger, K.L. Bimberger, A. FatehMoghadam, E. Heilbronn, "Passively transfered myasthenia gravis" protection of mouse endplates by Fab frogments from human myasthenic JgG, fowmal of Nixulogy, Neurosurgery and Psychiaty $43(1980) \mathrm{pp} .836 .840$.

[2] Pinching, A.I., D.K. Peters, "Remission of myasthenia gravis lollowing plasma-exchange", Lancet $2(1976)$ pp. $1373-1376$.

13] Gravs, Y.E. M.H de Baets, P.W. Parren, S. Berrih-Akrin, I. Wokke, P.I. van Breda Vriesman, D.R. Burton, "Human anti-nicotinic acelylcholine feceptor recombinant fab fragments isolated from thymus-derived phage display libranes from myasthenfo gravis 
patients reflect predominant specificities in serum and block the action of pathogenic serum antibodies", Joumal of Immunology 158 (1997) pp. $1919-1929$.

(4) Aalberse, R.C., I. Schutrnan, "IgG4 breaking the rules", Immunology 105 (2002) pp. 9-19.

[5] Hoedemaekers, A. I.L. Bessereau, Y. Grous, T. Guyon, I.P. Changeux, S. Bermh-Aknin, P. van Breda Vriesman, M.H. De Baets, "Role of the target organ in determining susceptibility to experimental autoimmune myasthenia gravis" foumal of Neuroimmunology 89 (1998) pp. 131-141.

[6] Ohno, K. A.G. Engel, X.M. Shen, D. Selcen, I. Brengman, C.M. Harper, A. Tsujino, M. Milone, "Rapsyn Mutations in Humans Cause Endplate Acetylcholine-Receptor Deficiency and Myasthenic Syndrome", American Journal of Human Genetics 70 (2002) pp. 4.

[7] Ohno, K. M. Sadeh, I. Blatt, I.M. Brengman, A.G. Engel, "E-box mutations in the RAPSN promoter reglion in elght cases with congenital myasthenic syndrome" Human Molecular Genetics 12 (2003) pp. $739-748$.

[8] Han, H., P.G. Noakes, W.D. Phillips, "Overexpression of rapsyn inhibits agrin-induced acetylcholine receptor clustering in muscle cells", Journal of Neurocytology 28 (1999) pp. $763-775$

[9] Yoshihara, C.M., ZW. Hall, "Increased expression of the 43-kD protein disrupts acetylcholine receptor clustering in myotubes" "Journal of Cell Biology 122 (1993) pp. 169 179.

[10] Han, H. S.H. Yang. W.D. Phillips, "Overexpression of rapsyn modifies the intracellular trafficking of acetylcholine receptors", Joumal of Neuroscience Research 60 (2000) pp. 155 163.

[11. Mir, L.M. M.F. Bureau, I. Gehl, R Rangara, D. Rouy, J.M. Cailloud, P. Delaere, D. Branellec, B. Schwartz, D. Scherman, "High-efficiency gene transfer into skelletal muscle mediated by electric pulses" ,Proceedings of the National Academy of Sciences of the United States of America 96 (1999) pp. 4262-4267. 


\section{Samenvatting}

Het menselijk lichaam wordt beschermd door het immuunsysteem tegen virussen, bacteriën en parasieten, maar ook tegen kwaadaardige tumoren die gezond weefsel binnendringen. Voor een adequate immuunrespons moet het immuunsysteem de binnendringers herkennen, met andere woorden het moet een onderscheid maken tussen (gezond) eigen en vreemd. Antilichamen en T-celreceptoren (TCR'en) zijn de eiwitten die de identificatie van lichaamsvreemde antigenen verzorgen en na herkenning een, respectieveli $\mathrm{jk}$, humorale of een cellulaire immuunrespons te weeg brengen. Falen van het immuunsysteem in het tolerant zijn voor eigen kan leiden tot de ongewenste situatie waarin TCR'en en antilichamen binden aan eigen onderdelen, wat resulteert in een auto-immuunziekte.

Myasthenia gravis (MG) is een prototypische auto-immuunziekte, omdat de antilichaam-gemedieerde pathogenese is beperkt tot én doelwit namelijk de postsynaptische membraan van de neuromusculaire junctie (NM). De musculaire acetylcholinereceptor (AChR) is het belangrijkste autoantigen dat zich bevindt in de postsynaptische membraan. Autoantilichamen gericht tegen de AChR verlagen het aantal functionele $A C h R$ "en, wat resulteert in een vermoeibare zwakte van skeletspieren.

In hoofdstuk 1 wordt de rol van autoantilichamen in $\mathrm{MG}$ gereviewd. Het merendeel van de MG-patiënten heeft autoantilichamen tegen de AChR. Ondanks dat anti-AChR-antilichamen de belangrijkste MG-antilichamen zijn, kunnen MG-patiënten seronegatief voor deze antilichamen zijn of kunnen ze daamaast ook antilichamen hebben die gericht zijn tegen andere spierantigenen. Voor de diagnose van $\mathrm{MG}$ kan naast elektromyografie (EMG) en single-fiber EMG (SFEMG) ook de analyse van autoantilichamen in patiëntensera worden gebruikt, dat tevens kan leiden tot de vroege diagnose van een thymoma. De immunopathogenese van seropositieve $\mathrm{MG}$ is gedetaileerd onderzocht. Anti-AChR-antilichamen verlagen de functionele concentratie aan $A C h R$ 'en ter hoogte van de motoreindplaat door: het aaneenschakelen van $\mathrm{AChR}$ 'en, wat resulteert in een verhoogde internalisatie en afbraak (antigene modulatie); complementactivering, wat resulteert in de focale lyse van de postsynaptische membraan; en functionele hindering van de functie van ionkanaal van de AChR. Het verlies aan AChR'en leidt tot een verslechterde neuromusculaire transmissie, wat de spierzwakte van MGpatiënten verklaart. De etiologie van $\mathrm{MG}$ is niet duidelijk. De thymus speelt echter een belangrijke rol in MG, gezien het feit dat thymoma en hyperplastische thymusmedulla's worden gevonden in veel MG-patienten. Experimentele auto-immunn-MG (EAMG) is een proefdiermodel dat nauw overeenkomt met $M G$ bij de mens. Het kan worden geinduceerd door immunisering met AChR of transfusie met MG-sera. EAMG wordt gebruikt 
ter bestudering van $\mathrm{MG}^{-}$en EAMG-antilichomen, de rol van complement en macrofagen, de resistentie tegen de inducering van de ziekte en de behandeling van MG.

In hoofdstuk 2 wordt een nieuw EAMG-model beschreven dat humane anti-AChR-antilichamen opwekt in muizen. Muizen die transgeen zijn voor de humane $\mu_{-}, \quad \gamma$ - en $\kappa$-kiemlijngenen (HuMAb-Muizen) werden geïmmuniseerd met $\mathrm{AChR}$ van de Torpedo californica (tAChR). Serumtiters van anti-tAChR-antilichamen bevonden zich in het nanomolaire bereik en anti-ratten-AChR-antilichamen bevonden zich in het picomolaire bereik. Sommige HuMAb-Muizen hadden klinische symptomen, wat hun vatbaarheid woor EAMG aantoond. Complexen van humane antilichamen en muizen-AChR'en werden gevonden ter hoogte van de NMJ, terwijl het verlies aan $\mathrm{AChR}$ tot $65 \%$ bedroeg. Milt en lymfknopen werden gebruikt om hybridoma's te maken. Van de anti-tAChR monoclonale antilichamen $\left(\mathrm{mAb} \mathrm{b}^{\prime} \mathrm{s}\right)$ vertoonde $2 \%$ kruisreactiviteit met ratten-AChR en geen met humaan AChR. Immunisering met een fusie-eiwit, Trx-Ho1-210, dat het humane main immunogenic region (MIR) bevat, resulteerde niet in EAMG of in het opwekken van humaan anti-humaan AChR mAb's. Deze experimenten tonen aan dat de HuMAb-Muis een geschikt model is voor het opwekken en bestuderen van humane anti-AChR-antilichamen in vivo.

In hoofdstuk 3 werd een mogelijke grootschalige productiemethode voor het potentieel therapeutische $F_{a b} 637$ onderzocht. $F_{a b} 637$ beschermt de $\mathrm{AChR}$ tegen antigene modulatie in vitro. $\mathrm{Om} \mathrm{F}_{\mathrm{p} b \mathrm{~b}} 637$, die enkel met primaatAChR kruisreageert, in vivo te testen zijn grote hoeveelheden aan gezuiverd $F_{\text {it }}$ nodig voor een apen-EAMG-model. Echter, het huidige bacterieel expressiesysteem is niet toereikend voor dit doel. The methylotrofische gist Pichia pastoris werd succesvol gebruikt door anderen voor de productie van antilichamen en antilichaamfragmenten. P. pastoris werd getransfecteerd met plasmiden die coderen voor de $\lambda$ lichte keten ( $\lambda 637$ ) en de zware keten van $\mathrm{F}_{\mathrm{aj}} 637\left(\mathrm{~F}_{\mathrm{d}} 637\right)$. Stabiel getransfecteerde gistcellen produceerden circa $100 \mathrm{mg} / \mathrm{l} \lambda 637$, dat werd uitgescheiden als homodimeer. Echter, co- of supertransfectie van het $F_{41} 637$-plasmide resulteerde niet in de productie van $F_{\text {w }}$ of $F_{4} 637$. Alhoewel $F_{4} 637$ niet werd geproduceerd door P. pastoris, werd het mRNA wel afgeschreven. Een plasmide dat codeerde voor een single-chain variable fragment $\left(\mathrm{scF}_{\mathrm{v}}\right)$-variant van $\mathrm{F}_{\mathrm{vtb}} 6.37$ produceerde geen scF in $P$. pastoris. Deze gegevens tonen aan dat het expressieprobleem van $\mathrm{F}_{4} 637$ mogelijk afhangt van de sequentie van het variabele domein van de zware keten.

In hoofdstuk 4 werd de $\mathrm{scF}_{\mathrm{v}}$-variant van $\mathrm{F}_{\mathrm{at}} 637, \mathrm{scF}_{v} 637$, geconstrueerd en gekarakteriseerd. Bacterieel geproduceerde $\mathrm{SCF}_{w} 637$ was in staat om humaan en apen-AChR te binden, net als het oorspronkelijke $F_{a b} 637$. Bovendien inhibeerde $\mathrm{ScF}_{v} 637$ de binding van zijn intacte $\operatorname{IgG} 1$ isotypevariant (IgG1-637), anti-AChR mAb35 en MG-patiëntensera aan de humane AChR met, respecievelijk, maximaal 33, 73 en $46 \%$. ScF, 637 is hiermee een altematieve kandidaat voor immunotherapie van $M G$.

Hoofdstuk 5 beschrijft een volledig humaan $\gamma 1$ immunoglobuline dat werd gereconstrueerd uit een $\mathrm{F}_{\mathrm{et}} 637,19 \mathrm{~g} 1-637$. De coderende sequenties 
van $\lambda 637$ en $F_{d} 637$ werden gecloneerd in éen expressieplasmide. De $F_{6} 637$ werd genetisch gefuseerd met de humane $\gamma 1 F_{c}$, wat resulteerde in een coderende sequentie voor een complete IgG1-zware keten. Monoklonale, getransfecteerde chinese hamster ovary (CHO)-cellen produceerden $55 \mathrm{mg}$ gezuiverd IgGI-637 per liter. IgG1-637 bond aan humaan en apen-AChR, wat de gehandhaafde specificiteit aantoont na reconstructie. De pathogeniteit van het gereconstrueerde MG-autoantilichaam werd getest in een apen-EAMG-model. Drie dagelijkse doses van 1,7 tot $5 \mathrm{mg} \mathrm{IgG-637}$ per $\mathrm{kg}$ lichaamsgewicht resulteerde in klinische EAMG symptomen in de rhesus apen. IgG1-637 kan worden gebruikt voor de enzymatische productie van het potentieel therapeutische $F_{i k} 637$ of kan dienen als basis voor een therapeutisch IgG-achtig molecuul, dat een hogere serum halfwaardetijd heeft dan een $\mathrm{F}_{\mathrm{nb}}$.

In hoofdstuk 6 wordt aangetoond dat overexpressie van rapsyne de inductie van EAMG vóórkomt. Bij de leeftijdsafhankelijke resistentie tegen EAMG is de postsynaptische membraan van oudere ratten resistent tegen antigene modulatie. Rapsyne, dat $A C h R^{\prime}$ en klustert en verankert, is upgereguleerd in oude Brown Norway (BN)-ratten. Om te testen of rapsyneoverexpressie de resistentie kan overdragen op gevoelige ratten, werden de spieren in vivo geëlektroporeerd met een rapsyne-expressieplasmide. Getransfecteerde spiervezels hadden rapsyneclusters buiten de synaps, in tegenstelling tot niet-getransfecteerde vezels. De rapsyneoverexpressie verhoogde het AChR-niveau in de spieren met $42 \%$. Twee weken na transfectie werd $E A M G$ passief geïnduceerd. Spieren die rapsyne tot overexpressie brachten hadden geen verlies aan $A C h R$, in tegenstelling tot controle spieren van dezelfde dieren. Bovendien lieten repetitieve zenuwstimulaties geen decrement zien van de actiepotentialen van behandelde spieren, terwijl controle spieren van dezelfde EAMG-ratten dit wel vertoonde. Elektronenmicroscopisch onderzoek van de motoreindplaten van EAMG-ratten toonde aan dat de morfologie van de postsynaptische vouwen normaal was in spieren die rapsyne tot overexpressie brengen, maar de vouwen waren beschadigd in controle spieren. Deze resultaten wijzen op een belangrijke rol voor rapsyne in de vatbaarheid voor EAMG.

Een specifieke therapie voor $\mathrm{MG}$ zou de bijwerkingen van aspecifieke behandelingen kunnen reduceren. De hypotetische immunotherapie met een eiwit dat is afgeleid van een humaan anti-AChR-antilichaam zou MGpatiënten kunnen helpen die in een myasthene crisis verkeren. MG. patiënten worden behandeld met plasmaferesis gedurende een myasthene crisis, zodat de circulerende autoantilichamen worden verwijderd. Om het remissie-effect van de plasmaferesis te verlengen, zouden therapeutische antilichamen de AChR kunnen afschermen tegen nieuw gevormde autoantilichamen. Een recombinant antilichaam met de bindingskarakteristieken van $F_{0 i s} 637$ en de bispecifieke en nietcomplementactiverende karakteristiek van IgG4 zou de voordelen combineren van $F_{\text {n:s }}$ en IgG. Het resulterende IgG-achtige molecuul zou de

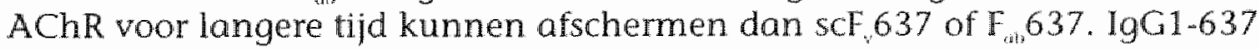


en zijn mutanten IgG1-637 $\mathrm{CC} 1 \mathrm{q}$, die geen complement activeert, en IgG1637/CDR3APLKP, die aspecifiek is, kunnen de basis vormen voor de constructie van een therapeutisch antilichaam.

Gentherapie is daarintegen een potentiële therapie met een langdurige werking. Allhoewel de overexpressie van rapsyne de inductie van EAMG vóórkomt, moet het effect hiervan op reeds geinduceerde EAMG nog worden onderzocht. Daarnaast moeten de effecten van langdurige overexpressie van rapsyne worden bepaald, zoals een mogelijke antirapsynerespons. Indien wordt aangetoond dat gentherapie met rapsyneDNA niet alleen preventief maar ook therapeutisch is, zou een selecte groep spieren, bijvoorbeeld de ooglidspieren, kunnen worden behandeld met in vivo elektroporatie.

Het expressieniveau van rapsyne speelt een belangrijke rol in de vatbaarheid voor myasthenie. Het verlagen van het niveau veroorzaakt een congenitaal myastheen syndroom, terwijl het verhogen een bescherming geeft tegen $\mathrm{MG}$. Kleinere veranderingen in het endogeen rapsyneniveau zouden kunnen correleren met de ernst van MG. Het zou daarom interessant zijn het rapsyneniveau te vergelijken tussen patiëntengroepen die verschillen in de mate van $M G$. 


\section{Dankwoord/Acknowledgements}

Het is onmogelijk alleen wetenschappelijk onderzoek te doen. Ik wil dan ook een ieder die op welke wijze dan ook een positieve bijdrage heeft geleverd aan de tot stand koming van dit proefschrift van harte bedanken.

Dr. M.H. De Baets, beste Marc. Als neuro-immunoloog, met een grote kennis van myasthenia gravis, en als nieuwsgierige wetenschapper leidde je mijn onderzoek. Zeker als je een interessant artikel had gelezen over een nieuwe techniek, dan wou je meteen de mogelijke toepassing daarvan in het myasthenie-onderzoek verkennen. Zo ook met de gentherapie met rapsyne-DNA. Een project dat ik sceptisch benaderde, omdat ik niet kon geloven dat het tot overexpressie brengen van één eiwit van de spier het beoogde effect zou kunnen verwezenlijken.

De collegae van Marcs neuro-immunologiegroep (Neurim): Diplombiologe Mario Losen, dr. Pilar "Piluca" Martínez-Martínez, dr. ir. Barbie Machiels en onze alumnus prof. dr. Fanping Meng. Beste Barbie, toen mijn werkplek verplaatste van Aken naar Maastricht hebben we met $z$ 'n tweeën succesvol recombinant DNA-technieken en celkweek geïntroduceerd op de laboratoria van onderzoeksinstituut Hersenen \& Gedrag (H\&G). Dear Fanping, I enjoyed our discussions, especially those about antibody therapy, which led to the concept of a bispecific IgG4-like molecule. It's a pity that the distance between your own department and Maastricht made contact difficult later on. Beste Mario, jouw aanwezigheid sinds de laatste twee jaar van mijn promotie-onderzoek heeft vooral door jouw toewijding voor het werk - al mag best wat vaker iemand anders het licht op werk uit doen - en door je collegialiteit van Neurim eindelijk een echte groep gemaakt. "It's alive, Igor!" Dear Piluca, your enthusiasm for our research during your own Spanish PhD project ensured a post-doc position in Neurim. Taken together with your friendship, you ensured a position as one of my paranymphs.

Bedanken voor het in mij gestelde vertrouwen wil ik mijn promotores, prof. dr. Jaap Troost en prof. dr. Harry Steinbusch, die als leider van divisie 3 van $H \& G$ de lastige taak had het jonge Neurim een plaats binnen zijn divisie te geven.

De overige medewerkers van divisie 3 van $\mathrm{H} \& \mathrm{G}$ will ik ook bedanken voor hun bijdrage, waarvan de volgende bij naam, mede omdat ze me niet hebben \aten bungelen aan $H \& G$ als een myasthene spier aan het perifeer zenuwstelsel. Ing. Marjanne Markerink-van Ittersum, dé analiste met hart voor de zaak. Dr. ir. Nicole Senden, voormalig mede-paranimf, bedankt voor je hulp. Ing. Hellen Steinbusch, ik doe liever talkie talkie tijdens het overhandigen van een exemplaar van dit proefschrift, om het maar in het Helleniaans uit te drukken. De secretaresses Lillian Swaen en Akke Spauwen, fijn dat ik altijd het secretariaat kon binnen vallen. Dra. Marjo van de Waarenburg, niet voor niets één van mijn paranimfen. 
Prof. dr. Frank Spaans, altijd bereid om de "kleine patiëntjes" met kleine voltages te diagnotiseren na hun behandeling door mij met wat hogere stroompulsen.

Coworkers of the RWTH Aachen, Dr. Stephan "Joe" Hellwig and Dr. Stefan Schillberg. Dear Stefan, thank you for helping me to plan the production of our $F_{\text {nat }}$ in yeast and your support, in spite that the heavy-chain fragment was a "difficult fragment $\left(F_{j}\right)$, as you call it. Dear Joe, thank you for introducing me to biotechnology during your own PhD project. I would also like to thank Nicole Raven, MSC, and Yvonne Helgers, who were a great help during the beginning of my yeast experiments. Prof. Dr. Rainer Fischer, thank you for your hospitality in your Institute of Molecular Biotechnology.

Alle mede-promovendi en studenten die mij in enige vorm hebben geholpen de afgelopen vijf jaar wil ik bedanken, waarvan de volgende in het bijzonder/I wish to thank all (fellow PhD) students who helped me in the last five years, a specially the following. Drs. Ronald "Sjors" Deumens, bedankt voor de gesprekken over "normen- en waardendingen" onder het genot van een kop llunchsoep. Dr. ir. Simone Dorfmüller, jouw hulp als ondermeer Dolmetscher was onontbeerlijk gedurende mijn beginfase in Aken. Dr. Dieter Peschen, it seems that single-chains are easier then whole antibodies. Anouk Roemen, je humor en ongecompliceerd karakter maakte van het histologielab een onvergetelijk gezellige en toch bedrijvige werkplek (een bezige bij zoemt). Andrea Scheepers, MSc, I really enjoyed your company. Many times you shouted in the lab: "Alle Männer sind Sweine! AuBer dich, Moritz", Danke. Monica Sica, MSc, come on!

Dr. René Hoet, jouw begeleiding gedurende mijn stage in Nijmegen was de perfecte basis voor mijn promotie-onderzoek.

Dr. Patrick Starremans, we hebben zo'n beetje gedurende onze hele lifescience-carrière met elkaar gediscussieerd, van fundamenteel tot over de grens van sciencefact en sciencefiction. Helaas door onze promoties minder frequent, maar daarom niet minder. Ir. Jan-Willem Deumens, onze roots gaan terug tot onze kleutertijd.

Kees en Riek Pauw. Oma, bedankt voor uw steun gedurende mijn gehele opleiding. Jammer dat opa, die ons eerder dit jaar op 91-jarige leeftijd heeft moeten verlaten, dit net niet meer heeft mogen meebeleven. Marinke van de Ven-Stassen, mijn biologisch geweten. Léon en Annie Stassen. Mam, pap, bedankt. 


\section{Bibliography}

Original papers

1. Teunissen, S.W., M.H. Stassen, G.J. Pruijn, W.J. van Venrooij, R.M. Hoet, "Characterization of an anti-RNA recombinant autoantibody fragment (scFv) isolated from a phage display library and detailed analysis of its binding site on U1 snRNA.", RNA 4 (1998) pp. 1124-1133.

2. Hoet, R.M., M. Pieffers, M.H. Stassen, I. Raats, R. de Wildt, G.J. Pruijn, F. van den Hoogen, W.J. van Venrooij, "The importance of the light chain for the epitope specificity of human anti-U1 small nuclear RNA autoantibodies present in systemic lupus erythematosus patients", Joumal of Immunology 163 (1999) pp. 3304-3312.

3. Meng, F., M.H. Stassen, S. Schillberg, R. Fischer, M.H. De Baets, "Construction and characterization of a single-chain antibody fragment derived from thymus of a patient with myasthenia gravis", Autoimmunity 35 (2002) pp. 125-133.

4. De Haes, A., J.H. Proost, M.H. De Baets, M.H. Stassen, M.C. Houwertjes, J.M. Wierda, "Pharmacokinetic-pharmacodynamic modeling of rocuronium in case of a decreased number of acetylcholine receptors: a study in myasthenic pigs", Anesthesiology 98 (2003) pp. 133-142.

5. Stassen, M.H., F. Meng, E. Melgert, B.M. Machiels, S.H. Im, S. Fuchs, A.F. Gerritsen, M.A. van Dijk, I.G. van de Winkel, M.H. De Baets, "Experimental autoimmune myasthenia gravis in mice expressing human immunoglobulin loci", Journal of Neuroimmunology 135 (2003) pp. 56-61.

Reviews

1. De Baets, M., M.H. Stassen, "The role of antibodies in myasthenia gravis", Joumal of the Neurological Sciences 202 (2002) pp. 5-11.

2. De Baets, M.H., M.H. Stassen, M. Losen, X. Zhang, B.M. Machiels, "Immunoregulation in experimental autoimmune myasthenia gravis about T cells, antibodies and endplates", Annals of the New York Academy of Sciences 998 (2003) pp. 308-317.

Abstracts

1. Stassen, M.H., A.F. Gerritsen, F. Meng, M.A. van Dijk, I.G. van de Winkel, M.H. De Baets, "Joint Annual Meeting 2000 of the German and Dutch Societies of Immunology, Abstract K. 32: Experimental autoimmune myasthenia gravis in mice expressing human immunoglobulins (HuMAb-Mice)", Immunobiology 203 (2000) pp. 226227.

2. Stassen, M.H., A.F. Gerritsen, F. Meng, M.A. van Dijk, J.G. van de Winkel, M.H. De Baets, "Experimental autoimmune myasthenia gravis 
in mice expressing human immunoglobulin loci (Special symposia abstracts, 500)", Journal of Neuroimmunology 118 (2001) pp. 151-163.

3. Stassen, M.H., B.M. Machiels, E. Fostieri, S. Tzartos, S. Berrih-Aknin, E. Bosmans, P.W. Parren, M.H. De Baets, "Characterization of a fully human IgG1 reconstructed from an anti-AChR Fab", Annals of the New York Academy of Sciences 998 (2003) pp. 399-400.

Submitted original papers

1. De Haes, A., J.H. Proost, M.H. De Baets, M.H. Stassen, M.C. Houwertjes,

I.M. Wierda, "Pharmacokinetic-pharmacodynamic modelling of neuromuscular blocking agents in myasthenic rats, taking into account the unbound acetylcholine receptor concentration".

2. Stassen, M.H., M. Losen, B.M. Machiels, H. Veldman, F. Spaans, M.H. De Baets, "Overexpression of rapsyn in muscles prevents experimental. autoimmune myasthenia gravis".

3. Stassen, M.H., S. Hellwig, S. Schillberg, R. Fischer, M. De Baets, "Expression of an anti-acetylcholine receptor Fab in Pichia pastoris".

Original paper in preparation

1. Stassen, M.H., B.M. Machiels, E. Fostieri, S. Tzartos, S. Berrih-Aknin, A. Roos, M.R. Daha, E. Bosmans, P.W. Parren, M.H. De Baets, "Characterization of a human IgG1 reconstructed from an antiacetylcholine receptor Fab".

Poster presentations

1. Stassen, M.H., S. Hellwig, S. Schillberg, R. Fischer, M.H. De Baets, Largescale expression of a therapeutic anti-AChR recombinant antibody fragment, Euro Junction '99: From Nerve to Muscle (satellite to the IX ENS Meeting, Milan, Italy), Sportilia (Fo), Italy, June 10-12, 1999.

2. Stassen, M.H. A.F. Gerritsen, F. Meng, M.A. van Dijk, I.G. van de Winkel, M.H. De Baets, Experimental autoimmune myasthenia gravis in mice expressing human immunoglobulins (HuMAb-Mice), loint Annual Meeting of the German and Dutch Societies of Immunology, Duisseldorf, Germany, November 29-December 2, 2000.

3. Stassen M.H. A.F. Gerritsen, F. Meng, M.A. van Dijk, J.G. van de Winkel, M.H. De Baets, Experimental autoimmune myasthenia gravis in mice expressing human immunoglobulin loci, 6th International Congress of Neuroimmunology, Edinburgh, United Kingdom, September 4-7, 2001.

4. Meng, F., M.H. Stassen, S. Schillberg, R. Fischer, M.H. De Baets, Construction and characterization of a single-chain antibody fragment derived from thymus of a patient with myasthenia gravis, Xth International Conference on Myasthenia Gravis and Related Disorders, Key Biscayne, Florida, USA, May 29-Iune 1, 2002.

5. Stassen, M.H., B.M. Machiels, E. Fostieri, S. Tzartos, S. Berrih-Aknin, E. Bosmans, P.W. Parren, M.H. De Baets, Characterization of a fully human IgGI reconstructed from an anti-AChR Fab, Xth International Conference 
on Myasthenia Gravis and Related Disorders, Key Biscayne, Florida, USA, May 29-June 1, 2002.

Oral presentation

1. Stassen, M.H., Rapsyn overexpression prevents experimental autoimmune myasthenia gravis, Joined Meeting of the Belgian (BIS) and Dutch (NVVI) Immunology Societies, Veldhoven, The Netherlands, December 18-20, 2002. 


\section{Curriculum vitae}

Maurice Stassen is geboren op 28 februari 1971 te Geleen. Hij is opgegroeid in Limbricht en behaalde in 1988 zijn mavo-en in 1990 zijn havodiploma. In 1990 begon hij de opleiding chemische technologie van het hoger technisch onderwijs aan de voormalige Hogeschool Heerlen (nu Hogeschool Zuyd), maar veranderde zijn specialisatie in biochemie door in het propedeutisch jaar over te stappen naar de chemische laboratoriumopleiding van het hoger laboratoriumonderwijs aan dezelfde school. Na de achtmaandse afstudeerstage, die werd gelopen bij de vakgroep Pathologie van de voormalige Rijksuniversiteit Limburg (nu Universiteit Maastricht) onder leiding van dr. Ton de Goeij, behaalde hij in 1995 de titel van ingenieur. In datzelfde jaar startte hij zijn biologiestudie aan de Katholieke Universiteit Nijmegen (KUN). Vanaf december 1996 tot en met september 1997 werd de eerste doctoraalstage gelopen bij de vakgroep Biochemie van de KUN, onder leiding van prof. dr. Walter van Venrooij en dr. René Hoet. De tweede doctoraalstage werd gelopen vanaf november 1997 tot en met april 1998 bij de Target Discovery unit Oss van NV Organon, onder leiding van dr. Christine Boersma. Het doctoraalexamen in de medische biologie werd in 1998 behaald. In datzelfde jaar werd begonnen aan het promotie-onderzoek beschreven in dit proefschrift, binnen het onderzoeksinstituut Hersenen \& Gedrag aan de Universiteit Maastricht, onder leiding van dr. Marc De Baets. Gedurende de eerste twintig maanden werd het promotie-onderzoek verricht op de laboratoria van het Institut für Molekulare Biotechnologie, Rheinisch-Westfälische Technische Hochschule Aachen, Duitsland, in samenwerking met dr. Stephan Hellwig en dr. Stefan Schillberg.

Maurice Stassen was born in Geleen, the Netherlands on the $28^{\text {th }}$ of February 1971. He completed his secondary education in 1990 and started his study of biochemistry at the former college of technology "Hogeschool Heerlen" (now "Hogeschool Zuyd"), the Netherlands the same year. After his internship at the Department of Pathology of the former State University of Limburg (now University of Maastricht), the Netherlands under the supervision of Dr. Ton de Goeij, he took his BSC degree in 1995. In the same year, he started his study of medical biology at the Catholic University of Nijmegen, the Netherlands. For this study, his first internship was at the Department of Biochemistry, Catholic University of Nijmegen under the supervision of Prof. Dr. Walter van Venrooij and Dr. René Hoet from December 1996 till September 1997. After his second and final internship at the Target Discovery Unit Oss of NV Organon, the Netherlands under the supervision of Dr. Christine Boersma from November 1997 till April 1998, he took his MSc degree. In 1998, he became PhD student at the Research Institute of Brain and Behavior, University of Maastricht, the Netherlands under 
the supervision of Assoc. Prof. Dr. Marc De Baets. The experiments carried out as a PhD student are described in this thesis. Part of these experiments was performed at the Institute of Molecular Biotechnology, the university of rechnology "RWTH Aachen", Germany in collaboration with Drs. Stephan Hellwig and Stefan Schillberg. 